addendum

\section{Magnetoresistance from quantum interference effects in ferromagnets}

N. Manyala, Y. Sidis, J. F. DiTusa, G. Aeppli, D. P. Young \& Z. Fisk

Nature 404, 581-584 (2000).

Our attention has been drawn to an earlier report ${ }^{1}$ on the zero-field resistivity of ferrimagnetic amorphous films containing mixtures of gadolinium with cobalt and iron. This paper mentions the possible relevance of electron-electron interactions to the low-temperature properties of such films, and displays the Al'tshuler-Aronov equation $^{2}$ for the zero-field temperature dependence of the resistivity of a disordered conductor. To understand the magnetoresistance data in our Letter, which deals with a crystalline semiconductor that undergoes a transition from insulating paramagnet to metallic magnet, a useful theoretical guidance comes from the earlier paper of Millis and Lee ${ }^{3}$, which contains explicit formulae for the field-dependent resistance.

1. Kopelevich, Ya. V., Makarov, V. V. \& Sapozhnikova, L. M. Electrical conductivity of amorphous ferrimagnetic metals. Fiz. Tverd. Tela 28, 3674-3679 (1986) and Sov. Phys. Solid State 28, 2069-2072 (1986).

2. Al'tshuler, B. L., Aronov, A. G., Gershenson M. E. \& Sharvin, Yu. V. Quantum effects in disordered metal films. Sov. Sci. A Phys. 9, 223-354 (1987)

3. Millis, A. J. \& Lee, P. A. Spin-orbit and paramagnon effects on magnetoconductance and tunneling Phys. Rev. B 30, 6170-6173 (1984) and 31, 5523-5524(E) (1985).

\section{correction}

\section{Ultrasensitive pheromone detection by mammalian vomeronasal neurons}

Trese Leinders-Zufall, Andrew P. Lane, Adam C. Puche, Weidong Ma, Milos V. Novotny, Michael T. Shipley \& Frank Zufall

Nature 405, 792-796 (2000).

In Fig. 3, panel $\mathrm{f}$ was inadvertently duplicated in panel d. The correct Fig. $3 \mathrm{~d}$ is shown below.

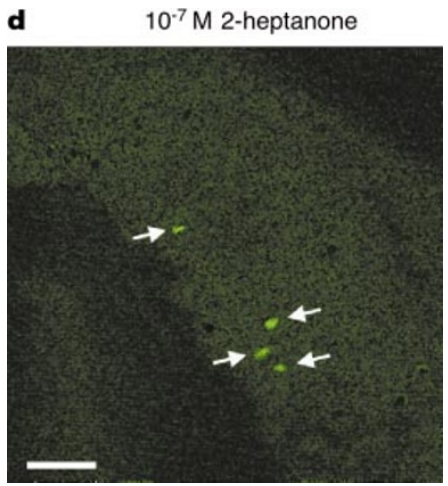

errata

\section{Tom22 is a multifunctional organizer of the mitochondrial preprotein translocase}

Sandra van Wilpe, Michael T. Ryan, Kerstin Hill, Ammy C. Maarse, Chris Meisinger, Jan Brix, Peter J. T. Dekker, Martin Moczko, Richard Wagner, Michiel Meijer, Bernard Guiard, Angelika Hönlinger \& Nikolaus Pfanner

Nature 401, 485-489 (1999).

In this paper, part of the labelling of Fig. 3 was printed incorrectly. The half-tones of Fig. 3a should have been labelled from left to right: Anti-Tom22 (lanes 1 and 2); Anti-Tom40 (lanes 3 and 4); AntiTom 20 (lanes 5 and 6); Anti-Tom70 (lanes 7 and 8). In addition, the axes of the ordinates of Fig. $3 \mathrm{~b}$ should have been labelled from top to bottom: Co-precipitated Tom20; Co-precipitated Tom22; Co-precipitated Tom70.

\section{Embryonic lethality in mice homozygous for a processing- deficient allele of Notch1}

Stacey S. Huppert, Anh Le, Eric H. Schroeter, Jeffrey S. Mumm, Meera T. Saxena, Laurie A. Milner \& Raphael Kopan

Nature 405, 966-970 (2000).

The contrast of Fig. la was too low to see all of the protein bands. Figure la should have appeared as below.

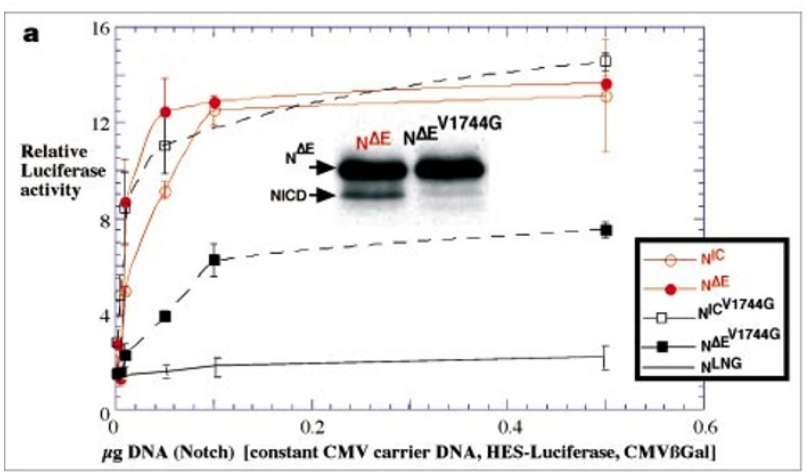


4. Poyatos, J. F., Cirac, J. I. \& Zoller, P. Quantum gates with hot trapped ions. Phys. Rev. Lett. 81, 1322 1325 (1998)

5. Steane, A. The ion trap quantum information processor. Appl. Phys. B 64, 623-642 (1997).

6. Turchette, Q. A. et al. Deterministic entanglement of two trapped ions. Phys. Rev. Lett. 81, 3631-3634 (1998).

Roos, Ch. et al. Quantum state engineering on an optical transition and decoherence in a Paul trap. Pre-print quant-ph/9909038 at 〈xxx.lanl.gov〉 (1999).

8. Sorensen, A. \& Molmer, K. Quantum computation with ions in thermal motion. Phys. Rev. Lett. 82, 1971-1974 (1999).

9. Wineland, D. J. et al. Experimental issues in coherent quantum-state manipulation of trapped atomic ions. J. Res. Natl Inst. Stand. Technol. 103, 259 (1998).

10. Jaksch, D., Briegel, H.-J., Cirac, J. I., Gardiner, C. W. \& Zoller, P. Entanglement of atoms via cold controlled collisions. Phys. Rev. Lett. 82, 1975-1978 (1999).

11. Brennen, G. K., Caves, C. M., Jessen, P. S. \& Deutsch, I. H. Quantum logic gates in optical lattices. Phys. Rev. Lett. 82, 1060-1063 (1999).

12. Calarco, T. et al. Quantum gates with neutral atoms: Controlling collisional interactions in time dependent traps. Pre-print quant-ph/9905013 at 〈xxx.lanl.gov〉 (1999).

13. Pellizzari, T., Gardiner, S. A., Cirac, J. I. \& Zoller, P. Decoherence, continuous observation, and quantum computing: a cavity QED model. Phys. Rev. Lett. 75, 3788-3791 (1995).

14. Turchette, Q. A., Hood, C. J., Lange, W., Mabuchi, H. \& Kimble, H. J. Measurement of conditional phase shifts for quantum logic. Phys. Rev. Lett. 75, 4710-4713 (1995).

15. Maitre, X. et al. Quantum memory with a single photon in a cavity. Phys. Rev. Lett. 79, 769-772 (1997).

16. Cory, D. G., Fahmy, A. F. \& Havel, T. F. Ensemble quantum computing by NMR spectroscopy. Proc. Natl Acad. Sci. USA 94, 1634-1639 (1997).

17. Gershenfeld, N. A. \& Chuang, I. L. Bulk spin-resonance quantum computation. Science 275, 350-356 (1997).

18. Kane, B. E. A silicon-based nuclear spin quantum computer. Nature 393, 133-137 (1998).

19. Loss, D. \& DiVincenzo, D. P. Quantum computation with quantum dots. Phys. Rev. A 57, 120-126 (1998).

20. Makhlin, Y. \& Schön, G. Josephson-junction qubits with controlled couplings. Nature 398, 305-307 (1999).

21. Beckman, D., Chari, A. N., Devabhaktuni, S. \& Preskill, J. Efficient networks for quantum factoring. Phys. Rev. A 54, 1034-1063 (1996).

22. Steane, A. M. Efficient fault-tolerant quantum computing. Pre-print quant-ph/9809054 at $\langle x x x$. lanl.gov $\rangle$ (1998)

23. DeVoe, R. G. Elliptical ion traps and trap arrays for quantum computation. Phys. Rev. A 58, 910-914 (1998).

24. Friebel, S., D’Andrea, C., Walz, J., Weitz, M. \& Hänsch, T. W. $\mathrm{CO}_{2}$ laser optical lattice with cold rubidium atoms. Phys. Rev. A 57, R20-R23 (1998).

25. Lloyd, S. Universal quantum simulators. Science 273, 1073-1078 (1996).

\section{Acknowledgements}

We thank R. Blatt, D. Leifried and D. Wineland for comments. This work was supported by the Austria Science Foundation, TMR networks from the European Community, and the Institute for Quantum Information $\mathrm{GmbH}$.

Correspondence and requests for materials should be addressed to P.Z. (e-mail: peter.zoller@uibk.ac.at).

Magnetoresistance from quantum interference effects in ferromagnets

\author{
N. Manyala*, Y. Sidis ${ }^{\star} \dagger$, J. F. DiTusa* ${ }^{\star}$, G. Aeppli $\neq$, D.P. Young $₫ \&$ Z. Fisk $\S$
}

* Department of Physics and Astronomy, Louisiana State University, Baton Rouge, Louisiana 70803, USA

$\ddagger N E C$, 4 Independence Way, Princeton, New Jersey 08540, USA

$\$$ National High Magnetic Field Facility, Florida State University, Tallahassee,

Florida 32306, USA

The desire to maximize the sensitivity of read/write heads (and thus the information density) of magnetic storage devices has stimulated interest in the discovery and design of new magnetic materials exhibiting magnetoresistance. Recent discoveries include the 'colossal' magnetoresistance in the manganites ${ }^{1-4}$ and the enhanced magnetoresistance in low-carrier-density ferromagnets $^{4-6}$. An important feature of these systems is that the electrons involved in electrical conduction are different from those responsible for the magnetism. The latter are localized

† Present address: Laboratoire L’eon Brillouin, CEA-CNRS, CE Saclay, 91191 Gif-Sur-Yvette, France. and act as scattering sites for the mobile electrons, and it is the field tuning of the scattering strength that ultimately gives rise to the observed magnetoresistance. Here we argue that magnetoresistance can arise by a different mechanism in certain ferromagnets-quantum interference effects rather than simple scattering. The ferromagnets in question are disordered, lowcarrier-density magnets where the same electrons are responsible for both the magnetic properties and electrical conduction. The resulting magnetoresistance is positive (that is, the resistance increases in response to an applied magnetic field) and only weakly temperature-dependent below the Curie point.

The oxides of manganese that are known to have high magnetoresistance are derived from chemical doping of insulators that are also magnetically ordered. Thus, the local moments that are ordered in the doped materials already exist in the insulator, with the result that, to a first approximation, metallicity and magnetism are independent properties ${ }^{6}$. The electrical resistance is reduced when there is less scattering of the conduction electrons by the spins of the localized electrons. To the extent that an external field reduces the disorder among the local spins, the scattering will be reduced, resulting in a negative magnetoresistance. When searching for different mechanisms for magnetoresistance, we need to consider compounds where the insulating parent is non-magnetic. In addition, the parent should have strong electron-electron interactions so that magnetism appears readily upon doping. Insulators which satisfy this criterion are referred to as strongly correlated, or Kondo insulators ${ }^{7}$. A particularly simple Kondo insulator is $\mathrm{FeSi}$, which has attracted attention for over 30 years because of its anomalous temperature-dependent electrical, optical and magnetic properties $^{7-11}$. Previous investigations reveal a metal-insulator transition with either Al substitution for $\mathrm{Si}$ (hole doping) or Co substitution for Fe (electron doping) at the level of 1\% (refs 12 and 13). The transition is very similar to that found in classic semiconductors such as phosphorus-doped silicon or antimony-doped germanium, except that the effective masses of the holes (electrons) are much larger. FeSi is isostructural (cubic B-20) and continuously miscible with the classic metallic ferromagnet $\mathrm{MnSi}$ (see, for example, ref. 14) and the diamagnetic metal CoSi (ref. 8); it is therefore possible to control the carrier sign - positive (holes) for substitution of Mn for Fe and negative (electrons) for substitution of $\mathrm{Co}$ - and the density throughout a magnetically interesting phase diagram, shown in Fig. 1. Modest $(20 \%)$ dilution of $\mathrm{Mn}$ by Fe destroys the ferromagnetism of $\mathrm{MnSi}$ while retaining metallicity. In contrast, the alloy $\mathrm{Fe}_{1-y} \mathrm{Co}_{y} \mathrm{Si}$ is remarkable in that although the two end members $(y=0)$ and $(y=1)$ are both non-magnetic, it is magnetic for almost all intermediate compositions ${ }^{8,15,16,17}$. This is the alloy that displays unusual magnetoresistance, clearly distinguishable from that found in more ordinary magnets such as MnSi.

Our samples were either polycrystalline pellets or small single crystals grown from Sb and Sn fluxes. We produced polycrystalline samples from high purity starting materials by arc melting in an argon atmosphere. To improve homogeneity, the $\mathrm{Fe}_{1-y} \mathrm{Co}_{y} \mathrm{Si}$ $\left(\mathrm{Fe}_{1-x} \mathrm{Mn}_{x} \mathrm{Si}\right.$ ) samples were annealed for 24 hours at $1,200^{\circ} \mathrm{C}$ (four days at $1,000{ }^{\circ} \mathrm{C}$ ) in evacuated quartz ampoules. Powder X-ray spectra showed all samples to be single phase with a lattice constant that is linearly dependent on $\mathrm{Co}$ and $\mathrm{Mn}$ concentration. The linearity demonstrates that Co or Mn successfully replaces Fe over the entire concentration range $(0 \leqslant x \leqslant 1 ; 0 \leqslant y \leqslant 1)$. Energy dispersive X-ray microanalysis yielded results consistent with the nominal concentrations. The Hall effect data establish the sign and density of the carriers in our samples and demonstrate a systematic increase in carrier density $(n)$ proportional to the Co and $\mathrm{Mn}$ concentration at small $x$ and $y$. They clearly show the existence of a metallic state in the concentration range studied $(0.03 \leqslant x \leqslant 1 ; 0.05$ $\leqslant y \leqslant 0.30$ ), with only a small variation of $n$ with temperature $(T)$. In particular, $n$ does not appear to change as the Curie temperature $\left(T_{\mathrm{C}}\right)$ is traversed. 
Figure 1 summarizes the low-field measurements of the resistivity $(\rho)$ and magnetization $(M)$ throughout the alloy series. Figure 1a shows that the generic behaviour is metallic (increasing conductivity with decreasing $T$ ) except in a narrow sliver of temperaturecomposition space around pure, insulating FeSi. Figure 1b, displaying $M$ measured at $1 \mathrm{~T}$, shows how spin order, with Curie temperatures of $50 \mathrm{~K}$ and below, is found in two distinct regions of the phase diagram. It is surprising that substitution of $\mathrm{Mn}$ - with its great tendency towards magnetism, as demonstrated by the order found in the end member, $\mathrm{MnSi}$-yields behaviour not very different from substitution of $\mathrm{Al}$ for Si (ref. 12). Thus, at low doping, $\mathrm{Mn}$ is like $\mathrm{Al}$, in that it inserts holes into the valence band of FeSi. That the outcome is largely independent of the site used to introduce holes represents a great and unexpected simplification of the physics of FeSi and its derivatives. Figure 1c gives the saturation magnetizations $\left(P_{\mathrm{S}}\right)$ in the ordered states. The result is that the polarization rises in nearly linear fashion with low Co concentration, with a constant of proportionality which is $1 \pm 0.12 \mu_{\mathrm{B}}$ per Co ion $^{18}$. Because the Hall effect yields one electron per Co ion in the same regime, it seems that we have a fully spin-polarized electron gas. In contrast, in the weak itinerant ferromagnet $\mathrm{MnSi}$, we see a substantially reduced moment of $0.43 \pm 0.05 \mu_{\mathrm{B}}$ per Mn ion.

We now discuss our main result: a new type of magnetoresistance in the metallic magnets found on the Co-doped side of the phase diagram. Figure $2 \mathrm{a}$ and $\mathrm{c}$ show temperature-dependent resistivities measured in various external fields for $\mathrm{Fe}_{0.8} \mathrm{Co}_{0.2} \mathrm{Si}$, where $T_{\mathrm{C}}=35 \mathrm{~K}$,

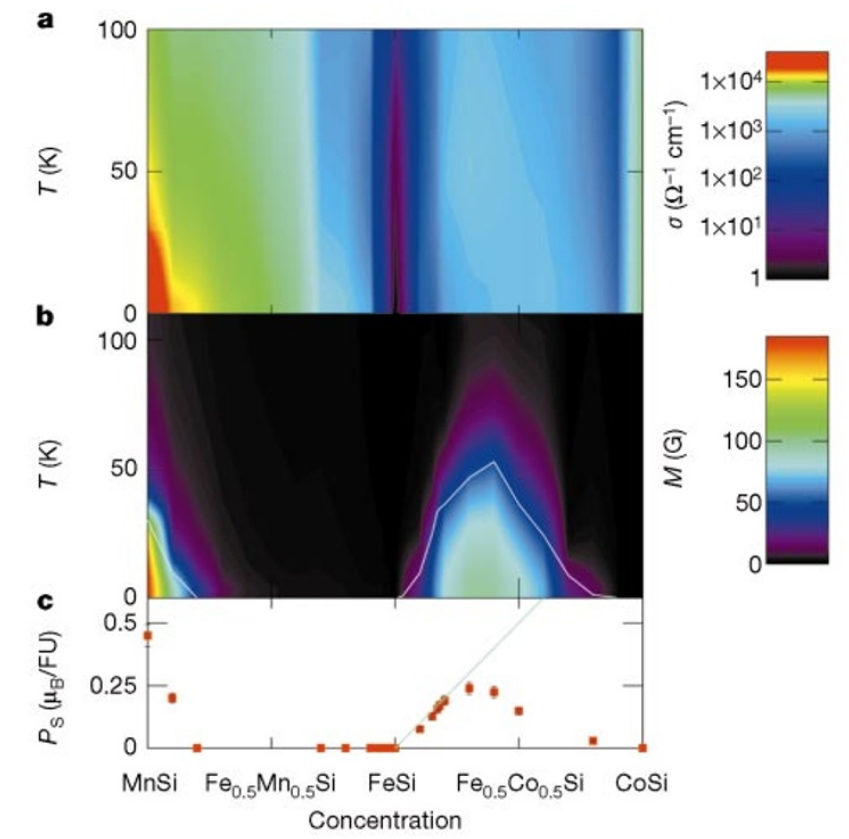

Figure 1 Phase diagram of $\mathrm{Fe}_{1-x} \mathrm{Mn}_{x} \mathrm{Si}$ and $\mathrm{Fe}_{1-y} \mathrm{C} \mathrm{C}_{y} \mathrm{Si}$. a, Conductivity $\sigma$ versus temperature and concentration. $\mathbf{b}$, Magnetization $M$ at $1 \mathrm{~T}$ versus temperature and concentration. White line represents the Curie temperature in zero field. c, Spontaneous magnetization $\left(P_{\mathrm{s}}\right)$ as determined from the saturated value of the magnetization at high magnetic field versus concentration. FU, formula unit. Light-blue line represents behaviour at $1 \mu_{\mathrm{B}}$ per $\mathrm{Co}$ ion. The electrical conductivity was measured on rectangular samples with thin platinum wires attached with silver paste. We collected transverse and longitudinal magnetoresistance and Hall effect data at $19 \mathrm{~Hz}$ using lock-in techniques. Magnetization measurements were made between 1.7 and $400 \mathrm{~K}$ in fields from -5.0 to 5.0 T in a SQUID magnetometer and from 0 to $32 \mathrm{~T}$ in a vibrating reed magnetometer at the National High Magnetic Field Laboratory. Technically all of the magnetic materials investigated in our experiments are helimagnets: ferromagnets with long-period helical spin structure. However, in these materials the carrier mean free-paths are much shorter than the helix period ${ }^{15,28}$. Therefore, for the purposes of discussing the carrier transport, they are essentially ferromagnetic and are referred to as such. as well as for $\mathrm{MnSi}$, with a similar $T_{\mathrm{C}}$ of $30 \mathrm{~K}$, whereas Fig. $2 \mathrm{~b}$ and $\mathrm{d}$ show the corresponding magnetoresistance ratios $\Delta \rho / \rho$. The differences between the compounds are striking. The MnSi data display the temperature dependence expected for an itinerant ferromagnet ${ }^{14}$. Near $T_{\mathrm{C}}, d \rho / d T$ has a peak, due to carrier scattering from spin fluctuations ${ }^{8,19}$. A magnetic field $(H)$ suppresses the scattering, resulting in the magnetoresistance ${ }^{19}$ shown in Fig. $2 \mathrm{~d}$ : $(\rho(T, H)-\rho(T, 0)) / \rho(T, 0)$. A strong negative magnetoresistance (over $20 \%$ ) occurs only around $T_{\mathrm{C}}$ (ref. 20). Our $\mathrm{Fe}_{1-y} \mathrm{Co}_{y} \mathrm{Si}$ samples display a zero-field $\rho$ an order of magnitude larger than that of the MnSi sample, but it becomes comparable when multiplied by the number of carriers. The difference between $\mathrm{MnSi}$ and $\mathrm{Fe}_{1-y} \mathrm{Co}_{y} \mathrm{Si}$ is that $\rho$ increases continuously with $T$ below $T_{\mathrm{C}}$ (ref. 15). Furthermore, a magnetic field does not suppress the increase, but instead enhances it, not only near $T_{\mathrm{C}}$ but for all $T<T_{\mathrm{C}}$. Thus, the magnetoresistance in $\mathrm{Fe}_{1-y} \mathrm{Co}_{y} \mathrm{Si}$ is positive; and, although it turns on near $T_{\mathrm{C}}$ as well as showing a small peak there, its existence is not tied to the magnetic critical fluctuations found near the Curie point. The magnetoresistance shown in Fig. $2 \mathrm{~b}$ can be as large as $7 \%$ near $T_{\mathrm{C}}$ and falls off gradually below this temperature. The effect is enhanced as $n$ is decreased, growing with proximity to the metalinsulator transition with our $10 \%$ sample having the largest magnetoresistance ( $10 \%$ at $4 \mathrm{~K}$ and $5 \mathrm{~T}$ ).

Figure 3 shows the field dependence of $\rho$ and $M$ for $\mathrm{Fe}_{0.85} \mathrm{Co}_{0.15} \mathrm{Si}$ at a variety of temperatures. As $T$ is reduced below $T_{\mathrm{C}}=25 \mathrm{~K}$, the magnetization varies almost discontinuously with $H$ near 0 , exactly as expected for this nearly ferromagnetic helimagnet (see Fig. 1 legend). At the lowest $T$, the saturation value of $M$ is approached almost immediately for $H>0$ and $H<0$. The magnetoresistance ratio $\Delta \rho / \rho$ does not behave analogously: it grows with $H$ at a rate weakly dependent on $T$. So, in contrast to what occurs for essentially all magnetoresistive materials ranging from $\mathrm{MnSi}$ to the many oxides of manganese, the magnetization $M$ is very far from being the dominant controlling factor of $\rho$. Even so, it is clear that $M$ does have a role to play for small $H$ : above $T_{\mathrm{C}}$ where $M$ is a smooth

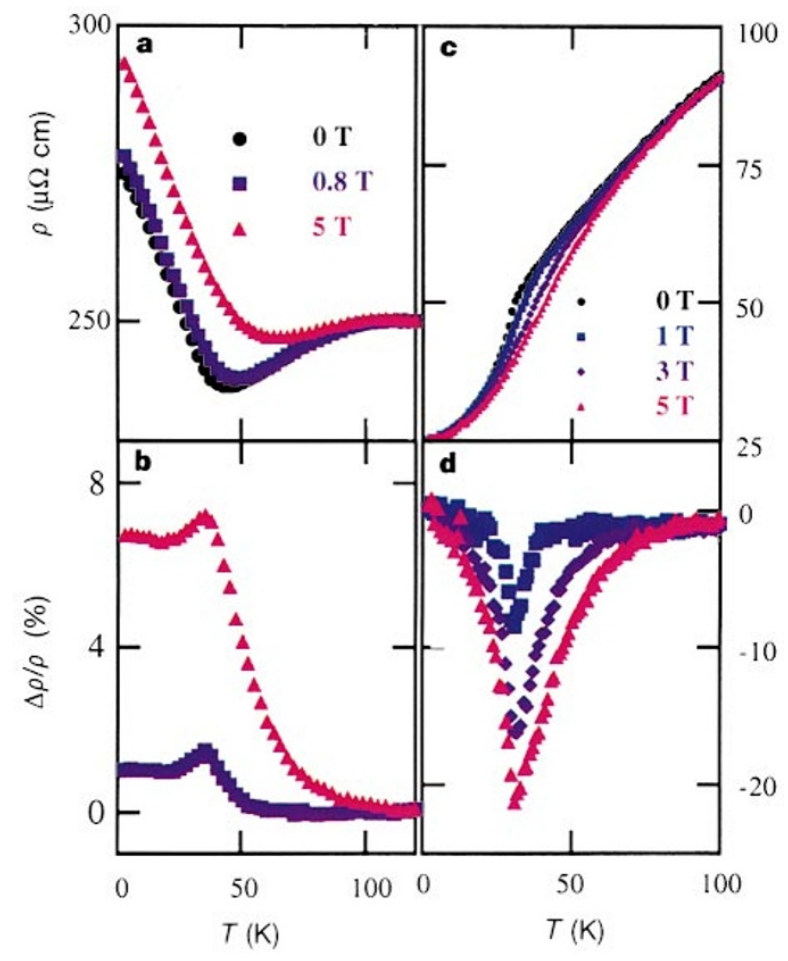

Figure 2 Temperature dependence. $\mathbf{a}-\mathbf{d}$, The resistivity $\rho(\mathbf{a}, \mathbf{c})$ and magnetoresistance $\Delta \rho / \rho(\mathbf{b}, \mathbf{d})$ for crystalline $\mathrm{Fe}_{0.8} \mathrm{C}_{0.2} \mathrm{Si}(\mathbf{a}, \mathbf{b})$ and polycrystalline MnSi $(\mathbf{c}, \mathbf{d})$ versus temperature. Magnetic fields are given in the figure. 
(linear) function of $H$, the magnetoresistance is a parabolic function of $H$, whereas below $T_{\mathrm{C}}$, when $M(H)$ appears to be singular near $H=0$, the magnetoresistance acquires a cusp-like minimum near $H=0$.

Mechanisms for the unusual magnetoresistance in $\mathrm{Fe}_{1-y} \mathrm{Co}_{y} \mathrm{Si}$ can involve grain boundaries, orbital effects, or electron spins in the bulk of the material. Because we find positive and weakly temperature-dependent magnetoresistance of comparable magnitude in our single crystals, grain boundaries are unlikely to play any role ${ }^{21}$. Furthermore, the similarity of longitudinal and transverse magnetoresistance (Fig. 3a) make orbital effects, which would contribute in the transverse but not the longitudinal geometry, a minor contributor to the magnetoresistance (see, for example, ref. 22; ref. 23)

This leaves coupling to the bulk electron spins as the most likely cause of the anomalous magnetoresistance. Figure $4 \mathrm{a}$ and $\mathrm{b}$ suggests aspects of the microscopic origin of the observations. First, the conductivity $(\sigma=1 / \rho)$ is $T$ - and $H$-dependent down to the lowest temperatures measured $(200 \mathrm{mK})$. Furthermore, $\sigma$ is well described by a $T^{1 / 2}$ dependence, whereas for large $H, \sigma(H, T)$ approaches an

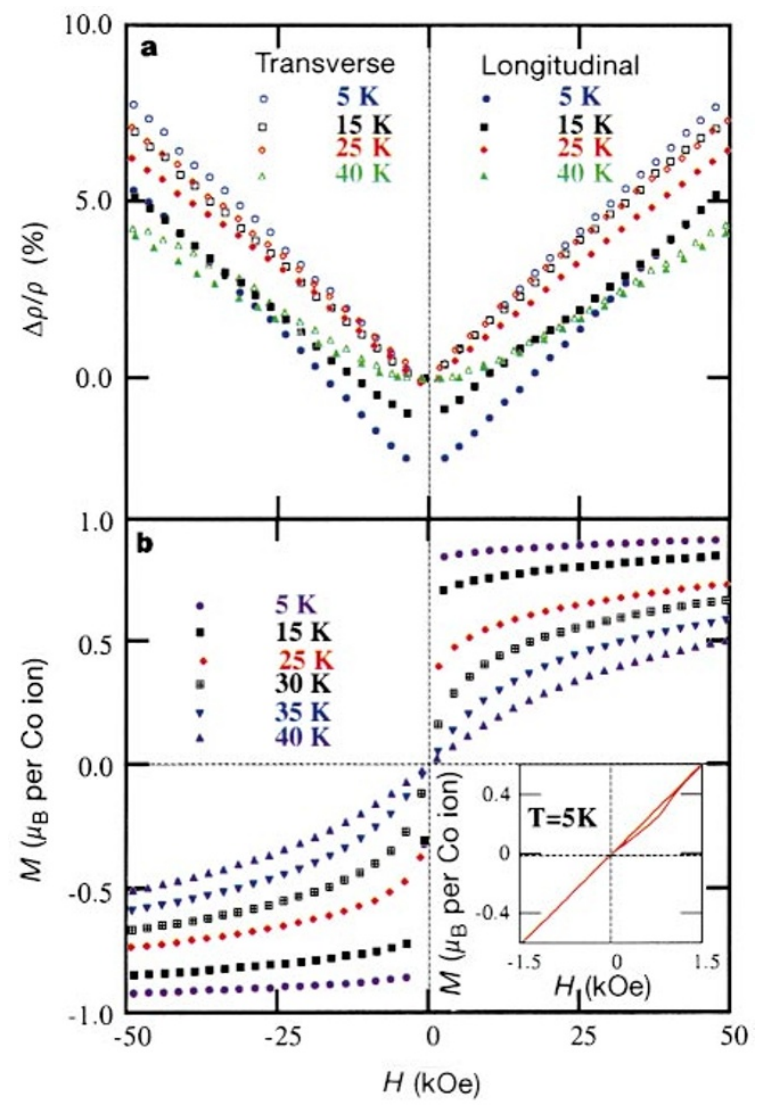

Figure 3 Field dependence of magnetoresistance and magnetization. $\mathbf{a}$, Longitudinal and transverse magnetoresistance of $\mathrm{Fe}_{0.85} \mathrm{CO}_{0.15} \mathrm{Si}$ at various temperatures. $\mathbf{b}$, Magnetization of $\mathrm{Fe}_{0.85} \mathrm{Co}_{0.15} \mathrm{Si}$ at various temperatures. Inset, history dependence of the magnetization showing a small hysteresis upon increasing the field from zero. The sample was initially cooled to $5.0 \mathrm{~K}$ in zero field and the magnetization was measured at positive increasing fields and then cycled through negative fields to zero. At low $H$ and low $T$ the longitudinal magnetoresistance is negative, probably as a result of the anomalous magnetoresistance common to ferromagnets ${ }^{22}$. This magnetoresistance results from strong spin-orbit coupling in much the same way as the anomalous Hall effect does and is dependent on the orientation between $\mathbf{M}$ and the current density, $\mathbf{J}$. After subtraction of this low-field anisotropic magnetoresistance there are only slight differences between the transverse and longitudinal magnetoresistance. Thus, we conclude that there is little contamination of our data from an ordinary Lorentz magnetoresistance which is anisotropic and dependent on the orientation of $\mathbf{J}$ and $\mathbf{B}$ (ref. 22). The symmetry of our magnetoresistance data about $H=0$ shows that there is negligible contamination from the (asymmetric) Hall effect. asymptote roughly proportional to $H^{1 / 2}$.

Has behaviour of the type shown in Fig. $4 \mathrm{a}$ and $\mathrm{b}$ been seen before? In classic paramagnetic materials, theory has predicted and exhaustive experiments have shown that near the metal-insulator transition the Coulomb interactions between carriers are enhanced by the diffusive nature of the transport $\mathrm{t}^{24-26}$. The enhancement results from the finite probability of two carriers interacting more than once within a phase-breaking scattering time ${ }^{24}$. The scattering amplitudes interfere coherently, leading to an increased Coulomb coupling and a square-root singularity in the electronic density-ofstates at the Fermi energy. The resulting $\sigma(H, T)$, which measures the energy-dependent density-of-states either thermally or by the Zeeman effect, has $H^{1 / 2}$ (for $T=0$ ) and $T^{1 / 2}$ dependences ${ }^{24,25}$. Our experiments on $\mathrm{FeSi}_{1-z} \mathrm{Al}_{z}$ have demonstrated that such electronelectron interaction effects dominate the low $T$ transport ${ }^{12}$. For comparison we have included in Fig. $4 \mathrm{a}$ and $\mathrm{b}$ our data for $\mathrm{FeSi}_{0.95} \mathrm{Al}_{0.05}$ and $\mathrm{Fe}_{0.92} \mathrm{Mn}_{0.08} \mathrm{Si}$ which have similar $n$ and $\sigma$, but remain paramagnetic at low $T$. We can see that the $T$ dependence for the two samples is similar. Indeed, for $H=9 \mathrm{~T}$, a field chosen to be well above that required to saturate $M$ up to high temperatures in $\mathrm{Fe}_{1-y} \mathrm{Co}_{y} \mathrm{Si}$, the prefactors of the $T^{1 / 2}$ term are within $30 \%$ of each other for the very different dopants. The field dependences are also similar approaching asymptotes proportional to $H^{1 / 2}$, although the amplitudes of the asymptotes are more diverse, but still remain within factors of three of each other for the different dopants.

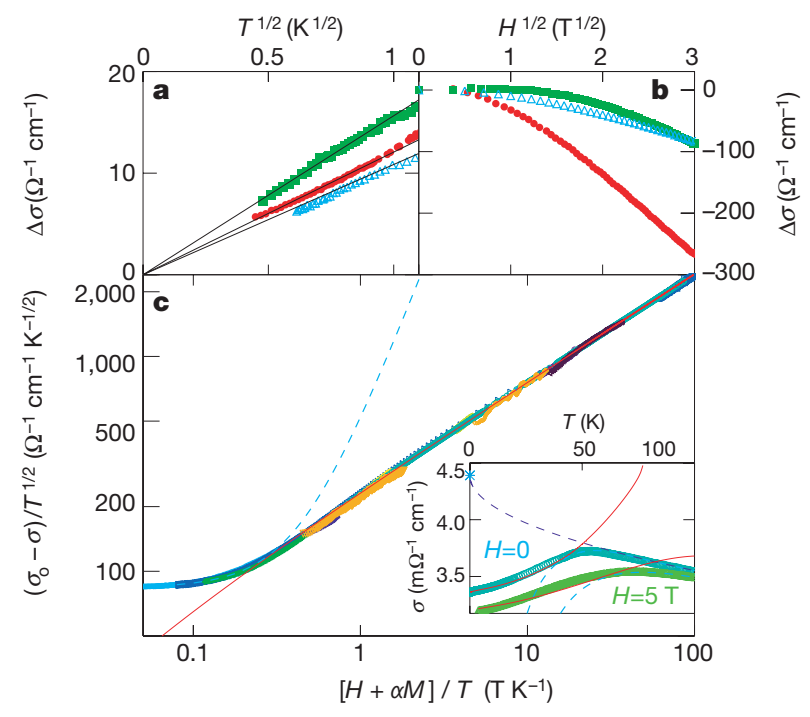

Figure 4 Magnetotransport. a, Magnetoconductivity of $\mathrm{Fe}_{0.9} \mathrm{CO}_{0.1} \mathrm{Si}$ (red circle), $\mathrm{FeSi}_{0.95} \mathrm{Al}_{0.05}$ (blue triangle) and $\mathrm{Fe}_{0.92} \mathrm{Mn}_{0.08} \mathrm{Si}$ (green square). Change in conductivity, $\Delta \sigma=\sigma(H, T)-\sigma(H, 0)$ with $\sigma(H, 0)$ determined from fits of the data to a $T^{1 / 2}$ dependence), versus $T^{1 / 2}$ at $H=9$ T. $\sigma(0,0)=1,910 \Omega^{-1} \mathrm{~cm}^{-1}$ for $\mathrm{Fe}_{0.9} \mathrm{C}_{0.1} \mathrm{Si}, 1,260 \Omega^{-1} \mathrm{~cm}^{-1}$ for $\mathrm{FeSi}_{0.95} \mathrm{Al}_{0.05}$ and $1,540 \Omega^{-1} \mathrm{~cm}^{-1}$ for $\mathrm{Fe}_{0.92} \mathrm{Mn}_{0.08} \mathrm{Si}$. b, $\Delta \sigma=\sigma(H, T)-\sigma(0, T)$ versus $H^{1 / 2}$ at $T=0.25 \mathrm{~K}$. Symbols represent the same samples as in a. c, Scaling plot of the conductivity $\left(\sigma-\sigma_{0}\right) / T^{1 / 2}$ versus $H_{\text {eff }} / T$ for $\mathrm{Fe}_{0.7} \mathrm{Co}_{0.3} \mathrm{Si}$, with $H_{\text {eff }}$ taken as $H+\alpha M$ and with $\sigma_{0}$ and $\alpha$ determined by the best scaling of all our $T$ - and $H$-dependent data. The data shown include temperature sweeps at constant fields of $0(0.2-100 \mathrm{~K}$, teal circle), $0.8 \mathrm{~T}$ (2-100 K, light-blue filled circle), $3 \mathrm{~T}$ (2-100 K, dark-blue forward arrow) and $5 \mathrm{~T}$ (2-100 $\mathrm{K}$, green upright cross). Also shown are constant-temperature field sweeps at temperatures of $0.3 \mathrm{~K}(0-9 \mathrm{~T}$, dark-blue square), $1.2 \mathrm{~K}(0-32 \mathrm{~T}$, black backward arrow), $1.5 \mathrm{~K}(0-9 \mathrm{~T}$, purple dotted circle), $4 \mathrm{~K}(0-32 \mathrm{~T}$, orange diamond), $5 \mathrm{~K}(0-5 \mathrm{~T}$, yellowgreen asterisk), $15 \mathrm{~K}(0-5 \mathrm{~T}$, yellow cross) and $30 \mathrm{~K}(0-5 \mathrm{~T}$, violet triangle, and $0-32 \mathrm{~T}$, red inverted triangle). Light-blue dashed line represents a fit to the data for $H_{\text {eff }} / T<0.25$ in the form: $a+b\left(H_{\text {eff }} / T\right)^{2}$. Solid red line represents a fit to the data for $H_{\text {eff }} / T>0.25$ in the form: $c+d\left(H_{\mathrm{eff}} / T\right)^{1 / 2}$. Inset, red line and dashed light-blue line represent the same fits as in the main part of the figure. The dashed purple line represents the zero $H_{\text {eff }}$ conductivity in our model. Light-blue asterisk represents $\sigma_{0}$, the zero-temperature, zeromagnetic-field value of the conductivity determined from the scaling of the data. 
Given the similarities between the data for paramagnetic Al- and $\mathrm{Mn}$-doped $\mathrm{FeSi}$ and ferromagnetic $\mathrm{Fe}_{1-y} \mathrm{Co}_{y} \mathrm{Si}$, and because the parameters found in the detailed comparison between theory and experiment for $\mathrm{FeSi}_{1-z} \mathrm{Al}_{z}$ are reasonable, we propose that the lowtemperature magnetotransport in $\mathrm{Fe}_{1-y} \mathrm{Co}_{y} \mathrm{Si}$ is due to electronelectron interactions enhanced by disorder. The proposal is phenomenological, so that its success in describing the data does not exclude underlying physical explanations different from ours.

The standard theory for paramagnetic disordered metals usefully encapsulates $\sigma(H, T)$ by $\left(\sigma-\sigma_{0}\right) / T^{1 / 2}=f\left(g \mu_{\mathrm{B}} H / k_{\mathrm{B}} T\right)$ where $f(x)$ is a scaling function whose limiting form is $x^{2}$ for $x \ll 1$ and $x^{1 / 2}$ for $x \gg 1$ (refs 24 and 25). Because $\mathrm{Fe}_{1-y} \mathrm{Co}_{y} \mathrm{Si}$ is, to our knowledge, the first ordered ferromagnet for which the $T^{1 / 2}$ and $H^{1 / 2}$ terms are present, no theory is available for ferromagnets. Even so, it seems reasonable to believe that the main difference between paramagnets and ferromagnets is simply that for the ferromagnet, in addition to the external field, there is a large spontaneous field due to the ordered moment. Thus, the effective field is really $H_{\text {eff }}=H+\alpha M$ (where $\alpha$ is a constant) rather than $H$ alone. We then imagine that for the ferromagnet, we should simply insert $H_{\text {eff }}$ where $H$ appears in the expressions for $\sigma(H, T)$ derived for disordered paramagnets with electron-electron interactions ${ }^{27}$.

We have checked whether the scaling theory, posited for the paramagnets and generalized by the replacement of $H$ by $H_{\text {eff }}$, works for ferromagnetic $\mathrm{Fe}_{1-y} \mathrm{Co}_{y} \mathrm{Si}$. Figure $4 \mathrm{c}$ shows the outcome, where we have plotted all of our temperature- and field-dependent data below $100 \mathrm{~K}$ for the $x=0.30$ sample in the form $\left(\sigma-\sigma_{0}\right) / T^{1 / 2}$ versus $H_{\text {eff }} / T$ with $\alpha=1,900$ and $\sigma_{0}=4,400 \Omega^{-1} \mathrm{~cm}^{-1}$ chosen to minimize the difference of the data from a piecewise linear form. Note that $\sigma_{0}$ represents the zero- $H_{\text {eff }}$, zero- $T$ conductivity shown in the inset to Fig. 4c. The data scale well and result in a $\left(H_{\text {eff }} / T\right)^{2}$ form for $H_{\text {eff }} / T$ $<0.25 \mathrm{~T} \mathrm{~K}^{-1}$ (dashed blue line) and a $\left(H_{\mathrm{eff}} / T\right)^{1 / 2}$ form for $H_{\mathrm{eff}} / T>$ $0.25 \mathrm{~T} \mathrm{~K}^{-1}$ (solid red line). The data for the $y=0.1,0.15$ and 0.20 samples scale equally well. The inset to Fig. $4 \mathrm{c}$ shows the $H=0$ and $5 \mathrm{~T}$ conductivity of the $y=0.30$ sample, along with the simple asymptotes extracted from the scaling analysis of the main part of Fig. 4, with $H_{\text {eff }}$ calculated using the bulk magnetometry data. We conclude from the quality of both the scaling and the fits that, outside of small low-field effects, the field and T-dependent conductivity up to $100 \mathrm{~K}$ appears entirely determined by a square-root singularity in the density-of-states probably associated with enhanced electron-electron interactions in a disordered low $n$ ferromagnet. Until now, such $E^{1 / 2}$ terms have been deemed relevant only at ultra-low temperatures $(<1 \mathrm{~K})$. Thus, our discovery of a positive magnetoresistance not only shows a new mechanism for magnetoresistance in ferromagnets, but also demonstrates the relevance of quantum interference effects to electrical properties measured well outside the sub-Kelvin domain of low-temperature physics.

Received 21 October 1999; accepted 1 February 2000.

1. Searle, C. W. \& Wang, S. T. Studies of the ionic ferromagnet $(\mathrm{LaPb}) \mathrm{MnO}_{3}$. III Ferromagnetic resonance studies. Can. J. Phys. 47, 2703-2708 (1969).

2. Jin, S. et al. Thousandfold change change in the resistivity in magnetoresistive La-Ca-Mn-O films. Science 264, 413-415 (1994).

3. Tokura, Y. et al. Origins of colossal magnetoresistance in perovskite-type manganese oxides. J. Appl. Phys. 79, 5288-5291 (1996).

4. Shimakawa, Y., Kubo, Y. \& Manako, T. Giant magnetoresistance in $\mathrm{Tl}_{2} \mathrm{Mn}_{2} \mathrm{O}_{7}$ with the pyrochlore structure. Nature 379, 53-55 (1996).

5. Ramirez, A. P. \& Subramanian, M. A. Large enhancement of magnetoresistance in $\mathrm{Tl}_{2} \mathrm{Mn}_{2} \mathrm{O}_{7}$ : pyrochlore versus perovskite. Science 277, 546-549 (1997).

6. Majumdar, P. \& Littlewood, P. B. Dependence of magnetoresistivity on charge-carrier density in metallic ferromagnets and doped magnetic semiconductors. Nature 395, 479-481 (1998).

7. Aeppli, G. \& Fisk, Z. Kondo insulators. Comments Condens. Matter Phys. 16, 155-165 (1992).

8. Wernick, J. H., Wertheim, G. K. \& Sherwood, R. C. Magnetic behavior of the monosilicides of the 3dtransition elements. Mater. Res. Bull. 7, 1431-1441 (1972).

9. Jaccarino, V., Wertheim, G. K., Wernick, J. H., Walker, L. R. \& Arajs, S. Paramagnetic excited state of FeSi. Phys. Rev. 160, 476-482 (1967).

10. Schlesinger, Z. et al. Unconventional charge gap formation in FeSi. Phys. Rev. Lett. 71, 1748-1751 (1993).

11. van der Marel, D., Damascelli, A., Schulte, K. \& Menovsky, A. A. Spin, charge, and bonding in transition metal mono-silicides. Physica B 244, 138-147 (1998).
12. DiTusa, J. F. et al. Metal-insulator transitions in the Kondo insulator FeSi and classic semiconductors are similar. Phys. Rev. Lett. 78, 2831(1997); erratum 78, 4309 (1997).

13. Chernikov, M. A. et al. Low-temperature transport, optical, magnetic, and thermodynamic properties of $\mathrm{Fe}_{1-x} \mathrm{Co}_{x} \mathrm{Si}$. Phys. Rev. B 56, 1366-1375 (1997).

14. Moriya, T. Spin Fluctuations in Itinerant Electron Magnetism (ed. Fulde, P.) (Springer, Berlin/ Heidelberg/New York/Tokyo, 1985).

15. Beille, J., Voiron, J. \& Roth, M. Long period helimagnetism in the cubic $\mathrm{B} 20 \mathrm{Fe}_{x} \mathrm{Co}_{1-x} \mathrm{Si}$ and $\mathrm{Co}_{x} \mathrm{Mn}_{1-x}$ Si alloys. Solid State Commun. 47, 399-402 (1983).

16. Ishimoto, K., Ohashi, M., Yamauchi, H. \& Yamaguchi, Y. Itinerant electron ferromagnetism in $\mathrm{Fe}_{0.8} \mathrm{Co}_{0.2} \mathrm{Si}$ studied by polarized neutron diffraction. J. Phys. Soc. Jpn 61, 2503-2511 (1992).

17. Kawarazaki, S., Yasuoka, H., Nakamura, Y. \& Wernick, J. H. Magnetic properties of $\left(\mathrm{Fe}_{1-\mathrm{x}} \mathrm{Co}_{\mathrm{x}}\right) \mathrm{Si}$. J. Phys. Soc. Jpn 41, 1171 (1976).

18. Paschen, S., Pushin, D., Ott, H. R., Young, D. P. \& Fisk, Z. Magnetism and electrical transport in $\mathrm{Fe}_{0.9} \mathrm{TM}_{0.1} \mathrm{Si}$, TM $=\mathrm{Co}$, Rh, Ru. Physica B 259-261, 864-865 (1999).

19. Ueda, K. Effect of a magnetic field on spin fluctuations in weakly ferromagnetic metals. Solid State Commun. 19, 965-968 (1976).

20. Kadowaki, K., Okuda, K. \& Date, M. Magnetization and magnetoresistance of MnSi. I. J. Phys. Soc. Jpn 51, 2433-2438 (1982)

21. Hwang, H., Cheong, S.-W., Ong, N. P. \& Batlogg, B. Spin-polarized intergrain tunneling in $\mathrm{La}_{2 / 3} \mathrm{Sr}_{1 / 3} \mathrm{MnO}_{3}$. Phys. Rev. Lett. 77, 2041-2044 (1996).

22. Campbell, I. A. \& Fert, A. Ferromagnetic Materials Vol. 3 (ed. Wohlfarth, E. P.) 751-804 (NorthHolland, Amsterdam, 1982).

23. Xu, R. et al. Large magnetoresistance in non-magnetic silver chalcogenides. Nature 390, 57-60 (1997). 24. Lee, P. A. \& Ramakrishnan, T. V. Disordered electronic systems. Rev. Mod. Phys. 57, 287-337 (1985).

25. Al'tshuler, B. L., Aronov, A. G., Gershenson, M. E. \& Sharvin, Yu. V. Quantum effects in disordered metal films. Sov. Sci. Rev. A Phys. 9, 223-354 (1987).

26. Rosenbaum, T. F. et al. Metal-insulator transition in a doped semiconductor. Phys. Rev. B 27, 75097523 (1983)

27. Millis, A. J. \& Lee, P. A. Spin-orbit and paramagnon effects on magnetoconductance and tunneling. Phys. Rev. B 30, 6170-6173 (1984); erratum 31, 5523-5524 (1985).

28. Ishikawa, Y., Tajima, K., Bloch, D. \& Roth, M. Helical spin structure in manganese silicide MnSi. Solid State Commun. 19, 525-528 (1976).

\section{Acknowledgements}

We thank E. Abrahams, P.W. Adams, D.A. Browne, P. Littlewood and A. Ruckenstein for discussions. J.F.D. acknowledges the support of the Louisiana Board of Regents. J.F.D. and Z.F. acknowledge the support of the National Science Foundation.

Correspondence and requests for materials should be addressed to J. F. D.

(e-mail: ditusa@phys.lsu.edu.)

\section{Communication at millimetre- submillimetre wavelengths using a ceramic ribbon}

\section{Yeh ${ }^{\star}$, F. Shimabukuro ${ }^{\star} \dagger$, P. Stanton ${ }^{\star}$, V. Jamnejad ${ }^{\star}$, W. Imbriale ${ }^{\star}$ \& F. Manshadi ${ }^{*}$}

* Jet Propulsion Laboratory, California Institute of Technology,

4800 Oak Grove Drive, Pasadena, California 91109, USA

$\dagger$ The Aerospace Corp., El Segundo, California 90009, USA

Following the discovery by Kao and Hockman ${ }^{1-3}$ that ultra-lowloss optical fibres could be made from pure silica through the elimination of impurities, the ability to guide signals effectively at optical wavelengths has been assured. But there remains an important region of the spectrum-from 30 to $3,000 \mathrm{GHz}$ (the millimetre-submillimetre band) - where low-loss waveguides are unknown. The main problem here in finding low-loss solids is no longer one of eliminating impurities, but is due to the presence of intrinsic vibration absorption bands ${ }^{4-6}$. And the use of highly conducting materials is also precluded owing to high skindepth $\operatorname{losses}^{7,8}$ in this part of the spectrum. Here we show that a combination of material and waveguide geometry can circumvent these difficulties. We adopt a ribbon-like structure with an aspect ratio of 10:1, fabricated from ceramic alumina (Coors' 998 Alumina), and the resulting waveguide has an attenuation factor of less than $10 \mathrm{~dB} \mathrm{~km}^{-1}$ in the millimetre-submillimetre band. This attenuation is more than 100 times smaller than that of a 
Table 3 Stochastic forecasts of combined sex life expectancy at birth $\left(e_{o}\right)$, compared with official forecasts

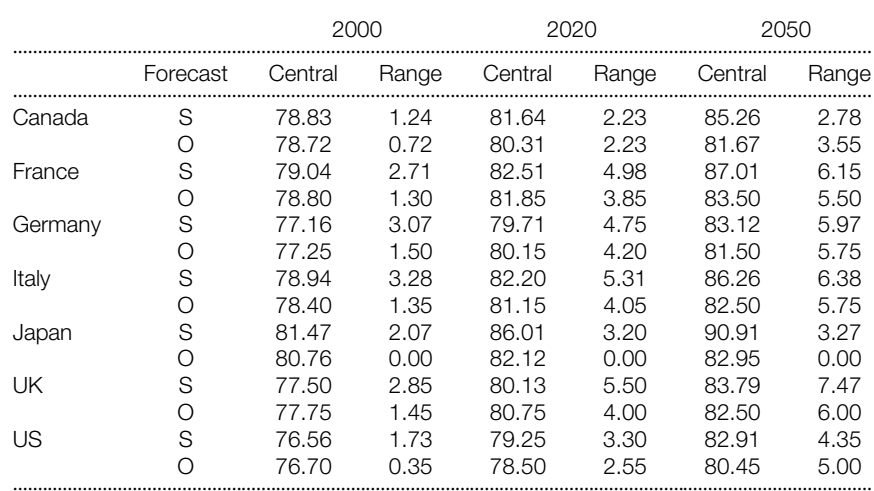

Official forecasts have 'high', 'medium', and 'low' variants, except that there is only one officia forecast for Japan ${ }^{23}$. For France, Germany, Italy and the UK, mortality forecasts are those published by Eurostat (Data Shop Eurostat, Luxembourg) ${ }^{24}$. For Canada, the forecasts follow assumptions of the Canadian Pension Plan ${ }^{25,26}$. S, stochastic forecast: central (50\%), range (95-5\%). O, official forecast: central (medium), range (high-low).

where $\mathrm{z}>0$, and $\epsilon_{t}$ is a series of independent normal stochastic disturbances. This model has been used earlier to forecast mortality $^{13}$ and population ${ }^{21}$ for the US. In countries other than Japan, age-specific mortality over age 85 is estimated using a model schedule ${ }^{7,17}$.

The rate of decline $z$ (Table 2, first row) is in the range of 0.3 to 0.5 per year in the US, Canada and the European countries, and is highest in Japan at about 0.8 per year. Note that exponential decline at a constant rate implies that the absolute annual decrement in mortality will diminish over time so that, for example, the rate of decline of life expectancy will also diminish over time. There is substantial short-term variability in the annual rates of decline (Table 2, second row).

Our forecasts advance from a launch date using the stochastic model to generate a probability distribution of forecast values in each year. Figure 2 exemplifies the difference between our stochastic forecasts of $\mathrm{e}_{0}$ and official forecasts based on scenarios. For example, the median (50th percentile of probability) stochastic forecast for France is about $3.5 \mathrm{yr}$ higher in 2050 than the central official forecast. Comparisons for all countries (Table 3 ) show stochastic median forecasts in 2050 that are higher than official ones by an astounding $8 \mathrm{yr}$ for Japan, to a relatively low $1.3 \mathrm{yr}$ for the UK. Official forecasts may be strongly influenced by short-term slowdowns in mortality change or by conservative expert opinion ${ }^{7,12}$. To see why this matters, note that a 1 -yr difference in $e_{0}$ corresponds to a difference of over $5 \%$ in the dependency ratio (population over 65 divided by population ages 20-64; we use the life-table ratio here, a good approximation for the G7). The dependency ratio is a useful direct index of the costs of ageing, so we project median dependency ratios, and thus costs of ageing, higher by between 6 and $40 \%$ than do official forecasts. Beyond 2050, this forecast divergence would increase, because virtually all official scenarios assume that mortality decline will eventually slow (or stop) ${ }^{22}$. Figure 2 and Table 3 also display differences in forecast uncertainty, which provides a measure of demographic and policy risk. Uncertainty grows much more quickly in the stochastic forecast, but by 2050, official 'high' and 'low' patterns spread over about the same range.

Our forecasts have large implications for the financing of public programs of old-age support and pensions, as well as private and public health insurance. In the US, for example, the finances of Social Security and medical care for the elderly will be driven by the ageing of the baby boom in the next two decades, but the longer term finances will turn on the sustained increase in human life span. The demographic forecasts that shape policy analyses related to oldage support should reflect the regularity of mortality change that we describe.
Received 11 January; accepted 16 March 2000

1. Smith, D. W. Human Longevity. (Oxford Univ. Press, New York, 1993)

2. Preston, S. H. in Forecasting The Health of Elderly Populations (eds Manton, K. G., Singer, B. H. \& Suzman, R. M.) 51-77 (Springer, New York, 1991).

3. Preston, S. H. Mortality Patterns in National Populations, with Special Reference to Recorded Cause of Death. (Academic, New York, 1976).

4. Lee, R. D. in Demography of Aging (eds Martin, L. G. \& Preston, S.H.) 8-49 (National Academy Press, Washington DC, 1994)

5. World Bank Policy Research Report Averting the Old Age Crisis: Policies to Protect the Old and Promote Growth (Oxford Univ. Press, Oxford, 1994).

6. McKeown, T. The Modern Rise of Population (Academic, New York, 1976)

7. Tuljapurkar, S. \& Boe, C. Mortality change and forecasting: How much and how little do we know? $N$. Am. Actuarial J. 2, 13-47 (1998).

8. Horiuchi, S. \& Wilmoth, J. Age patterns of the life-table ageing rate for major causes of death: Aging, disease and mortality in Japan, 1951-1990. J. Gerontol. A 52, B67-B77 (1996).

9. Wilmoth, J. R. Are mortality projections always more pessimistic when disaggregated by cause of death? Math. Popul. Stud. 5, 293-319 (1995).

10. Manton, K. G., Stallard, E. \& Tolley, D. H. Limits to human life expectancy. Popul. Dev. Rev. 17, 603637 (1991).

11. Meslé, F. Classifying causes of death according to an aetiological axis. Popul. Stud. 53, 97-105 (1999). 12. Wilmoth, J. R. in Health and Mortality among Elderly Populations (eds Caselli, G. \& Lopez, A.) 266287 (Oxford Univ. Press, Oxford, 1996).

13. Lee, R. D. \& Carter, L. Modeling and forecasting the time series of US mortality. J. Am. Stat. Assoc. 87, 659-671 (1992).

14. von Storch, H. Comment on statistics and physical oceanography. Stat. Sci. 9, 215-221 (1994).

15. Broomhead, D. \& King, G. Extracting qualitative dynamics from experimental data. Physica D 20, 217-236 (1986).

16. de León, J. Empirical EDA Models to Fit and Project Time Series of Age Specific Mortality Rates. Technical Report No. 50. (Central Bureau of Statistics, Oslo, 1990).

17. Himes, C. L., Preston, S. H. \& Condran, G. A. A relational model of mortality at older ages in low mortality countries. Popul. Stud. 48, 269-291 (1994).

18. Lee, R. D. \& Skinner, J. in Assessing Knowledge of Retirement Behavior (eds Hanushek, E. A. \& Maritato, N. L.) 195-243 (National Academy Press, Washington DC, 1996).

19. Wilmoth, J. R. The future of human longevity: a demographer's perspective. Science 280, 395-397 (1998).

20. Bell, W. Comparing and assessing time series methods for forecasting age-specific fertility and mortality rates. J. Official Stat. 13, 279-303 (1997).

21. Lee, R. D. \& Tuljapurkar, S. Stochastic population forecasts for the United States: Beyond high, medium, and low. J. Am. Stat. Assoc. 89, 1175-1189 (1994).

22. Preston, S. H. Evaluation of postwar mortality projections in the United States, Canada, Australia, New Zealand and Japan. World Health Statistics Report 27, 719-745 (1974).

23. Population Projection of Japan: 1996-2050. Technical Report (National Institute of Population and Social Security Research, Tokyo, 1997).

24. de Beer, J. \& de Jong, A. National population scenarios for countries of the European Economic Area. Maandstatistiek van de Bevolking 44, 7-19 (1996).

25. Goss, S., Wade, A., Bell, F. \& Dussault, B. Historical and projected mortality for Mexico, Canada, and the United States. N. Am. Actuarial J. 2, 108-126 (1998).

26. Canada Pension Plan, Seventeenth Actuarial Report, (Office of the Chief Actuary, Office of the Superintendent of Financial Institutions, Canada, 1998).

\section{Acknowledgements}

We thank M. Anderson, R. Lee and K. Wachter for comments. This work was supported by the US National Institute of Aging and the John Simon Guggenheim Foundation (S.T.).

Correspondence and requests for materials should be addressed to S.T.

(e-mail: tulja@mvr.org).

\section{Ultrasensitive pheromone detection by mammalian vomeronasal neurons}

\section{Trese Leinders-Zufall ${ }^{\star}$, Andrew P. Lane ${ }^{\star}$, Adam C. Puche ${ }^{\star}$, Weidong Ma $\dagger$, Milos V. Novotny $\dagger$, Michael T. Shipley ${ }^{\star} \&$ Frank Zufall*}

* Department of Anatomy and Neurobiology and Program in Neuroscience, University of Maryland School of Medicine, Baltimore, Maryland 21201, USA $\dagger$ Department of Chemistry, Indiana University, Bloomington, Indiana 47405, USA

The vomeronasal organ (VNO) is a chemoreceptive organ that is thought to transduce pheromones into electrical responses that regulate sexual, hormonal and reproductive function in mammals ${ }^{1-5}$. The characteristics of pheromone signal detection by vomeronasal neurons remain unclear ${ }^{3,5}$. Here we use a mouse VNO slice preparation to show that six putative pheromones 
evoke excitatory responses in single vomeronasal neurons, leading to action potential generation and elevated calcium entry. The detection threshold for some of these chemicals is remarkably low, near $10^{-11} \mathrm{M}$, placing these neurons among the most sensitive chemodetectors in mammals. Using confocal calcium imaging, we map the epithelial representation of the pheromones to show that each of the ligands activates a unique, nonoverlapping subset of vomeronasal neurons located in apical zones of the epithelium. These neurons show highly selective tuning properties and their tuning curves do not broaden with increasing concentrations of ligand, unlike those of receptor neurons in the main olfactory epithelium. These findings provide a basis for understanding chemical signals that regulate mammalian communication and sexual behaviour.

We investigated six structurally diverse ligands that have pheromonal activity in recipient female mice: 2,5-dimethylpyrazine, 2-sec-butyl-4,5-dihydrothiazole, 2,3-dehydro-exo-brevicomin, a mixture of $E, E-\alpha$-farnesene and $E$ - $\beta$-farnesene (referred to as farnesene), 2-heptanone, and 6-hydroxy-6-methyl-3-heptanone (Table 1). Each ligand is involved in diverse chemosignalling functions including oestrus induction or synchronization and puberty delay or acceleration (Table 1$)^{6-10}$. First, we used an intact VNO preparation to record extracellular field potentials from the microvillous surface of the sensory epithelium. These field poten-
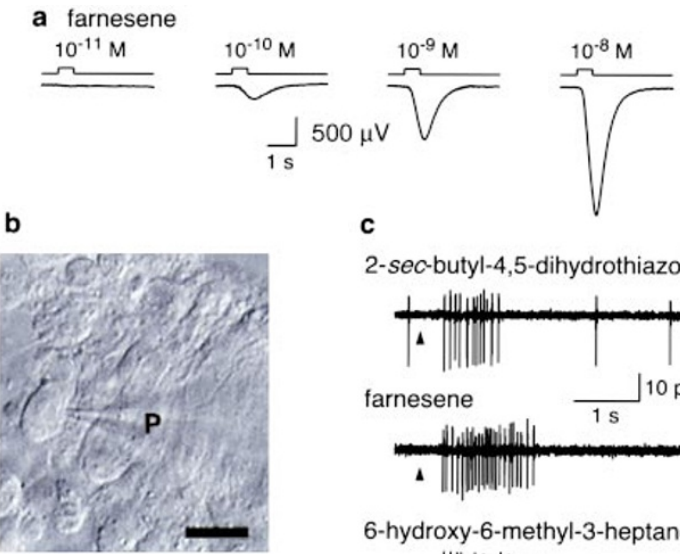

c

2-sec-butyl-4,5-dihydrothiazole

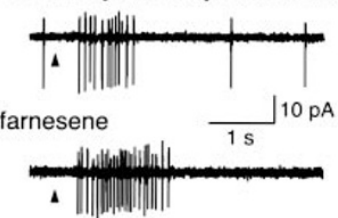

6-hydroxy-6-methyl-3-heptanone
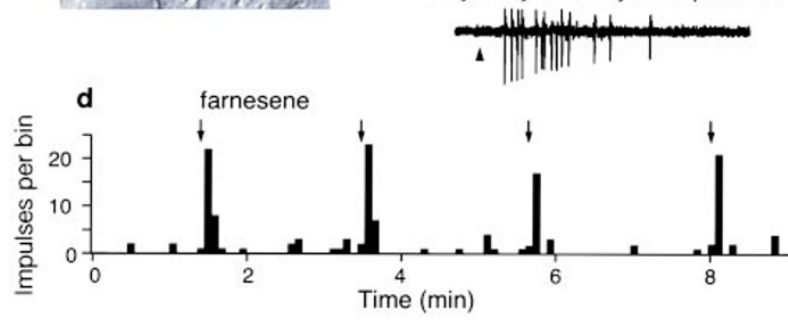

Figure 1 Pheromone-induced excitatory electrical responses in VNO. a, Negative field potentials in intact VNO and their dose-dependency produced by 500-ms pulses of increasing concentrations of farnesene. Ligands were focally applied to the microvillous surface of the sensory epithelium by a multi-barrelled stimulation pipette. b, Infrareddifferential interference contrast micrograph showing VNO tissue slice. Individual VN somata are clearly visible. P, patch electrode. Scale bar, $10 \mu \mathrm{m}$. c, Trains of extracellularly recorded, action-potential-driven, capacitive currents produced by bath application of 2-sec-butyl-4,5-dihydrothiazole, farnesene or 6-hydroxy-6-methyl-3heptanone (all at $10^{-7} \mathrm{M}$ ). Each response was from a different VN using the approach shown in b. Pipette potential was $0 \mathrm{mV}$. Arrowheads, start of bath application (duration, $1-3 \mathrm{~s})$. d, Analysis of the rate of spontaneous and stimulus-induced impulse discharges in a VN. Binwidth, $5 \mathrm{~s}$. The same stimulus (farnesene, $10^{-7} \mathrm{M}$ ) was applied four times to show the repeatability of the responses. The level of spontaneous activity was low compared with stimulus-induced discharges. Although there is a slight decrease in the responses to stimulus three and four, it remains to be seen whether this is due to adaptation. tials, the electro-vomeronasogram (EVG), register summed local activities of vomeronasal neurons (VNs) and provide a measure of electrical responses to the ligands. Brief pulse-like applications of farnesene evoked negative field potentials in a concentrationdependent manner in the VNO of female mice (Fig. 1a). Only very low concentrations of farnesene, ranging from $10^{-11}$ to $10^{-10} \mathrm{M}$, were required to evoke a threshold response (Fig. 1a). Similar responses, but with different thresholds $\left(10^{-11}-10^{-8} \mathrm{M}\right)$, were evoked by the remaining ligands (Table 1).

Because all six compounds produced negative deflections in the EVG response, we inferred that they generate ionic currents causing membrane depolarization leading to impulse generation in single VNs. To test this, we developed a VNO slice preparation ${ }^{11}$ and used infrared videomicroscopy and extracellular loose-patch recordings to register activity from optically identified VNs (Fig. 1b). The probability of evoking stimulus-induced responses from a randomly selected VN was low. Of $52 \mathrm{VNs}$ that were challenged sequentially with each of the six ligands, only three exhibited a chemoresponse and none responded to more than one compound. The responses consisted of a transient increase in impulse frequency (Fig. 1c, d). This indicates that VNs may be sharply tuned to specific a

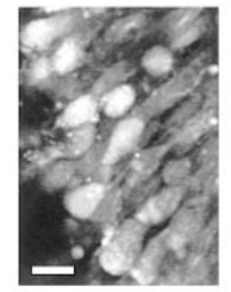

C

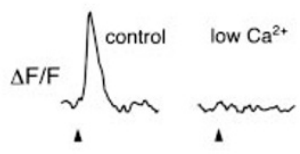

e farnesene b

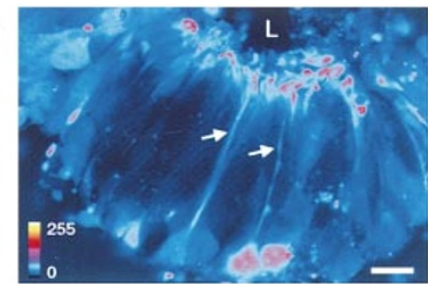

d farnesene
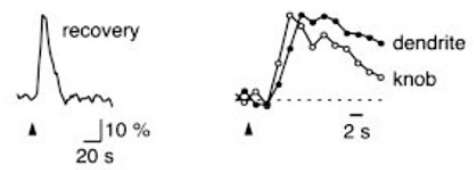
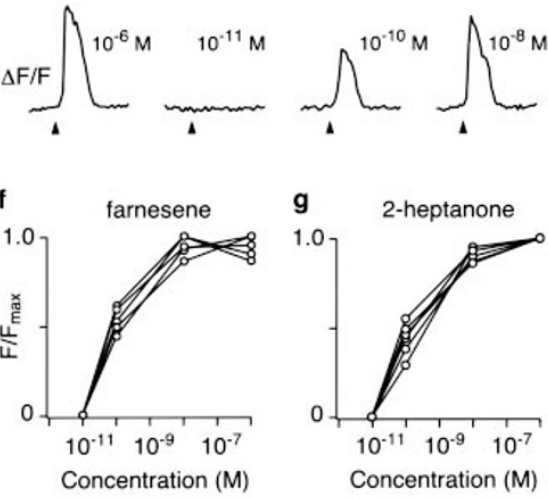

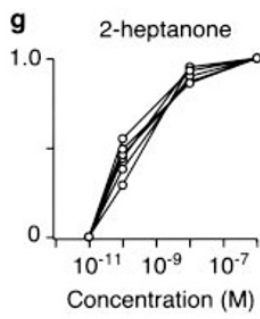

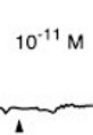

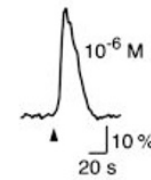

Figure 2 Pheromone-induced $\mathrm{Ca}^{2+}$ elevations in single VNs. a, Confocal fluorescence image (grey scale, acquired at rest) of a VNO slice loaded with fluo-4/AM showing $\sim 50 \mathrm{VN}$ somata. Scale bar, $10 \mu \mathrm{m}$. b. Confocal fluorescence image acquired at rest (pseudocolour scale) showing subcellular structures of VNs such as single dendrites (arrows) projecting to the lumen $(L)$ ending in knob-like swellings. Optical section was $\sim 3 \mu \mathrm{m}$ thick. Scale bar, $10 \mu \mathrm{m}$. c, Waveform of somatic $\mathrm{Ca}^{2+}$ transient of a single VN evoked by bath-applied 2-heptanone $\left(10^{-7} \mathrm{M}\right)$. The response was reversibly abolished by lowering the $\mathrm{Ca}^{2+}$ concentration in the bath solution to $0.6 \mu \mathrm{M}$. d, Comparison of the time course of a farnesene-induced $\mathrm{Ca}^{2+}$ response $\left(10^{-8} \mathrm{M}\right)$ between $\mathrm{knob}$ dendrite of the same VN. e, Dose-dependency and reproducibility of farnesene-induced $\mathrm{Ca}^{2+}$ elevations measured in a single VN. $\mathbf{f}-\mathbf{h}$, Plots showing the dose-dependency of stimulus-induced peak $\mathrm{Ca}^{2+}$ responses of 17 different VNs. Each neuron responded either to farnesene, 2-heptanone or 2,5 dimethylpyrazine. 
a

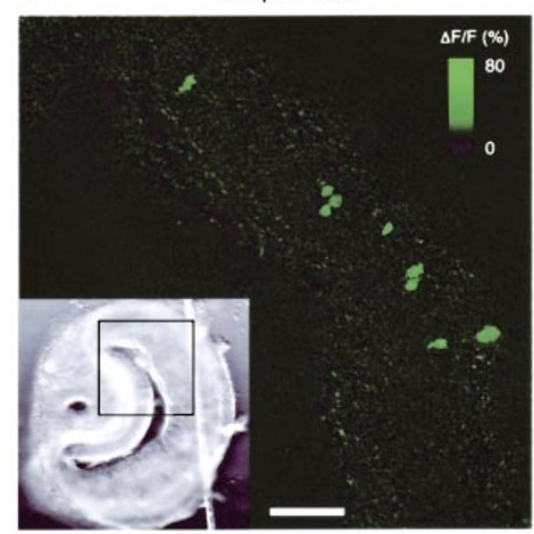

d

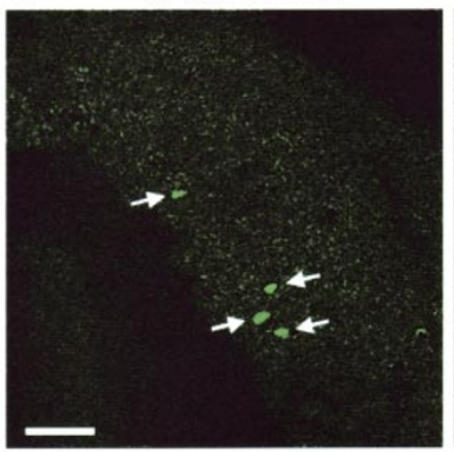

b

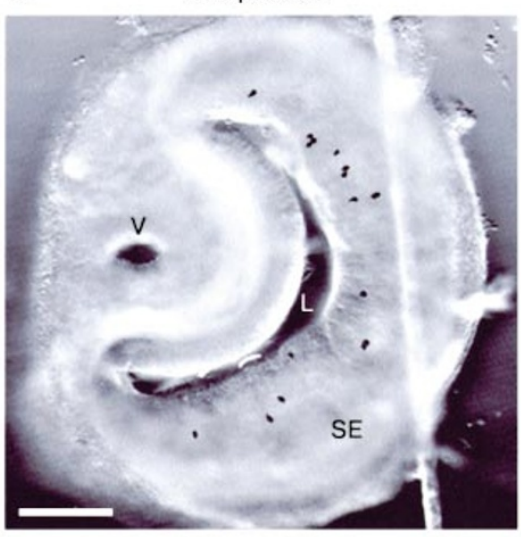

c

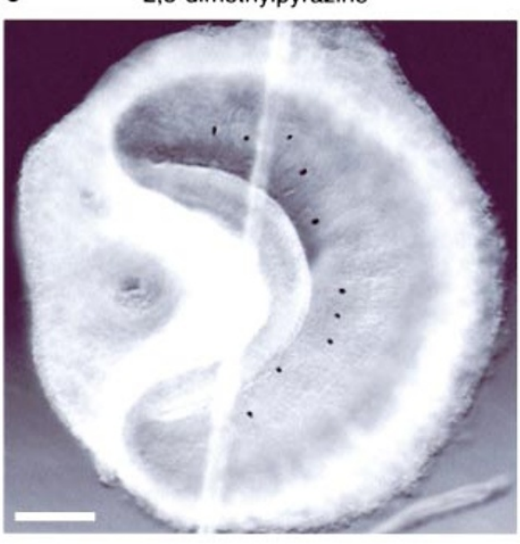

e $\quad 10^{-5} \mathrm{M}$ 2-heptanone

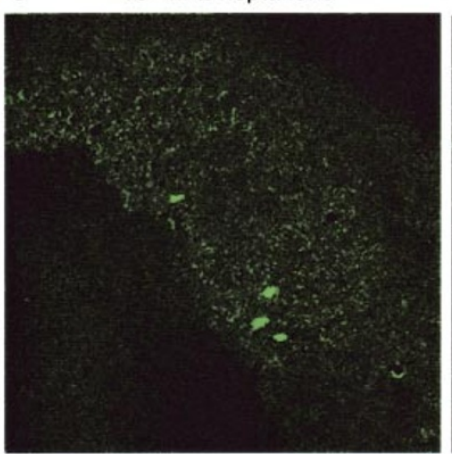

f

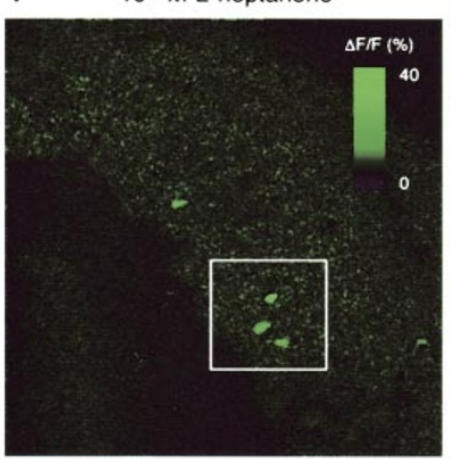

g

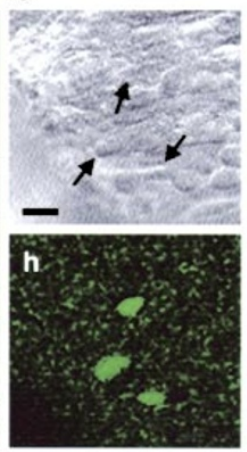

Figure 3 Spatial representation of functional, pheromone-induced activity in VNO. a, Pseudocolour image of the relative increase in stimulus-induced $\mathrm{Ca}^{2+}$-dependent fluorescence (ratio between the peak fluorescence before and after stimulation, $\Delta F / F$ ) produced by bath-applied 2-heptanone $\left(10^{-7} \mathrm{M}\right)$, revealing nine activated VNs. Box in inset, position of the imaged region within the coronal VNO slice. Scale bar, $50 \mu \mathrm{m}$. b, c, Reconstructed $\mathrm{VN}$ response maps $\left(\Delta \mathrm{F} / \mathrm{FCa}^{2+}\right.$ images digitally superimposed onto a transmitted light image of the same slice) for 2-heptanone $\left(10^{-7} \mathrm{M}\right)$ and 2,5-dimethylpyrazine $\left(10^{-7} \mathrm{M}\right)$, showing that VNs activated by each of the two ligands (black dots) were interspersed within the apical zone of the sensory epithelium (SE). V, vein. L, lumen. Scale bar, $100 \mu \mathrm{m}$. d-f, Concentration-independence of VN response maps. Successive stimulation using increasing concentrations of 2-heptanone $\left(10^{-7} \mathrm{M}\right.$, $10^{-5} \mathrm{M}$ and $10^{-3} \mathrm{M}$ ) evoked an identical activity pattern consisting of four active VNs (arrows). Scale bar, $50 \mu \mathrm{m}$. g, the region delimited by the white box was plotted at higher magnification (transmitted light and fluorescence images) to show that the location of the fluorescence signals matched the location of single VNs. Scale bar, $10 \mu \mathrm{m}$. pheromones such that only a small percentage of VNs respond to a given chemical. If so, recordings from one neuron at a time would be an impractical strategy for a systematic analysis of $\mathrm{VN}$ chemoresponsivity.

We therefore devised an optical imaging approach by which the responses of hundreds of VNs could be detected simultaneously. In olfactory receptor neurons (ORNs) of the main olfactory epithelium (MOE), odours induce a transient rise in intracellular $\mathrm{Ca}^{2+}$, owing to the opening of $\mathrm{Ca}^{2+}$-permeable transduction channels ${ }^{12-14}$. Given that pheromones caused strong excitation, we hypothesized that VNs, too, would generate a $\mathrm{Ca}^{2+}$ elevation following chemostimulation. To test this, we loaded VNO slices with the $\mathrm{Ca}^{2+}$ indicator fluo-4/AM and used confocal microscopy to image them at cellular and subcellular resolution (Fig. 2a, b). Almost all VNs responded to extracellular application of $\mathrm{KCl}$ $(60 \mathrm{mM})$ with a transient increase in $\mathrm{Ca}^{2+}$ (not shown). Spontaneous $\mathrm{Ca}^{2+}$ oscillations, which are often seen in developing VNs (results not shown), were not detected in older VNO slices. When we tested each of the six putative pheromones, all produced robust and reproducible increases in $\mathrm{Ca}^{2+}$ (measured at the soma) in a subset of VNs (Fig. 2c-g, see also Figs 3 and 4). The duration of these somatic $\mathrm{Ca}^{2+}$ responses were similar and, in some cases, shorter than odour-induced $\mathrm{Ca}^{2+}$ transients in ORNs ${ }^{13,14,24}$. Removal of extracellular $\mathrm{Ca}^{2+}$ eliminated the responses in a reversible manner, providing evidence that they were triggered primarily by $\mathrm{Ca}^{2+}$ entry into the cells (Fig. $2 \mathrm{c}, n=3$ ). As in ORNs ${ }^{14}, \mathrm{Ca}^{2+}$ responses were initiated at the distal end of the dendrite following chemostimulation, suggesting that they are a consequence of transduction events in the microvilli (Fig. $2 \mathrm{~d}, n=6$ ).

To investigate whether the low thresholds observed in the EVG responses are due to unusually high sensitivity of individual VNs, we analysed stimulus-response relationships of single VNs (Fig. 2f-h). Each stimulus-response curve was derived from a single VN responding either to farnesene (Fig. 2f, $n=5$ ), 2-heptanone (Fig. $2 \mathrm{~g}, n=7$ ) or 2,5-dimethylpyrazine (Fig. 2h, $n=5$ ). These curves allow several important inferences about the mechanisms of chemosensory coding in the VNO. First, single VNs have very low activation thresholds, near $10^{-11} \mathrm{M}$ for farnesene and 2-heptanone, showing that VNs are remarkably sensitive to specific chemicals. The curves obtained with 2,5-dimethylpyrazine were further to the right, indicating that there are significant differences in sensitivity among VNs. Second, the responses saturate over about 2-3 orders of magnitude of ligand concentration, showing that VNs can encode stimulus intensity over a given concentration range. Third, VNs responding to the same chemical exhibit almost identical stimulusresponse curves. Therefore, each of the cells responding to a given ligand may express a pheromone receptor with the same or very similar binding affinities.

To map the spatial organization of neurons responding to the same pheromone, we imaged larger regions of VNO slices while maintaining an optical resolution sufficient to detect responses in single VNs. Figure 3 a shows a spatial pattern of neuronal activation 


\begin{tabular}{|c|c|c|c|c|}
\hline Name & Chemical structure & Origin & $\begin{array}{l}\text { Possible chemosignalling function } \\
\text { in female mice }\end{array}$ & $\begin{array}{l}\text { Detection threshold } \\
\text { EVG response }\end{array}$ \\
\hline 2,5-dimethylpyrazine & & Female urine & Puberty delay ${ }^{6}$ & $10^{-8}-10^{-7} \mathrm{M}$ \\
\hline 2-sec-butyl-4,5-dihydrothiazole & & Male bladder urine & $\begin{array}{l}\text { Oestrus synchronization } \\
\text { Puberty acceleration }^{8}\end{array}$ & $10^{-10}-10^{-9} \mathrm{M}$ \\
\hline 2,3-dehydro-exo-brevicomin & & Male bladder urine & $\begin{array}{l}\text { Oestrus synchronization } \\
\text { Puberty acceleration }^{8}\end{array}$ & $10^{-10}-10^{-9} \mathrm{M}$ \\
\hline$\alpha$ - and $\beta$-farnesenes & & Male preputial gland & Puberty acceleration ${ }^{8}$ & $10^{-11}-10^{-10} \mathrm{M}$ \\
\hline 2-heptanone & 0 & Female or male urine & Oestrus extension ${ }^{9}$ & $10^{-11}-10^{-10} \mathrm{M}$ \\
\hline 6-hydroxy-6-methyl-3-heptanone & & Male bladder urine & Puberty acceleration $^{10}$ & $10^{-8}-10^{-7} \mathrm{M}$ \\
\hline
\end{tabular}

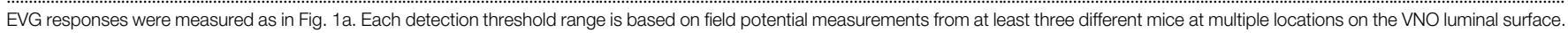

following chemostimulation, revealing nine activated VNs within the imaged region. We then reconstructed 'VNO activation maps' for two of the chemicals, 2-heptanone and 2,5-dimethylpyrazine, by obtaining chemoresponse images for entire epithelial slices and digitally superimposing the responses onto a transmitted light

a

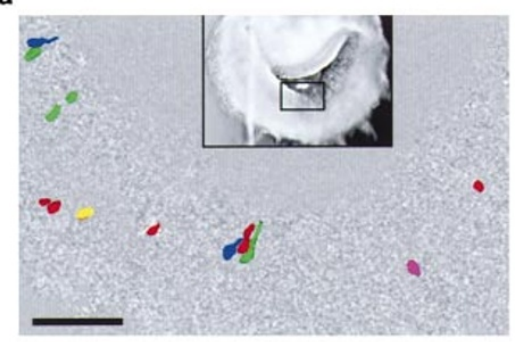

c

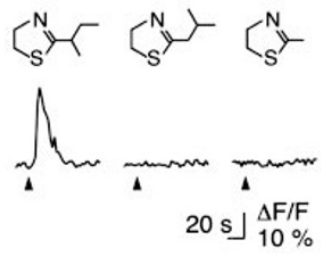

b Number of VNs

2-sec-butyl-4,5-dihydrothiazole 3,4-dehydro-exo-brevicomin farnesene

6-hydroxy-6-methyl-3-heptanone

2-heptanone

2,5-dimethylpyrazine

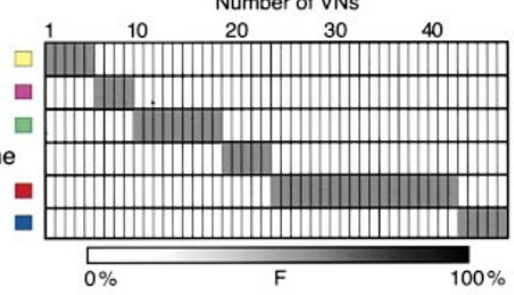

Figure 4 Chemoselectivity of VNs. a, VN activation map produced by successive stimulation with each of the six ligands listed in $\mathbf{b}$ (colour coded, each at $10^{-6} \mathrm{M}$ ). Each ligand activated a unique, nonoverlapping subset of VNs. Inset, low-power transmitted light image of the VNO slice; black box, imaged area. Scale bar, $50 \mu \mathrm{m}$. b. Summary of the tuning profiles of 47 VNs (out of $\sim 1,600$ imaged VNs) responding to the six ligands. For each VN, the magnitude of the $\mathrm{Ca}^{2+}$ response was plotted as a percentage of the maximal response to a given chemical. Dark grey, $100 \%$; white $0 \%$. Without exception, VNs responded to only one of the pheromones tested. Thus, computed tuning curves were identical for all VNs that responded to the same pheromone. c. Two structural analogues of 2-sec-butyl-4,5-dihydrothiazole, isobutyl-4,5-dihydrothiazole and methyl-4,5-dihydrothiazole, were unable to evoke a $\mathrm{Ca}^{2+}$ response in VNs (each tested at $10^{-6} \mathrm{M}$ ). This result was confirmed with EVG recordings using 70-fold higher concentrations of the two analogues (not shown). image of the same slice (Fig. 3b, c; $n=7$ ). Three conclusions can be drawn from this analysis. First, a given chemical is detected by only a small percentage $(0.2-3 \%)$ of all VNs (see also Fig. $4 \mathrm{~b})$. These values are strikingly similar to the percentage of cells that express the same putative pheromone receptor gene $e^{15-18}$. Second, VNs activated by a given chemical are widely distributed in the epithelium with no significant difference between dorsal and ventral areas of the VNO. Analysis of several sections through the entire VNO revealed that activated VNs are randomly distributed along the anterior-posterior axis (not shown). This distribution of activated VNs is very similar to that previously seen for pheromone receptor gene expression $^{15-18}$. Third, VNs activated by any of the six chemicals were preferentially localized to the apical one-third of the sensory epithelium. Previous studies have shown that VNs in this apical zone express the $\mathrm{G}$ protein $\mathrm{G} \alpha_{\mathrm{i}} 2$ (refs 19, 20) and one family of putative pheromone receptors (V1Rs) ${ }^{15}$. Therefore, activation of VNs by the ligands we have examined may be restricted to $\mathrm{G} \alpha_{\mathrm{i}} 2$ - and V1R-positive cells.

Olfactory receptor neurons in the MOE are relatively broadly tuned to odours; each cell is sensitive to a different, but overlapping, set of odours and their tuning curves become less specific as odour concentration is increased. Thus, ORNs with the lowest threshold for a given odorant are activated first, and the less sensitive ones are recruited at higher concentrations, giving rise to a combinatorial coding scheme $e^{21-25}$. We conducted two types of experiment to determine whether VNs employ such a combinatorial coding mechanism. First, we analysed the spatial patterns of VN activation as a function of stimulus concentration. Successive stimulations using increasing concentrations of 2-heptanone, from $10^{-7} \mathrm{M}$ to $10^{-3} \mathrm{M}$, evoked an identical activity pattern consisting of four active VNs in the imaged region (Fig. $3 \mathrm{~d}-\mathrm{j}, n=3$ ). Other experiments using increasing doses of farnesene and 2,5-dimethylpyrazine gave the same result $(n=5)$, indicating that VNO activation maps are concentration-invariant.

Because a concentration-independent activation pattern may indicate that VNs use an unusually narrow tuning profile for stimulus discrimination, we next determined the chemoselectivity of VNs. Responses to successive stimulation with each of the six 
compounds were mapped (Fig. 4a). Each pheromone activated an unique, non-overlapping, subset of VNs. We imaged around 1,600 VNs (in different slices from three mice) of which 47 cells responded to one of the six stimuli (Fig. 4b). In no case did a given $\mathrm{VN}$ respond to more than one of the six pheromones at any concentration tested. Sensitivity profiles were not only narrowly tuned but were identical for all VNs responding to the same pheromone (Fig. 4b). To investigate the tuning specificity of VNs further, we used two biologically inactive analogues ${ }^{6}$ of 2-sec-butyl-4,5-dihydrothiazole: isobutyl-4,5-dihydrothiazole and methyl-4,5-dihydrothiazole. None of the cells that were prefentially tuned for 2-sec-butyl-4,5dihydrothiazole responded to the two analogues (Fig. 4c, $n=7$ ). Furthermore, of about 1,300 imaged VNs with unknown tuning properties, none responded to the two analogues.

By combining electrophysiological and optical imaging techniques in VNO epithelial slices, we have systematically analysed responses to isolated pheromones in mammalian VNs. Our study establishes mouse VNs as ultrasensitive and highly selective pheromone detectors. The results indicate that the principles for processing of chemical information in the mammalian VNO may differ significantly from the combinatorial coding scheme used by the $\mathrm{MOE}^{21-25}$. Mammalian VNs appear to be tuned to recognize only one or perhaps very few pheromonal components, thus resembling the narrowly tuned pheromone-detecting neurons of insects ${ }^{25}$. With the ability to visualize pheromonal functional activity in the VNO in combination with genetic manipulation ${ }^{27,28}$ we can begin to decipher the logic of mammalian pheromonal communication.

\section{Methods}

\section{Tissue preparation}

Female 30-60-day-old CD-1 mice were used for all experiments. For the EVG recordings from intact VNO, animals were decapitated, following anaesthesia, and the vomer bone capsule surrounding the VNO opened. The cavernous tissue was then removed to gain access to the luminal surface of the sensory epithelium. The tissue was superfused continuously at $23^{\circ} \mathrm{C}$ with oxygenated saline $\left(95 \% \mathrm{O}_{2} / 5 \% \mathrm{CO}_{2}\right.$; solution A) containing (in $\mathrm{mM}$ ): $120 \mathrm{NaCl}, 25 \mathrm{NaHCO}_{3}, 5 \mathrm{KCl}, 5 \mathrm{BES}$ ( $N, N$-bis[2-hydroxyethyl]-2-aminoethansulphonic acid), $1 \mathrm{MgSO}_{4}, 1 \mathrm{CaCl}_{2}, 10$ glucose. For all other experiments, the dissected VNO was embedded in agarose, placed in ice-cold solution $\mathrm{A}$, and coronal slices $(250 \mu \mathrm{m})$ were prepared using a vibratome. After sectioning, slices were kept in solution A at $23^{\circ} \mathrm{C}$ for up to 5 hours. All chemicals were purchased from Sigma unless otherwise stated.

\section{Electrophysiology}

Field potentials were recorded using glass pipettes (resistance 1-3 M $\Omega$; tips filled with solution $\mathrm{B}$ in $1.5 \%$ agar) that were connected by an $\mathrm{Ag} / \mathrm{AgCl}$ wire to a differential amplifier (DP-301, Warner Instruments). Solution B consisted of (in mM): $145 \mathrm{NaCl}, 5 \mathrm{KCl}, 10$ Hepes, $1 \mathrm{MgCl}_{2}, 1 \mathrm{CaCl}_{2}$, adjusted to $\mathrm{pH} 7.3(\mathrm{NaOH})$ and $300 \mathrm{mOsm}$ (glucose). A second $\mathrm{Ag} / \mathrm{AgCl}$ wire connected to an agar bridge served as an indifferent electrode. The output signal was digitized, low-pass-filtered (8-pole Bessel; corner frequency $60 \mathrm{~Hz}$ ), and analysed on-line using Pulse software (Heka Electronics). Action-potential-driven capacitive currents were recorded using patch pipettes filled with solution B (seal resistance $\sim 80 \mathrm{M} \Omega$ ) connected to an EPC-9 patch clamp amplifier (sample rate $150 \mu \mathrm{s}$ per point).

\section{Confocal $\mathrm{Ca}^{2+}$ imaging}

Intracellular $\mathrm{Ca}^{2+}$ was monitored with fluo-4/AM (10 $\mu \mathrm{M}$, Molecular Probes) using a BioRAD MRC-1024 confocal laser system (on Olympus BX60 microscope; 10×, 20× or 40× water immersion objectives). Optical sections were $\sim 9 \mu \mathrm{m}$ thick unless otherwise stated. Images were acquired at $0.4 \mathrm{~Hz}$ (ref. 29) and analysed using NIH Image 1.63 and Igor pro software (Wavemetrics). An estimate of the intracellular $\mathrm{Ca}^{2+}$ concentration in $\mathrm{VN}$ somata using calibration methods described previously ${ }^{29}$ revealed resting values of $30-120 \mathrm{nM}$. Maximal somatic fluorescence changes $(\Delta F / F)$ caused by chemostimulation were $\sim 50 \%$, corresponding to a change in $\mathrm{Ca}^{2+}$ concentration of $\sim 550 \mathrm{nM}$ assuming a $K_{\mathrm{d}}$ value of $345 \mathrm{nM}$. Saturation would produce a relative increase of $\sim 80-110 \%$. These high values were usually not reached in our experiments, ruling out the possibility that dye saturation was a significant problem.

\section{Chemostimulation}

Pheromones were either bath-applied (slice experiments, laminar flow chamber, flow rate $\sim 100 \mu \mathrm{l} \mathrm{s}^{-1}$ ) or focally ejected (EVG recordings) using multi-barrelled stimulation pipettes $^{14,29}$. Interstimulus interval was 4 min unless otherwise noted. Pheromone concentrations refer to those in the bath reservoir or stimulation pipette. The concentrations at the site of action were probably lower by a factor of two to four because of local dilution.
Synthetic 4,5-dihydrothiazoles, 2,3-dehydro-exo-brevicomin, and 6-hydroxy-6-methyl-3heptanone were prepared as described ${ }^{10,26,30}$, and diluted to final concentrations using solution B. Farnesene (Bedoukian Research), 2-heptanone (Fluka) and 2,5-dimethylpyrazine (Aldrich) were prepared in dimethyl sulphoxide (DMSO) and diluted to the final concentration using solution B. Final DMSO concentrations $(<0.1 \%)$ had no effect on impulse discharges or $\mathrm{Ca}^{2+}$ concentrations.

Received 24 January; accepted 5 May 2000.

1. Halpern, M. The organization and function of the vomeronasal system. Annu. Rev. Neurosci. 10, 325362 (1987).

2. Wysocki, C. J. \& Meredith, M. in Neurobiology of Taste and Smell (eds Finger, T. E. \& Silver, W. L.) 125150 (Wiley \& Sons, New York, 1987).

3. Keverne, E. B. The vomeronasal organ. Science 286, 716-723 (1999).

4. Bargmann, C. I. Olfactory receptors, vomeronasal receptors, and the organization of olfactory information. Cell 90, 585-587 (1997).

5. Tirindelli, R., Mucignat-Caretta, C. \& Ryba, N. J. P. Molecular aspects of pheromonal communication via the vomeronasal organ of mammals. Trends Neurosci. 21, 482-486 (1998).

6. Novotny, M. V., Jemiolo, B., Harvey, S., Wiesler, D. \& Marchlewska-Koj, A. Adrenal-mediated endogenous metabolites inhibit puberty in female mice. Science 231, 722-725 (1986).

7. Jemiolo, B., Harvey, S. \& Novotny, M. V. Promotion of the Whitten effect in female mice by synthetic analogs of male urinary constituents. Proc. Natl Acad. Sci. USA 83, 4576-4579 (1986).

8. Novotny, M. V., Ma, W., Wiesler, D. \& Zidek, L. Positive identification of the puberty-accelerating pheromone of the house mouse: the volatiles associating with the major urinary protein. Proc. R. Soc. Lond. B 266, 2017-2022 (1999).

9. Jemiolo, B., Andreolini, F., Xie, T.-M., Wiesler, D. \& Novotny, M. V. Puberty-affecting synthetic analogs of urinary chemosignals in the house mouse, Mus domesticus. Physiol. Behav. 46, 293-298 (1989).

10. Novotny, M. V. et al. A unique urinary constituent, 6-hydroxy-6-methyl-3-heptanone, is a pheromone that accelerates puberty in female mice. Chem. Biol. 6, 377-383 (1999).

11. Inamura, K., Kashiwayanagi, M. \& Kurihara, K. Inositol-1,4,5-triphosphate induces responses in receptor neurons in rat vomeronasal sensory slices. Chem. Senses 22, 93-103 (1997).

12. Restrepo, D., Okada, Y. \& Teeter, J. H. Odorant-regulated $\mathrm{Ca}^{2+}$ gradients in rat olfactory neurons. J. Gen. Physiol. 102, 907-924 (1993).

13. Bozza, T. C. \& Kauer, J. S. Odorant response properties of convergent olfactory receptor neurons. J. Neurosci. 18, 4560-4569 (1998).

14. Leinders-Zufall, T., Greer, C. A., Shepherd, G. M. \& Zufall, F. Imaging odor-induced calcium transients in single olfactory cilia: specificity of activation and role in transduction. J. Neurosci. 18, 5630-5639 (1998).

15. Dulac, C. \& Axel, R. A novel family of genes encoding putative pheromone receptors in mammals. Cell 83, 195-206 (1995).

16. Herrada, G. \& Dulac, C. A novel family of putative pheromone receptors in mammals with a topographically organized and sexually dimorphic distribution. Cell 90, 763-773 (1997).

17. Matsunami, I. \& Buck, L. B. A multigene family encoding a diverse array of putative pheromone receptors in mammals. Cell 90, 775-784 (1997).

18. Ryba, N. J. P. \& Tirindelli, R. A new multigene family of putative pheromone receptors. Neuron 19 , 371-379 (1997).

19. Jia, C. \& Halpern, M. Subclasses of vomeronasal receptor neurons: differential expression of G protein (Gi $\alpha 2$ and $\mathrm{Go} \alpha$ ) and segregated projections to the accessory olfactory bulb. Brain Res. 719, 117-128 (1996).

20. Berghard, A. \& Buck, L. Sensory transduction in vomeronasal neurons: evidence for $G_{\alpha_{a^{2}}}, G_{\alpha_{\alpha_{2}}}$, and adenylyl cyclase II as major components of a pheromone signaling cascade. J. Neurosci. 16, 909-918 (1996).

21. Kauer, J. S. Contributions of topography and parallel processing to odor coding in the vertebrate olfactory pathway. Trends Neurosci. 14, 79-85 (1991).

22. Mori, K. \& Yoshihara, Y. Molecular recognition and olfactory processing in the mammalian olfactory system. Prog. Neurobiol. 45, 585-620 (1995).

23. Duchamp-Viret, P., Chaput, M. A. \& Duchamp, A. Odor response properties of rat olfactory receptor neurons. Science 284, 2171-2174 (1999).

24. Malnic, B., Hirono, J., Sato, T. \& Buck, L. B. Combinatorial receptor codes for odors. Cell 96, 713-723 (1999).

25. Hildebrand, J. G. \& Shepherd, G. M. Mechanisms of olfactory discrimination: converging evidence for common principles across phyla. Аnпu. Rev. Neurosci. 20, 595-631 (1997).

26. Zidek, L., Joo, A., Ma, W., Miao, Z. \& Novotny, M. V. 4,5-dihydrothiazoles exhibit no correlations between their puberty-acceleration and activity for soluble binding proteins in the house mouse. Chem. Senses (submitted).

27. Rodriguez, I., Feinstein, P. \& Mombaerts, P. Variable patterns of axonal projections of sensory neurons in the mouse vomeronasal system. Cell 97, 199-208 (1999).

28. Belluscio, L., Koentges, G., Axel, R. \& Dulac, C. A map of pheromone receptor activation in the mammalian brain. Cell 97, 209-220 (1999).

29. Leinders-Zufall, T., Rand, M. N., Shepherd, G. M., Greer, C. A. \& Zufall, F. Calcium entry through cyclic nucleotide-gated channels in individual cilia of olfactory receptor cells: spatiotemporal dynamics. J. Neurosci. 17, 4136-4148 (1997).

30. Novotny, M., Schwende, F. J., Wiesler, D., Jorgenson, J. W. \& Carmack, M. Identification of a testosterone-dependent unique volatile constituent of male mouse urine: 7-exo-ethyl-5-methyl-6,8dioxabicyclo[3.2.1]-3-octene. Experientia 40, 217-219 (1984).

\section{Acknowledgements}

This study was supported by grants from the NIH to T.L.-Z., M.V.N., M.T.S. and F.Z., and by an intramural grant from the University of Maryland (F.Z.). A.P.L. was a recipient of an NIDCD training grant. We thank R. Bock for programming spike analysis software.

Correspondence and requests for materials should be addressed to F.Z. (e-mail: fzufa001@umaryland.edu). 


\section{Acknowledgements}

We thank U. Hebling and L. Swaby for assistance with sequencing work. Reagents were provided by M. Asashima, K. Cho, W. Knöchel, C.-H. Heldin, D. Melton, M. Ueno, $\mathrm{M}$. Whitman and the Genetics Institute. This work was supported in part by a grant from the Deutsche Forschungsgemeinschaft to C.N. and an NIH grant to J.M., who is a Howard Hughes Medical Institute Investigator.

Correspondence and requests for materials should be addressed to C.N. (e-mail: Niehrs@DKFZ-Heidelberg.de) or to J.M. (e-mail: j-massague@ski.mskcc.org).

Tom22 is a multifunctional organizer of the mitochondrial preprotein translocase

Sandra van Wilpe ${ }^{\star}$, Michael T. Ryan $\dagger \#$, Kerstin Hill $\ddagger$, Ammy C. Maarse ${ }^{\star}$, Chris Meisinger $\dagger$, Jan Brix $\dagger$, Peter J. T. Dekker $\dagger$, Martin Moczko $\dagger$, Richard Wagner $\neq$, Michiel Meijer ${ }^{\star}$, Bernard Guiard\$, Angelika Hönlinger $\dagger$ \& Nikolaus Pfanner $\dagger$

* Institute for Molecular Cell Biology, BioCentrum Amsterdam, 1098 SM Amsterdam, The Netherlands

$\dagger$ Institut für Biochemie und Molekularbiologie, Universität Freiburg,

Hermann-Herder-Strasse 7, 79104 Freiburg, Germany

$\ddagger$ Biophysik, Universität Osnabrück, FB Biologie/Chemie, 49034 Osnabrück, Germany

$\$$ Centre de Génétique Moleculaire CNRS, Université Pierre et Marie Curie, 91190 Gif-sur-Yvette, France

\# These authors contributed equally to this work.

Mitochondrial preproteins are imported by a multisubunit translocase of the outer membrane (TOM), including receptor proteins and a general import pore ${ }^{1-5}$. The central receptor Tom 22 binds preproteins through both its cytosolic domain and its intermembrane space domain ${ }^{6-10}$ and is stably associated with the channel protein Tom40 (refs 11-13). Here we report the unexpected observation that a yeast strain can survive without Tom22, although it is strongly reduced in growth and the import of mitochondrial proteins. Tom 22 is a multifunctional protein that is required for the higher-level organization of the TOM machinery. In the absence of Tom 22 , the translocase dissociates into core complexes, representing the basic import units, but lacks a tight control of channel gating. The single membrane anchor of Tom 22 is required for a stable interaction between the core complexes, whereas its cytosolic domain serves as docking point for the peripheral receptors Tom 20 and Tom70. Thus a preprotein translocase can combine receptor functions with distinct organizing roles in a multidomain protein.

Only two Tom proteins, Tom 22 and Tom40, have been shown to be essential for cell viability ${ }^{6,14,15}$, as determined by a standard assay, namely disruption of one chromosomal copy of a gene in a diploid strain of the yeast Saccharomyces cerevisiae, followed by sporulation and analysis to determine whether the resulting haploid cells lacking the gene can grow ${ }^{16}$. Similarly, a sheltered disruption of TOM22 in Neurospora crassa indicated that Tom 22 is essential for cell viability ${ }^{17}$. In a second approach using $S$. cerevisiae, we investigated whether TOM 22 could be deleted directly from haploid cells by a one-step disruption, but no viable cells lacking TOM22 were obtained. In a third approach, a diploid yeast strain (OL551) lacking the TOM 22 coding region in one of its chromosomal copies received a plasmid containing TOM 22 and the URA3 marker. After sporulation, haploid cells containing the chromosomal disruption of TOM22 were selected, all of which carried the TOM22-URA3 plasmid. By adding 5-fluoroorotic acid (5-FOA), we found that cells (OL201) were selected that had lost the URA3-TOM22 plasmid and seemed to lack TOM 22 .

To exclude the possibility that only the URA3 marker was inactivated while the TOM22 gene was still present in OL201, we performed analytical polymerase chain reaction (PCR) with primers flanking the TOM22 gene. OL201 contained only the disrupted gene (Fig. 1a, lane 3), the control haploid strain OL223 contained the wild-type TOM22 gene (Fig. 1a, lane 2), and the diploid strain contained both the wild-type gene and the disrupted gene (Fig. 1a, lane 1). The absence of the TOM 22 coding region in OL201 was confirmed by Southern blot analysis, and northern blot analysis revealed the complete lack of TOM 22 messenger RNA (not shown). We conclude that the OL201 strain lacks the TOM22 gene, and so we now refer to it as tom $22 \Delta$. The tom $22 \Delta$ cells were devoid of mitochondrial DNA $\left(r h o^{0}\right)$. The control haploid strain (OL223) was converted to the $r{ }^{0}{ }^{0}$ state (referred to as wild type with regard to TOM22). On fermentable medium, the growth of tom $22 \Delta$ cells was about fourfold slower than that of OL223 cells.

The frequency of spontaneous loss of the URA3 plasmid from a control strain was about 0.1 , whereas the frequency for obtaining OL201 was $\sim 0.02$. This indicates that around $20 \%$ of the cells could survive the loss of TOM22. Moreover, a backcross of OL201 with the wild-type haploid also failed to provide evidence for a rapid generation of extragenic suppressor mutations to explain the viability of tom $22 \Delta$ cells. The analysis of more than 90 tetrads revealed a 2:2 segregation of viability, and all viable spores contained the wild-type TOM 22 gene, indicating that tom $22 \Delta$ spores cannot germinate productively. The strong growth defects of tom $22 \Delta$ cells provide a likely explanation of why the cells did not survive two standard procedures for gene deletion, leading to the previous assumption that Tom 22 is essential for viability. Only the mild approach involving plasmid loss allowed viable tom $22 \Delta$ cells to be recovered.

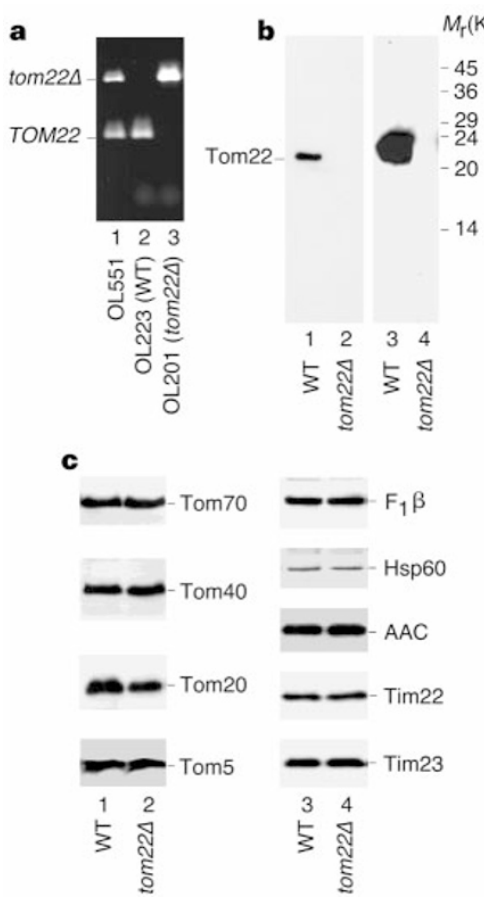

Figure $1 \mathrm{~A}$ yeast strain lacking TOM22. a, Analytical PCR yielding fragments typical for the intact TOM22 gene (409 base pairs (bp); WT, wild type) and the HIS3-disrupted TOM22 gene (1,1101 bp; tom22 $\Delta$ ). b, c, Analysis of the protein composition of tom22 $\Delta$ mitochondria. Isolated mitochondria ( $25 \mu \mathrm{g}$ of protein) were separated by SDS-PAGE and analysed by immunodecoration. $\ln \mathbf{b}$, lanes 3 and 4 received $200 \mu \mathrm{g}$ of mitochondrial protein. 
Mitochondria were isolated from tom $22 \Delta$ cells and the corresponding wild type. Immunodecoration demonstrated that the tom $22 \Delta$ mitochondria completely lacked Tom 22 (Fig. 1b, lane 2). No smaller fragments reacting with a polyclonal anti-Tom 22 serum were detected, even after extensive loading of the gel (Fig. 1b, lane 4). The amount of Tom 20 in tom $22 \Delta$ mitochondria was reduced to about $65 \%$ of that in the wild type (Fig. 1c, lane 2). All other proteins tested were found in similar amounts in wild-type and mutant mitochondria, including Tom70, Tom40 and Tom5 of the outer membrane (Fig. 1c, lanes 1 and 2), Tim23, Tim22 and the ADP/ATP carrier (AAC) of the inner membrane, the $\beta$-subunit of the $F_{1}$-ATPase $\left(F_{1} \beta\right)$ and the matrix chaperonin Hsp60 (Fig. 1c, lanes 3 and 4$)$.

To assay the protein import capacity of tom $22 \Delta$ mitochondria, in vitro-synthesized ${ }^{35} \mathrm{~S}$-labelled preproteins were incubated with the isolated mitochondria (Fig. 2a-c). Preproteins containing cleavable presequences were used that were destined for the intermembrane space (cytochrome $b_{2}$; not shown), the matrix side of the inner membrane $\left(\mathrm{F}_{1} \beta\right)$ or the matrix (the $\alpha$-subunit of the matrix processing peptidase and a fusion protein between the presequence of $\mathrm{F}_{\mathrm{o}}$-ATPase subunit 9 and dihydrofolate reductase). Non-cleavable precursors of AAC and the outer-membrane protein porin were also used. We found that tom $22 \Delta$ mitochondria were able to import preproteins, but with a strongly reduced efficiency of around 5$15 \%$ compared with the wild-type mitochondria (Fig. 2a, b, compare lanes 5-7 with 1-3; Fig. 2c, compare lanes 7-11 with 1-
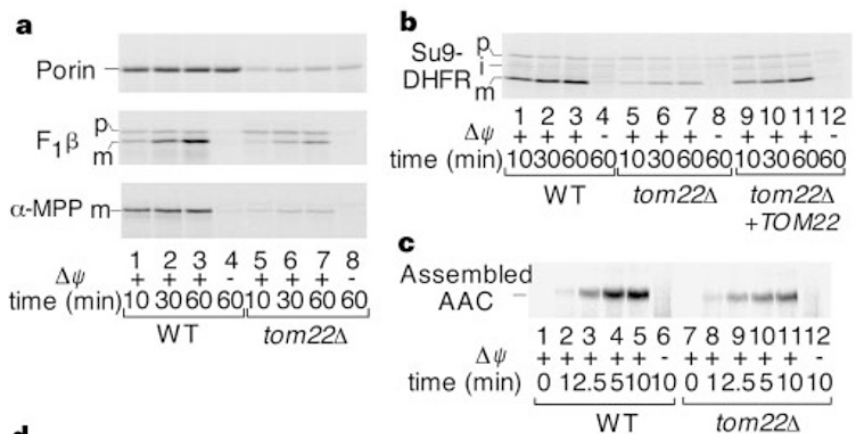

d
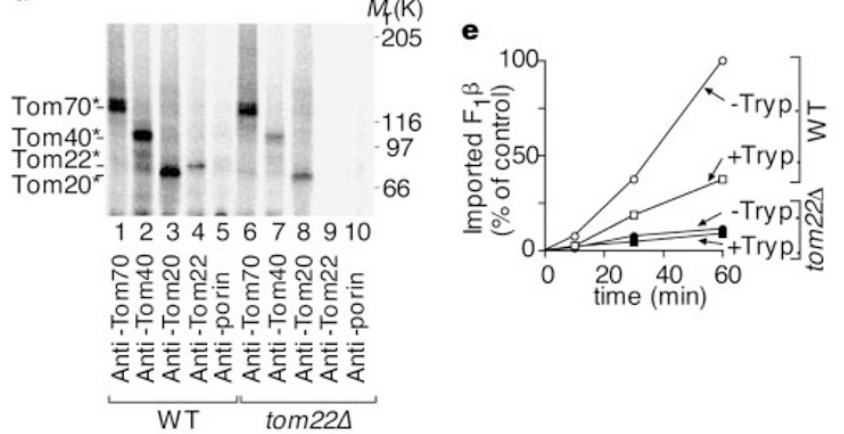

Figure 2 Inhibition of preprotein import into tom22 $\Delta$ mitochondria. a, ${ }^{35} \mathrm{~S}$-labelled preproteins were imported into isolated wild-type or tom22 $\Delta$ mitochondria in the presence or absence of a membrane potential $(\Delta \psi)$. After treatment with proteinase $\mathrm{K}$, the reisolated mitochondria were subjected to SDS-PAGE and storage phosphorimaging technology. b. Restoration of protein import by re-expressing Tom22, including mitochondria isolated from a tom22 $\Delta$ strain (lanes 9-12). Restoration of protein import was comparable if Tom22 was re-expressed from either a multicopy vector (Yep13) or a single-copy vector (pRS415). p, i, m indicate precursor-, intermediate- and mature-sized forms of a protein, respectively. c, Import and assembly of AAC are inhibited. Assembly to the dimeric form was assessed by blue native PAGE. $\mathbf{d}$, Crosslinking of AAC. AAC-DHFR was accumulated across the outer membrane in the presence of methotrexate. Reisolated mitochondria were crosslinked with EGS and analysed by immunoprecipitation. e, Bypass import into tom22 $\Delta$ mitochondria. Where indicated, mitochondria were pretreated with trypsin (tryp.) before the import of $F_{1} \beta$. Protein import into non-trypsinized wild-type mitochondria after $60 \mathrm{~min}$ was set to $100 \%$ (control).
5). The import into or across the inner membrane of tom $22 \Delta$ mitochondria was blocked by dissipation of the membrane potential (Fig. 2a, b, lanes 8; Fig. 2c, lane 12). By re-expression of Tom 22 from a plasmid carrying the TOM22 gene, protein import was largely restored (Fig. 2b, lanes 9-11), demonstrating that the strong effects on protein import were specific to the loss of Tom 22 (reduction of Tom 20 content would only slightly inhibit the import of cleavable preproteins to around $80 \%$ of that of the wild-type ${ }^{18}$ ).

To monitor the association of preproteins with Tom proteins, we used an AAC-DHFR fusion protein. Addition of methotrexate stabilizes the carboxy-terminal DHFR so it does not cross the outer membrane ${ }^{19}$, leading to the arrest of AAC-DHFR in the TOM machinery. When the cross-linking reagent ethylene glycol bis-(succinimidylsuccinate) (EGS) was added, Tom proteins in the vicinity of the preprotein were identified by immunoprecipitation under stringent conditions. The efficiency of crosslinking of AACDHFR to the first receptor Tom70 was similar in wild-type and tom $22 \Delta$ mitochondria (Fig. $2 \mathrm{~d}$, lanes 1 and 6 ), indicating that the lack of Tom 22 did not impair the initial binding of the preprotein to the mitochondrial surface. However, crosslinking of AAC-DHFR to Tom 40 was strongly reduced in tom $22 \Delta$ mitochondria (Fig. $2 \mathrm{~d}$, lane 7 ), indicating that transfer of the preprotein into the import pore was inhibited. Crosslinking to the second receptor Tom 20 was also reduced (Fig. 2d, lane 8), indicating that the lack of Tom 22 may impair the transfer of preprotein from Tom70 to Tom20. Antibodies
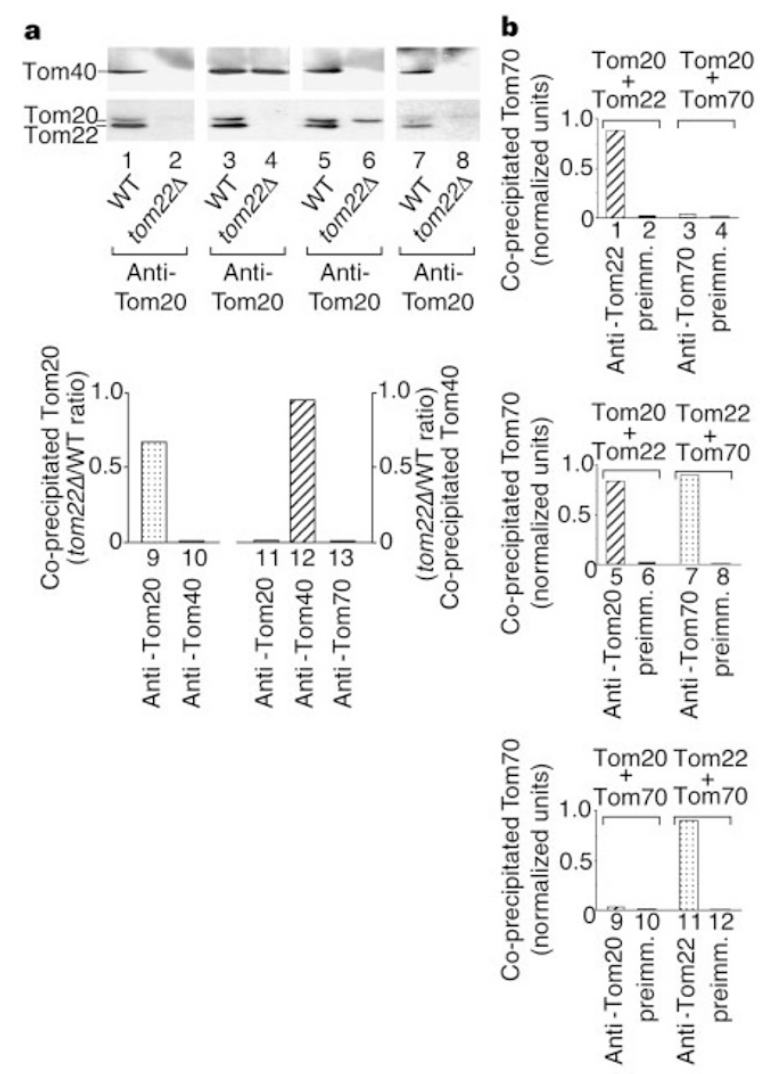

Figure 3 Tom22 as a docking point for Tom20 and Tom70. a, The lack of Tom22 inhibits the association of Tom20 and Tom70 with Tom40 (GIP). Digitonin-lysed wild-type and tom22 $\Delta$ mitochondria were co-immunoprecipitated with antibodies against Tom22, Tom40, Tom20 or Tom70. The co-precipitated proteins were separated by SDS-PAGE and immunodecorated with antibodies against Tom40, Tom22 and Tom20. Precipitated Tom20 and Tom40 were quantified and the ratio of tom22 $\Delta$ to wild type is shown. b. Interaction of the cytosolic domain of Tom22 with those of Tom20 and Tom70. The purified domains were mixed pairwise, followed by co-precipitation with antibodies against Tom20, Tom22, Tom70 or preimmune antibodies. The amount of direct precipitation of each domain with its genuine antibody was set to 1 (normalized units). 
against the abundant porin did not precipitate crosslinking products of AAC-DHFR (Fig. 2d, lanes 5 and 10), confirming the specificity of the approach.

We investigated whether the peripheral receptors Tom70 and Tom 20 partly substitute for the lacking receptor function of Tom 22 . Pretreatment of mitochondria with trypsin removes the cytosolic domains of all receptors and protein import is reduced in wild-type mitochondria to around $30 \%$ (bypass import) ${ }^{18,19}$ (Fig. 2e). With tom $22 \Delta$ mitochondria, however, trypsin pretreatment only slightly affected the residual import (Fig. 2e). This result surprisingly indicates that, without Tom 22 , preprotein import may be largely independent of the typical receptor proteins, leaving the trypsinresistant Tom5 as the only binding site for preproteins before insertion into the general import pore $(\mathrm{GIP})^{20}$.

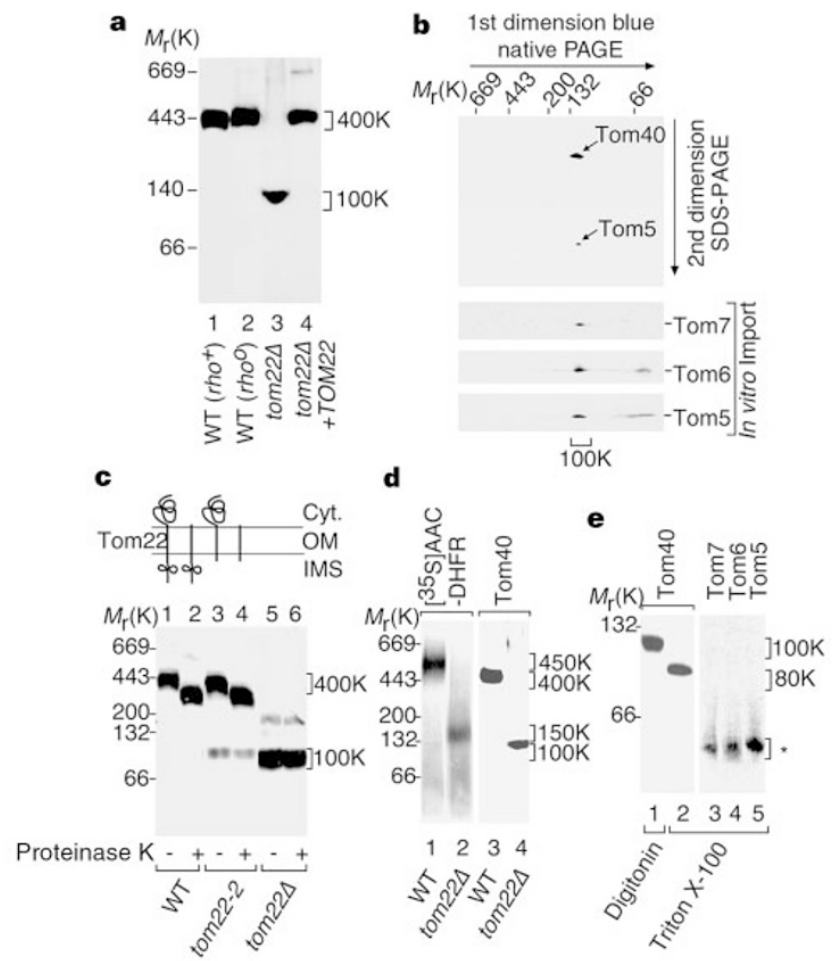

Figure 4 Lack of Tom22 causes dissociation of the 400K GIP complex. a, Dissociation to a $100 \mathrm{~K}$ complex and restoration by re-expression of Tom22. Mitochondria were isolated from wild-type yeast $\left(r h 0^{+}\right)$, wild-type $\left(r h 0^{9}\right)$, tom22 $\Delta$ and a tom22 $\Delta$ strain re-expressing Tom22. Samples were lysed in digitonin, subjected to blue native PAGE and immunodecorated with anti-Tom40. b, Tom40, Tom7, Tom6 and Tom5 are in the 100K complex. tom22 $\triangle$ mitochondria were lysed in digitonin, then separated by blue native PAGE and SDS-PAGE. Immunodecoration used anti-Tom40 and anti-Tom5. ${ }^{35}$ S-labelled Tom7, Tom6 and Tom5 were imported into tom22 $\Delta$ mitochondria and analysed by twodimensional PAGE and autoradiography. c, The membrane-spanning segment of Tom22 is required to stabilize the $400 \mathrm{~K} \mathrm{GIP} \mathrm{complex.} \mathrm{Mitochondria} \mathrm{were} \mathrm{isolated} \mathrm{from} \mathrm{wild-type}$ yeast, the tom22-2 strain expressing Tom22 without its intermembrane space (IMS) domain, and the tom22 $\Delta$ strain. Mitochondria were treated with or without proteinase $\mathrm{k}$, lysed in digitonin and analysed by blue native PAGE. Cyt, cytosolic side; OM, outer membrane. d. Accumulation of preprotein in the $100 \mathrm{~K}$ subcomplex of tom22 $\triangle$ mitochondria. ${ }^{35}$ S-labelled AAC-DHFR was precincubated with methotrexate and imported into wild-type and tom22 $\triangle$ mitochondria. Mitochondria were lysed in digitonin and analysed by blue native PAGE and autoradiography (lanes 1 and 2). For lanes 3 and 4 , digitonin-lysed mitochondria were analysed by blue native PAGE and immunodecoration for Tom40. e, Tom40 is present as a dimer in the $100 \mathrm{~K}$ complex. ${ }^{35} \mathrm{~S}$-labelled Tom7, Tom6 and Tom5 were imported into tom22 $\Delta$ mitochondria. Mitochondria were lysed with Triton X-100 (lanes 2-5) or digitonin (lane 1) and separated by blue native PAGE. Analysis was by immunodecoration for Tom40 (lanes 1 and 2) or autoradiography (lanes 3-5). Asterisk, position of small Toms close to the front of the gel.
It is possible that Tom 22 is required for the docking of Tom 20 and Tom70 to the GIP complex. The peripheral association of Tom 20 and Tom70 with the GIP complex (Tom40) can be assayed by coimmunoprecipitation experiments under mild conditions ${ }^{18,21,22}$. Antibodies against Tom40 co-precipitated Tom 20 from wild-type mitochondrial lysates, but not from tom $22 \Delta$ mitochondria (Fig. 3a, lanes 3 and 4, column 10). Similarly, anti-Tom 20 did not precipitate Tom 40 from tom $22 \Delta$ mitochondria (Fig. 3a, lane 6, column 11). Moreover, the precipitation of Tom 40 with anti-Tom70 was blocked with tom $22 \Delta$ mitochondria (Fig. 3a, lane 8, column 13). The specificity of the co-immunoprecipitation approach is underscored by the lack of precipitation of Tom 40 or Tom 20 by anti-Tom 22 from tom $22 \Delta$ mitochondria (Fig. 3a, lane 2). When TOM22 is reexpressed in the tom $22 \Delta$ strain, the association of Tom 20 and Tom70 with Tom40 was restored to wild-type levels (not shown). Thus, the lack of Tom 22 strongly reduces the interaction of the receptors Tom 20 and Tom 70 with the GIP.

To determine whether Tom 22 directly interacts with Tom 20 or Tom70, we assayed the interaction between the expressed and purified cytosolic domains of the receptors ${ }^{10}$. The cytosolic domains of Tom 20 and Tom 22 were mixed and subjected to co-immunoprecipitation. Tom 20 was co-precipitated with anti-Tom 22 (Fig. 3b, column 1), whereas no co-precipitation was observed with preimmune serum (Fig. 3b, column 2) or when Tom 22 was omitted from the incubation (not shown). Moreover, Tom22 was coprecipitated with anti-Tom 20 (Fig. 3b, column 5). Similarly, Tom 22 and Tom70 could be co-precipitated (Fig. 3b, columns 7 and 11). However, when Tom 20 and Tom 70 were mixed, only weak co-precipitation was observed (Fig. 3b, columns 3 and 9), demonstrating the selectivity of the association with Tom 22. The previously reported transient interactions between Tom 20 and Tom70

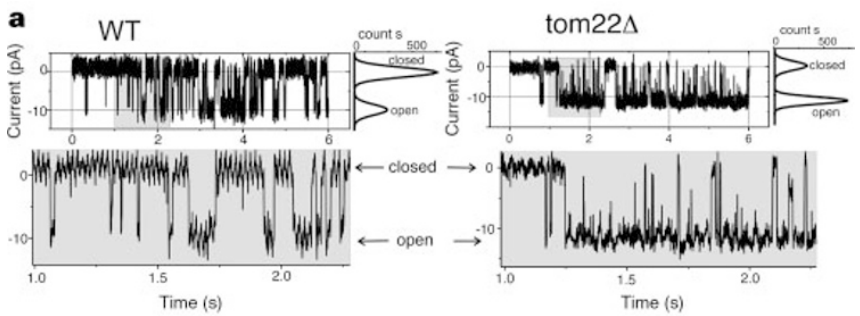

b WT +CoxIV tom $22 \Delta+$ CoxIV

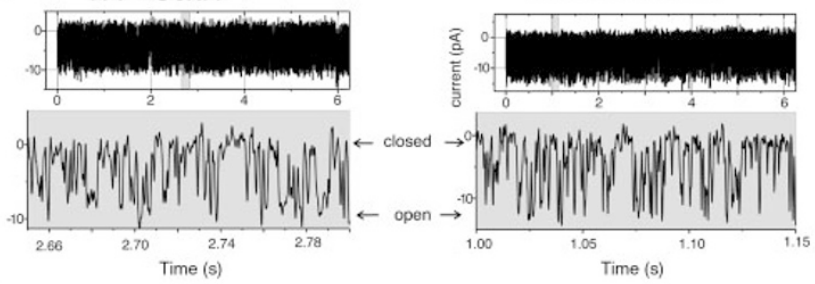

c
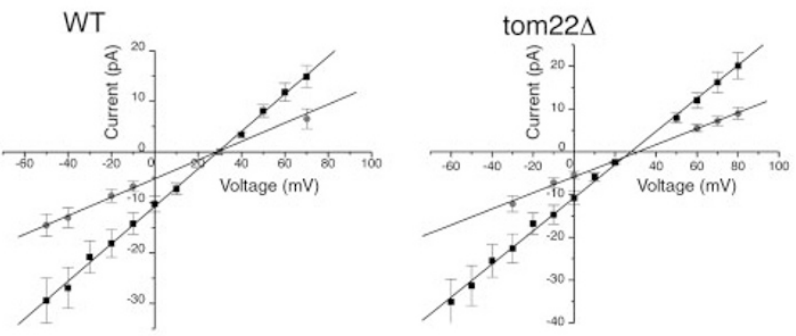

Figure $\mathbf{5}$ Increased open probability of the import channel of tom $22 \Delta$ mitochondria. a, Current traces from a bilayer fused with wild-type or tom22 $\Delta$ outer-membrane vesicles at a membrane potential of $0 \mathrm{mV}$. Bottom traces show time-scale-expanded current recordings from the top traces with high time resolution $(10 \mathrm{kHz})$. b, Current traces (as in a) after adding $10 \mu \mathrm{M}$ CoxIV(1-23) to the cis compartment. c, Current-voltage relation (without presequence peptide) of the fully open single channel (squares) and the most frequent subconductance level (circles). 
are apparently less stable and involve smaller fractions of the proteins $^{23}$ so they were not detected by our co-precipitation approach. We conclude that the purified cytosolic domain of Tom22 can associate with the cytosolic domains of Tom20 and Tom70.

In wild-type mitochondria, Tom22, Tom40 and the three small proteins Tom5, Tom 6 and Tom7 form the centre of the TOM machinery, the GIP complex of relative molecular mass 400,000 $\left(M_{\mathrm{r}} 400 \mathrm{~K}\right)$ that remains stable on blue native electrophoresis, while the peripheral subunits Tom 20 and Tom70 are mainly released ${ }^{13,20}$. This complex was also observed in mitochondria from a $r h o^{0}$ strain (Fig. 4a, lanes 1 and 2). With tom $22 \Delta$ mitochondria, however, the 400K GIP complex, detected with anti-Tom40, completely dissociated to a complex of $\sim 100 \mathrm{~K}$ (Fig. $4 \mathrm{a}$, lane 3 ). Mitochondria isolated from the tom $22 \Delta$ strain re-expressing Tom 22 from a plasmid contained a large GIP complex (Fig. 4a, lane 4), demonstrating that the dissociation of the GIP complex was selectively caused by the lack of Tom22. By two-dimensional electrophoresis of tom $22 \Delta$ mitochondria and subsequent immunodecoration, Tom 40 and Tom 5 were quantitatively found in the $100 \mathrm{~K}$ complex (Fig. $4 \mathrm{~b}$, top). The preproteins of Tom7 and Tom6, for which specific antibodies are not available, were synthesized and ${ }^{35}$ S-labelled in vitro and imported into the mitochondria. The bulk of Tom7 and Tom 6 migrated at the $100 \mathrm{~K}$ position (Fig. $4 \mathrm{~b}$, bottom), but a small amount of Tom6 was not assembled, as similarly observed with in vitro imported Tom 5 (Fig. 4b, bottom $)^{13}$. We conclude that the lack of Tom 22 causes dissociation of the GIP complex to a $100 \mathrm{~K}$ complex containing Tom40, Tom7, Tom6 and Tom5.

We then wondered which part of Tom 22 is required for the integrity of the 400K GIP complex. Treatment of wild-type mitochondria with protease removed the cytosolic domains of the Tom 22 molecules in the GIP complex, causing a shift of the GIP complex to $\sim 350 \mathrm{~K}$ but not to $100 \mathrm{~K}$ (Fig. $4 \mathrm{c}$, lane 2$)^{13}$. The GIP complex of tom 22-2 mutant mitochondria, lacking the Tom 22 intermembrane space domain ${ }^{9}$, preferentially migrated as a large complex (Fig. 4c, lane 3). When we removed both domains by treating tom 22-2 mitochondria with protease, we still observed a large GIP complex and very little $100 \mathrm{~K}$ complex (Fig. 4c, lane 4 ). We conclude that neither the cytosolic domain nor the intermembrane space domain of Tom 22 is required to maintain the stability of the bulk of GIP complexes. When the membrane anchor of Tom 22 was removed (tom $22 \Delta$ mitochondria), the GIP complex quantitatively dissociated and the vast majority of Tom 40 was found at the $100 \mathrm{~K}$ position (Fig. 4c, lane 5).

To determine whether the $100 \mathrm{~K}$ complex retained a functional protein-import site, we arrested ${ }^{35} \mathrm{~S}$-labelled AAC-DHFR across the outer membrane. The intermediate accumulated at $\sim 450 \mathrm{~K}$ in wildtype mitochondria (Fig. 4d, lane 1) and at $150 \mathrm{~K}$ in tom $22 \Delta$ mitochondria (Fig. 4d, lane 2). The fusion protein is $\sim 50 \mathrm{~K}$, indicating an accumulation in the $400 \mathrm{~K}$ and $100 \mathrm{~K}$ complexes, respectively. The $100 \mathrm{~K}$ subcomplex therefore forms a functional import site. The wild-type TOM complex contains about six molecules of Tom40 (ref. 13) and, as suggested by electron micrographic analysis in N. crassa, up to three import channels ${ }^{24}$, implying that a single import channel is formed by a dimer of Tom40. To test whether the $100 \mathrm{~K}$ subcomplex fulfilled this prediction, we used Triton X-100 to release the small TOM proteins from Tom40 (Fig. 4e, lanes $3-5)^{13}$. Tom 40 , now the only component of the complex, migrated at $80 \mathrm{~K}$ (Fig. 4e, lane 2). Monomeric Tom 40 , obtained after lysis of mitochondria with SDS, migrates at $40 \mathrm{~K}$ to $45 \mathrm{~K}$ (not shown). We propose that a dimer of Tom 40 present in the $100 \mathrm{~K}$ subcomplex forms the basic unit of one import channel.

To determine the electrophysiological characteristics of the translocase channel in tom $22 \Delta$ outer membranes, we isolated outer-membrane vesicles from wild-type and tom $22 \Delta$ mitochondria and analysed them using the planar lipid-bilayer technique ${ }^{12}$. A single type of cation channel was observed in both membranes
(Fig. 5a). We investigated the channel's conductance, selectivity and sensitivity to the synthetic mitochondrial presequence of cytochrome oxidase subunit IV (CoxIV). The wild-type channel revealed a reversal potential $\left(E_{\mathrm{rev}}\right)$ of $+30 \mathrm{mV}\left(P_{\mathrm{K}^{+}} / P_{\mathrm{Cl}^{-}}=4.4: 1\right)$, its slope conductance was $\Lambda=370 \pm 5 \mathrm{pS}$ for the main conductance and $\Lambda_{1}=180 \pm 6 \mathrm{pS}$ for the most frequent subconductant level (Fig. $5 \mathrm{c}$, left). The channel of tom $22 \Delta$ outer membranes revealed similar values: $E_{\text {rev }}$ was $+29 \mathrm{mV}$ with a slope conductance of $\Lambda=387 \pm 6 \mathrm{pS}$ and $\Lambda_{1}=187 \pm 5 \mathrm{pS}$ for the main conductance and the most frequent subconductant level, respectively (Fig. $5 c$, right). As observed with purified Tom40 (ref. 12), the direct transitions between the conductance levels and the comparatively high frequency of the states indicate that they represent distinct conductance states of a single channel, rather than the coupled opening of two or more individual channels. In support of this view, the ratio between the frequency of the main conductance state and that of the subconductance state did not change significantly between wild-type and tom $22 \Delta$ outer membranes. The channels from both sources were highly sensitive to the presence of the CoxIV presequence peptide. The peptide strongly increased the frequency of channel gating (flickering) of both the wild-type channel and the tom $22 \Delta$ channel (Fig. 5b). This effect was reversible by removal of the peptide. Thus, the basic properties of the channel are identical for wild-type outer membranes, tom $22 \Delta$ outer membranes and purified Tom 40 (ref. 12). However, a difference was observed for the open probability of the channel: in wild-type outer membranes, the channel was mainly in the closed state (Fig. 5a, left), whereas the channel of tom $22 \Delta$ outer membranes was mainly in the open state (Fig. 5a, right), resembling that observed with purified Tom40 (ref. 12). We conclude that Tom 22 is required to negatively regulate the open probability of the Tom 40 channel.

Our results point to a new principle of organization of a multisubunit preprotein translocase. The multidomain protein Tom 22 not only functions as a receptor and trans binding site for preproteins, but it also organizes the interaction between the channel and receptor subcomplexes at two levels. The following functions can be assigned to the three domains of Tom22: the cytosolic domain plays a dual role, specifically recognizing preproteins $s^{6,8,10}$ and serving as a docking point for the peripheral receptors Tom 20 and Tom70; the intermembrane space domain provides a trans binding site for presequences ${ }^{7,9}$; and the single membrane anchor of Tom 22 is crucial for the integrity of the GIP complex. In the absence of this membrane anchor, the GIP complex dissociates into small core complexes containing a dimer of Tom40 and the three small Toms. Such a $100 \mathrm{~K}$ core complex probably contains a single channel that retains the basic channel properties but is already open in the absence of preproteins. In contrast, in the presence of Tom22, the wild-type GIP complex contains tightly regulated channels (probably three channels ${ }^{24}$ ) that open when preproteins are present. Tom 22 apparently represents a component of the machinery that controls the gate. Tom40 is the only strictly essential protein of the outer membrane translocase (cells lacking Tom40 were non-viable with all methods of gene deletion applied ${ }^{14,25}$ (not shown)) and forms the basic import core, whereas Tom 22 is crucial for the organization of the core complexes into the large GIP complex, the interaction with the peripheral receptors, and the efficient and coordinated transfer of preproteins. Tom 22 is therefore the central organizer that converts a simple channel into the complex, dynamic and efficiently coordinated machinery for the recognition and translocation of preproteins.

\section{Methods}

\section{Generation and analysis of TOM22-deficient yeast}

A BamHI/SalI fragment containing the TOM22 open reading frame was ligated into the high-copy vector pFL44 with the MET25 promoter and the CYC1 terminator, yielding the plasmid BG3036 (URA3, TOM22). This plasmid was transformed into the diploid strain 


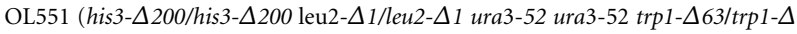
3 TOM22/tom 22::HIS3 $\mathrm{rho}^{+}$) and then sporulated. The resulting haploid strain (tom22::HIS3) containing BG3036 was plated on medium containing 5-FOA; colonies growing at $28^{\circ} \mathrm{C}$ were tested for the absence of the TOM 22 gene and one of them was designated OL201 (his3- $\Delta 200$ leu2- $\Delta 1$ ura3-52 trp1- $\Delta 63$ tom $22:: H I S 3$ rho ${ }^{\circ}$ ). The lack of mitochondrial DNA in OL201 cells was demonstrated by crossing the cells with a rho tester strain and by DAPI and HOECHST staining. The control haploid strain OL223 ( his3- $\Delta 200$ leu2- $\Delta 1$ ura3-52 $\operatorname{trp} 1-\Delta 63 r h o^{0}$ ) was generated by ethidium bromide mutagenesis of a TOM22-containing spore of OL551.

\section{In vitro import of preproteins into mitochondria and crosslinking}

${ }^{35} \mathrm{~S}$-labelled precursor proteins were synthesized in rabbit reticulocyte lysate ${ }^{19}$. The import assays included isolated yeast mitochondria and buffer (3\% (w/v) BSA, $250 \mathrm{mM}$ sucrose, $5 \mathrm{mM} \mathrm{MgCl}_{2}, 80 \mathrm{mM} \mathrm{KCl}, 10 \mathrm{mM} \mathrm{MOPS} / \mathrm{KOH}, \mathrm{pH}$ 7.2) in the presence of 2-4 mM ATP and $2-4 \mathrm{mM} \mathrm{NADH}$ at $25^{\circ} \mathrm{C}$. Phosphocreatine $(10-20 \mathrm{mM})$ and phosphocreatine kinase $\left(100-200 \mu \mathrm{g} \mathrm{ml}^{-1}\right)$ were added to allow efficient import into $r h o^{o}$ mitochondria. After the import reaction, mitochondria were treated with $50 \mu \mathrm{g} \mathrm{ml}^{-1}$ proteinase $\mathrm{K}$ for $15 \mathrm{~min}$ at $0^{\circ} \mathrm{C}($ refs 18,21$)$. The mitochondria were reisolated, washed and separated by SDS-PAGE. Pretreatment of mitochondria with trypsin or dissipation of the membrane potential was as described ${ }^{18,19}$. For crosslinking, ${ }^{35}$ S-labelled AAC-DHFR was accumulated at the outer mitochondrial membranes by adding $20 \mu \mathrm{M}$ methotrexate to the import reaction. Mitochondria were reisolated and subjected to crosslinking with $0.4 \mathrm{mM}$ EGS before immunoprecipitation under stringent conditions ${ }^{18}$.

\section{Blue native electrophoresis and co-precipitation of Tom proteins}

Mitochondrial pellets were lysed in $50 \mu \mathrm{l}$ ice-cold digitonin buffer ( $1 \%(\mathrm{w} / \mathrm{v})$ digitonin, $20 \mathrm{mM}$ Tris-HCl, pH 7.4, $0.1 \mathrm{mM}$ EDTA, $50 \mathrm{mM} \mathrm{NaCl}, 10 \%$ (v/v) glycerol, $1 \mathrm{mM}$ PMSF) before the addition of sample buffer ( $5 \%(\mathrm{w} / \mathrm{v})$ Coomassie brilliant blue G-250, $100 \mathrm{mM}$ Bis-Tris, pH 7.0, $500 \mathrm{mM}$ 6-aminocaproic acid). Blue native PAGE was performed using a $6-16.5 \%$ polyacrylamide gradient gel at $10^{\circ} \mathrm{C}$ (ref. 13). For co-precipitation of Tom proteins from mitochondria, isolated mitochondria $(250 \mu \mathrm{g}$ of protein) were lysed in $0.5 \%$ digitonin-containing buffer and incubated with protein A-Sepharose to which antibodies were covalently coupled ${ }^{18,21,22}$. After washing in digitonin-containing buffer, the bound proteins were analysed by SDS-PAGE and immunodecoration. For co-precipitation of purified Tom proteins, the expressed and purified cytosolic domains of Tom20, Tom 22 or Tom70 (100 pmol each) ${ }^{10}$ were incubated pairwise in $50 \mathrm{mM} \mathrm{KCl}, 10 \mathrm{mM}$ MOPS-KOH, pH 7.2, $0.5 \%$ BSA for $15 \mathrm{~min}$ at $25^{\circ} \mathrm{C}$ ( $200 \mu \mathrm{l}$ final volume). Aggregated material was removed by centrifugation for $20 \mathrm{~min}$ at $106,000 \mathrm{~g}$. The supernatant was incubated with anti-Tom antibodies coupled to protein A-Sepharose for $1 \mathrm{~h}$ at $4{ }^{\circ} \mathrm{C}$. After two washes with $50 \mathrm{mM} \mathrm{KCl}, 10 \mathrm{mM}$ MOPS-KOH, pH 7.2, the precipitate was analysed by SDS-PAGE, immunodecoration and fluoroimaging (Fuji).

\section{Electrophysiological measurements}

Planar lipid bilayers were made by using the painting technique ${ }^{12,26}$. After formation of a stable bilayer (cis chamber, $250 \mathrm{mM} \mathrm{KCl}, 10 \mathrm{mM} \mathrm{CaCl}_{2}, 10 \mathrm{mM} \mathrm{MOPS/Tris,} \mathrm{pH} \mathrm{7.0;} \mathrm{trans}$ chamber, $10 \mathrm{mM} \mathrm{KCl}, 10 \mathrm{mM} \mathrm{MOPS} /$ Tris, $\mathrm{pH}$ 7.0), outer-membrane vesicles were added to the cis chamber directly below the bilayer. All membrane potentials are referred to the trans compartment. Under these conditions, the porin channel was closed. The fusion rates of tom $22 \Delta$ outer-membrane vesicles with the planar lipid bilayer were significantly higher than that of wild-type outer-membrane vesicles, supporting the idea of a higher open probability for the tom $22 \Delta$ channel.

Received 11 May; accepted 20 July 1999.

1. Schatz, G. \& Dobberstein, B. Common principles of protein translocation across membrane. Science 271, 1519-1526 (1996)

2. Neupert, W. Protein import into mitochondria. Annu. Rev. Biochem. 66, 863-917 (1997).

3. Pfanner, N., Craig, E. A. \& Hönlinger, A. Mitochondrial preprotein translocase. Annu. Rev. Cell Dev. Biol. 13, 25-51 (1997).

4. Ryan, K. R. \& Jensen, R. E. Protein translocation across mitochondrial membranes: what a long, strange trip it is. Cell 83, 517-519 (1995).

5. Schatz, G. Protein transport: the doors to organelles. Nature 395, 439-440 (1998)

6. Hönlinger, A. et al. the mitochondrial receptor complex: Mom22 is essential for cell viability and directly interacts with preproteins. Mol. Cell. Biol. 15, 3382-3389 (1995).

7. Bolliger, L., Junne, T., Schatz, G. \& Lithgow, T. Acidic receptor domains on both sides of the outer membrane mediate translocation of precursor proteins into yeast mitochondria. EMBO J. 14, 63186326 (1995).

8. Mayer, A., Nargang, F. E., Neupert, W. \& Lill, R. MOM22 is a receptor for mitochondrial targeting sequences and cooperates with MOM19. EMBO J. 14, 4205-4211 (1995).

9. Moczko, M. et al. The intermembrane space domain of mitochondrial Tom22 functions as a trans binding site for preproteins with N-terminal targeting sequences. Mol. Cell Biol. 17, 6574-6584 (1997).

10. Brix, J., Dietmeier, K. \& Pfanner, N. Differential recognition of preproteins by the purified cytosolic domains of the mitochondrial import receptors Tom20, Tom22, and Tom70. J. Biol. Chem. 272, 20730-20735 (1997).

11. Vestweber, D., Brunner, J., Baker, A. \& Schatz, G. A $42 \mathrm{~K}$ outer-membrane protein is a component of the yeast mitochondrial protein import site. Nature 341, 205-209 (1989).

12. Hill, K. et al. Tom 40 forms the hydrophilic channel of the mitochondrial import pore for preproteins. Nature 395, 516-521 (1998)

13. Dekker, P. J. T. et al. The preprotein translocase of the outer mitochondrial membrane: molecular dissection and assembly of the general import pore complex. Mol. Cell. Biol. 18, 6515-6524 (1998).

14. Baker, K. P., Schaniel, A., Vestweber, D. \& Schatz, G. A yeast mitochondrial outer membrane protein essential for protein import and cell viability. Nature 348, 605-609 (1990).
15. Lithgow, T., Junne, T., Suda, K., Gratzer, S. \& Schatz, G. The mitochondrial outer membrane protein Mas22p is essential for protein import and viability of yeast. Proc. Natl Acad. Sci. USA 91, 1197311977 (1994).

16. Guthrie, C. \& Fink, G. R. Guide to yeast genetics and molecular biology. Methods Enzymol. 194 (Academic, San Diego, California, 1991).

17. Nargang, F. E. et al. 'Sheltered disruption' of Neurospora crassa MOM22, an essential component of the mitochondrial protein import complex. EMBO J. 14, 1099-1108 (1995).

18. Alconada, A., Gärtner, F., Hönlinger, A., Kübrich, M. \& Pfanner, N. Mitochondrial receptor complex from Neurospora crassa and Saccharomyces cerevisiae. Methods Enzymol. 260, 263-286 (1995).

19. Söllner, T., Rassow, J. \& Pfanner, N. Analysis of mitochondrial protein import using translocaton intermediates and specific antibodies. Methods Cell Biol. 3, 345-358 (1991).

20. Dietmeier, K. et al. Tom5 functionally links mitochondrial preprotein receptors to the general import pore. Nature 388, 195-200 (1997).

21. Hönlinger, A. et al. Tom7 modulates the dynamics of the mitochondrial outer membrane translocase and plays a pathway-related role in protein import. EMBO J. 15, 2125-2137 (1996).

22. Alconada, A., Kübrich, M., Moczko, M., Hönlinger, A. \& Pfanner, N. The mitochondrial receptor complex: the small subunit Mom8b/Isp6 supports association of receptors with the general insertion pore and transfer of preproteins. Mol. Cell. Biol. 15, 6196-6205 (1995).

23. Haucke, V., Horst, M., Schatz, G. \& Lithgow, T. The Mas20p and Mas70p subunits of the protein import machinery interact via the tetratricopeptide repeat motif in Mas20p: evidence for a single hetero-oligomeric receptor. EMBO J. 15, 1231-1237 (1996).

24. Künkele, K.-P. et al. The preprotein translocation channel of the outer membrane of mitochondria. Cell 93, 1009-1019 (1998).

25. Kassenbrock, C. K., Cao, W. \& Douglas, M. G. Genetic and biochemical characterization of ISP6, a small mitochondrial outer membrane protein associated with the protein translocation complex. EMBO J. 8, 3023-3034 (1993).

26. Hinnah, S., Hill, K., Wagner, R., Schlicher, T. \& Soll, J. Reconstitution of a chloroplast protein import channel. ЕMBO J. 16, 7351-7360 (1997).

\section{Acknowledgements}

We thank M. Jacquet, T. Lithgow and T. Krimmer for materials and discussion, and H. Müller for technical assistance. This work was supported by the Sonderforschungsbereich 388, the Fonds der Chemischen Industrie (N.P.), the Sonderforschungsbereich 431 (R.W.) and long-term fellowships of the Alexander-von-Humboldt Foundation (M.T.R.) and the Human Frontier Science Program (P.J.T.D.).

Correspondence and requests for material should be addressed to N.P. (e-mail: pfanner@ uni-freiburg.de).

\section{Negative regulation of erythropoiesis by caspase-mediated cleavage of GATA-1}

\author{
Ruggero De Maria ${ }^{\star} \dagger \|$, Ann Zeuner $\dagger \neq \|$, Adriana Eramo*, \\ Cristina Domenichelli $\neq$, Desiree Bonci $\neq$, Francesco Grignani $\neq \$$, \\ Srinivasa M. Srinivasula*, Emad S. Alnemri*, Ugo Testa $\ddagger$ \\ \& Cesare Peschle ${ }^{\star} \ddagger$
}

* Kimmel Cancer Center, Thomas Jefferson University, Philadelphia, Pennsylvania 19107-5541, USA

$\dagger$ Istituto di Patologia Generale, Universitá di Catania, Catania 95124, Italy $\ddagger$ Department of Haematology and Oncology, Istituto Superiore di Sanitá, Rome 00161, Italy

$\$$ Istituto di Medicina Interna e Scienze Oncologiche, Universitá di Perugia 06122, Italy

\| These authors contributed equally to the work.

The production of red blood cells follows the sequential formation of proerythroblasts and basophilic, polychromatophilic and orthochromatic erythroblasts, and is promoted by the hormone erythropoietin (Epo) in response to tissue hypoxia ${ }^{1}$. However, little is known about the negative regulation of this process ${ }^{2}$. Death receptors are a family of surface molecules that trigger caspase activation and apoptosis in a variety of cell types ${ }^{3-5}$. Here we show that immature erythroid cells express several death receptors whose ligands are produced by mature erythroblasts. Exposure of erythroid progenitors to mature erythroblasts or death-receptor ligands resulted in caspase-mediated degradation of the transcription factor GATA-1, which is associated with 
5668127). We treated $5 \mathrm{ml}$ log-phase rolling cultures of BCG (absorbance $\left.{ }_{540}=0.2\right)$ in $7 \mathrm{H} 9$ broth plus ADC enrichment cells with $25 \mu \mathrm{Ci}$ of ${ }^{14} \mathrm{C}-\mathrm{PA}-824$ at a concentration of $1 \mu \mathrm{g} \mathrm{ml}^{-1}$. We collected cells and prepared the lysate as above. The lysate was centrifuged for $10 \mathrm{~min}$ at $10,000 \mathrm{~g}$ and the resulting supernatant evaporated to dryness. We extracted the residue with $10 \mu \mathrm{H}_{2} \mathrm{O}$, and applied $3 \mu \mathrm{l}$ applied to a normal-phase silica TLC plate. The plate was developed in 1-butanol: $\mathrm{H}_{2} \mathrm{O}$ acetic acid (4:1:1). Radioactivity was recorded by phosphorimagery.

\section{Compound evaluation in animal infection models}

NAP compounds tested in animals were formulated in 10\% hydroxypropyl-b-cyclodextrin and $10 \%$ lecithins in water at a final concentration of $5 \mathrm{mg} \mathrm{ml}^{-1}$. In mice, all drugs were administered by oral gavage. Balb-C mice were infected by tail vein injection with $10^{6} \mathrm{CFU}$ of MTB-lux consisting of strain H37RV containing plasmid vector pMH102, a hygromycin resistant version of pMH30 (ref.11). Mycobacterial burden in mouse organ homogenates was measured by luminometry using relative light units (RLU) as a surrogate for CFUs as described ${ }^{11}$. Drugs were tested in MTB infected guinea pigs essentially as described $^{24}$. Outbred Hartley-strain guinea pigs (Charles River Breeding Laboratories) were infected with 5-10 viable organisms per animal by aerosol with a single-cell suspension of M. tuberculosis H37Rv (ATCC 27294). Each animal was randomly assigned a treatment group and sacrifice interval. Drug treatment was initiated 4 weeks postchallenge. PA-824 formulated as described was mixed with an equal volume of commercial pina colada mix ( $\mathrm{Mr}$ and Mrs $\mathrm{T}$ ) to increase palatability, and administered at $40 \mathrm{mg} \mathrm{kg}^{-1}$ per oral (p.o.) once daily. Each animal in the control group received a single dose of $0.5 \mathrm{~m}$ INH (Isoniazid; Sigma) daily p.o. containing $25 \mathrm{mg} \mathrm{kg}^{-1}$ INH in $50 \%$ sucrose (Sigma). Untreated animals received a single dose of $0.5 \mathrm{ml} 50 \%$ sucrose daily p.o. as a placebo. Guinea pigs were killed by the intraperitoneal injection of $1-3 \mathrm{ml}$ of sodium pentobarbital (Sleepaway, Fort Dodge Laboratories) at 8 weeks following respiratory challenge. The thoracic cavities were opened aseptically and the right lower lobe of the lung was removed for bacterial culture. Lung tissue was homogenized in sterile Teflon-glass homogenizers in $4.5 \mathrm{ml}$ of sterile physiological saline. The number of viable MTB organisms in each organ was determined by inoculating appropriate dilutions onto duplicate Middlebrook 7H10 agar plates (Remel, Lenexa, KS). The colonies were counted after 3 weeks incubation at $37^{\circ} \mathrm{C}$. Data were expressed as mean $\log _{10}$ number of viable organisms per lung lobe. All animal infections and subsequent drug treatments were performed in a BL3 biohazard facility designed for use with class 3 human pathogens. We used analysis of variance (general linear model) to test the effects of drug treatment on tissue bacterial load. When significant treatment effects were indicated, differences between means were assessed by Duncan's multiple range test. A $95 \%$ confidence level was set for all tests.

Received 23 February; accepted 10 May 2000,

1. Dye, C., Scheele, S., Dolin, P., Pathania, V. \& Raviglione, M. C. Consensus statement. Global burden of tuberculosis: estimated incidence, prevalence, and mortality by country. WHO Global Surveillance and Monitoring Project. J. Am. Med. Ass. 282, 677-686 (1999).

2. Bloom, B. R. \& Small, P. M. The evolving relation between humans and Mycobacterium tuberculosis. $N$. Engl. J. Med. 338, 677-678 (1998).

3 Kaufman, S. \& van Embden, J. Tuberculosis: a neglected disease strikes back. Trends Microbiol. 1, 2-5 (1993).

4. Bloom, B. R. \& Murray, C. J. Tuberculosis: commentary on a reemergent killer. Science 257, 1055 1064 (1992).

5. Fischl, M. A. et al. Clinical presentation and outcome of patients with HIV infection and tuberculosis caused by multiple-drug-resistant bacilli. Ann. Int. Med. 117, 184-190 (1992).

6. Agrawal, K. C. et al. Potential radiosensitizing agents. Dinitroimidazoles. J. Med. Chem. 22, 593-586 (1979).

7. Nagarajan, K., Shankar, R. G., Rajappa, S., Shenoy, S. J. \& Costa-Pereira, R. Nitroimidazoles XXI 2,3dihydro-6-nitroimidazo [2,1-b] oxazoles with antitubercular activity. Eur. J. Med. Chem. 24, 631-633 (1989).

8. Walsh, J. S. et al. Structural alterations that differentially affect the mutagenic and antitrichomonal activities of 5-nitroimidazoles. J. Med. Chem. 30, 150-156 (1987).

9. Ashtekar, D. R. et al. In vitro and in vivo activities of the nitroimidazole CGI 17341 against Mycobacterium tuberculosis. Antimicrob. Agents Chemother. 37, 183-186 (1993).

10. Wayne, L. G. \& Sramek, H. A. Metronidazole is bactericidal to dormant cells of Mycobacterium tuberculosis. Antimicrob. Agents Chemother. 38, 2054-2054 (1994).

11. Hickey, M. J. et al. Luciferase in vivo expression technology: use of recombinant mycobacterial reporter strains to evaluate antimycobacterial activity in mice. Antimicrob. Agents Chemother. 40, 400-407 (1996).

12. Yuan, Y. \& Barry, C. E. A common mechanism for the biosynthesis of methoxy and cyclopropyl mycolic acids in Mycobacterium tuberculosis. Proc. Natl Acad. Sci. USA 93, 12828-12833 (1996).

13. Samuelson, J. Why metronidazole is active against both bacteria and parasites. Antimicrob. Agents Chemother. 43, 1533-1541 (1999).

14. Edwards, D. I. Mechanism of antimicrobial action of metronidazole. J. Antibicrob. Chemother. 5, 499502 (1979).

15. Lisitsyn, N. \& Lisitsyn, N. W. M. Cloning the differences between two complex genomes. Science 259, 946-951 (1993).

16. Cole, S. T. et al. Deciphering the biology of Mycobacterium tuberculosis from the complete genome sequence. Nature 393, 537-544 (1998).

17. Purwantini, E. \& Daniels, L. Purification of a novel coenzyme F420-dependent glucose-6-phosphate dehydrogenase from Mycobacterium smegmatis. J. Bacteriol. 178, 2861-2866 (1996).

18. Purwantini, E. \& Daniels, L. Molecular analysis of the gene encoding F420-dependent glucose-6phosphate dehydrogenase from Mycobacterium smegmatis. J. Bacteriol. 180, 2212-2219 (1998).

19. Barry, C. E. et al. Mycolic acids: structure, biosynthesis and physiological functions. Prog. Lipid Res. 37, 143-179 (1998).

20. Yuan, Y., Zhu, Y., Crane, D. D. \& Barry, C. E. The effect of oxygenated mycolic acid composition on cell wall function and macrophage growth in Mycobacterium tuberculosis. Mol. Microbiol. 29, 1449-1458 (1998)

21. Holt, J. G., Krieg, N. R., Sneath, P. H. A., Staley, J. T. \& Williams, S. T. in Bergey's Manual of Determinative Bacteriology 9th edn 597 (Williams and Wilkins, Baltimore, 1994).

22. Arain, T. M., Resconi, A. E., Hickey, M. J. \& Stover, C. K. Bioluminescence screening in vitro (Bio-Siv) assays for high-volume antimycobacterial drug discovery. Antimicrob. Agents Chemother. 40, 15361541 (1996).

23. van Embden, J. D. et al. Strain identification of Mycobacterium tuberculosis by DNA fingerprinting: recommendations for a standardized methodology. J. Clin. Microbiol. 31, 406-409 (1993).

24. Smith, D. W., Balasubramanian, V. \& Wiegeshaus, E. H. A guinea pig model of experimental airborne tuberculosis for the evaluation of the response to chemotherapy: the effect on bacilli in the initial phase of treatment. Tubercle 72, 223-231 (1991).

Correspondence and requests for materials should be addressed to C.K.S. (e-mail: kstover@pathogenesis.com).

Embryonic lethality in mice homozygous for a processing-deficient allele of Notch1

\author{
Stacey S. Huppert*, Anh Le, Eric H. Schroeter*, Jeffrey S. Mumm, \\ Meera T. Saxena*, Laurie A. Milner $\dagger \&$ Raphael Kopan*
}

* Department of Molecular Biology and Pharmacology and the Department of Medicine (Division of Dermatology), Washington University School of Medicine, St Louis, Missouri 63110, USA

$\dagger$ The Fred Hutchinson Cancer Research Center and the University of Washington School of Medicine, Seattle, Washington 98109, USA

The Notch genes encode single-pass transmembrane receptors that transduce the extracellular signals responsible for cell fate determination during several steps of metazoan development. The mechanism by which extracellular signals affect gene transcription and ultimately cell fate decisions is beginning to emerge for the Notch signalling pathway. One paradigm is that ligand binding to Notch triggers a Presenilin1-dependent proteolytic release of the Notch intracellular domain from the membrane ${ }^{1}$, resulting in low amounts of Notch intracellular domain which form a nuclear complex with $\mathrm{CBF} 1 / \mathrm{Su}(\mathrm{H}) / \mathrm{Lag} 1$ to activate transcription of downstream targets ${ }^{2}$. Not all observations clearly support this processing model, and the most rigorous test of it is to block processing in vivo and then determine the ability of unprocessed Notch to signal. Here we report that the phenotypes associated with a single point mutation at the intramembranous processing site of Notch1, Val1,744 Gly, resemble the null Notch1 phenotype ${ }^{3,4}$. Our results show that efficient intramembranous processing of Notchl is indispensable for embryonic viability and proper early embryonic development in vivo.

The plausibility of the processing model has been demonstrated by biochemical experiments in vitro ${ }^{5-7}$ and genetic analyses in Drosophila ${ }^{5,8,9}$, which show that the Notch intracellular domain (NICD) gains access to the nucleus in a ligand-dependent manner. In addition, Presenilin-null mice and nematodes phenocopy animals lacking $\mathrm{CBF} 1 / \mathrm{Su}(\mathrm{H}) / \mathrm{Lag} 1(\mathrm{CSL})^{10-13}$, suggesting that the loss of nuclear Notch as a result of abolished Presenilindependent processing is the root cause of the observed phenotypes. But not all data support this model. In some transgenic flies, membrane-tethered Notch has a greater efficacy than NICD ${ }^{14}$; in addition, truncated versions of tethered Notch can signal in Presenilin-deficient flies ${ }^{15}$ and cells ${ }^{16}$. Consequently, either processing of the Notch protein is not obligate for its function or NICD is generated by other means in artificial situations (for example, truncated Notch proteins can be translated from a methionine within their transmembrane domain ${ }^{17}$, generating a NICD-like fragment independent of processing). 
To address this issue, we chose a reverse genetic approach, mutating the codon GTG (valine) to GGG (glycine) at aminoacid position 1,744 in the mouse Notch 1 gene. This position is the site for proteolytic cleavage and is critical for Notch1 intracellular processing in tissue-culture cells (Fig. 1a) ${ }^{6}$. In activated Notch 1 proteins, processing is not completely abolished in any of the single amino-acid substitutions that we tested at this time, and activity is observed when these mutant proteins are overexpressed ${ }^{6}$ (Fig. 1a;

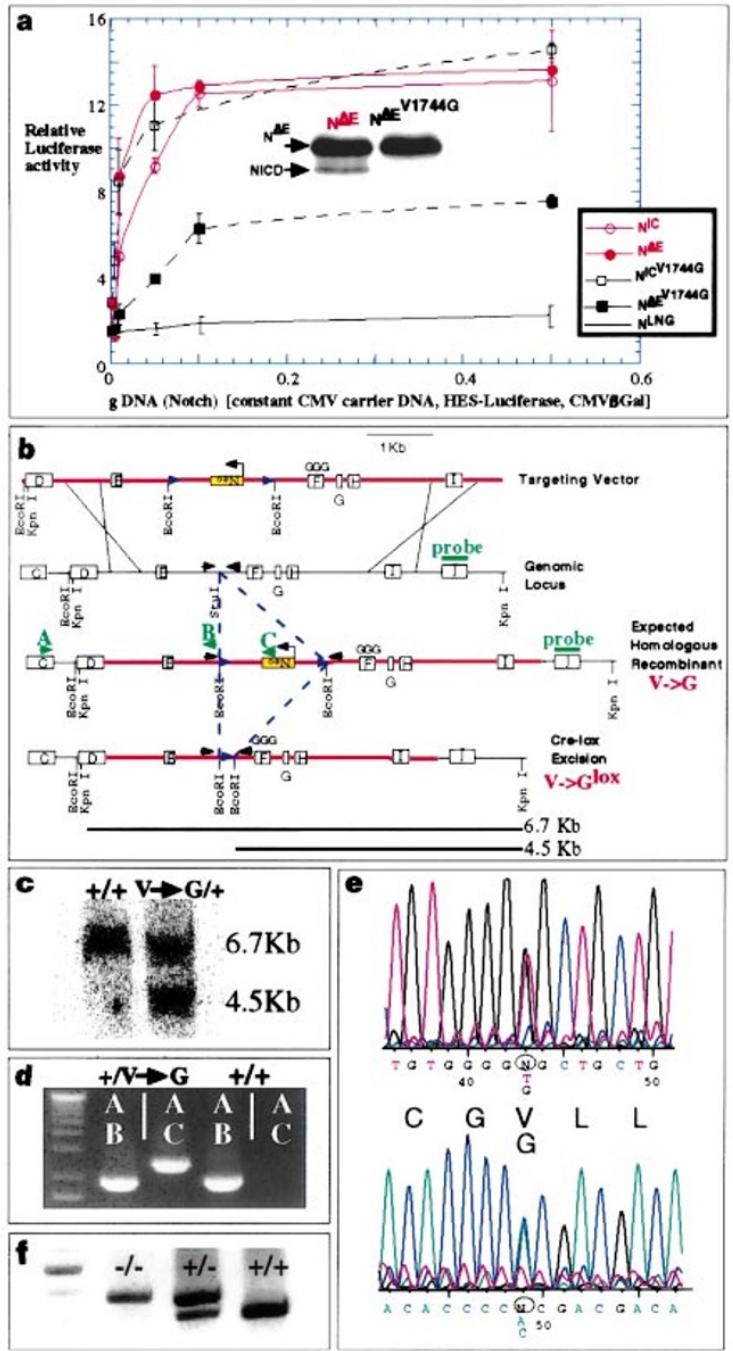

Figure 1 Strategy for generating a processing-deficient Notch1 allele. a, Effects of membrane tether on Notch and the Notch processing mutant V1744G. Western blot analysis shows a reduction in the amount of NICD produced in cells expressing the $\mathrm{N}^{\Delta \mathrm{EV} 1744 \mathrm{G}}$ variant (at $1 \mu \mathrm{g} \mathrm{ml}^{-1}$ ) compared with wild-type $\mathrm{N}^{\Delta \mathrm{E}}$ (inset, middle); however, the V1744G mutation does not affect signalling in a non-membrane-tethered form of Notch $\left(\mathrm{N}^{\text {ICV1744G)}}\right.$, as illustrated by HES-Luciferase reporter activity. b. The V1744G mutation was inserted into exon $F$ (nomenclature from ref. 28). A floxed neo-selection cassette was inserted into the intron separating exons $E$ and $F$ in the mutated genomic fragment, and the resulting construct was used to target the Notch1 processing mutation V1744G into the Notch1 gene. c, All G418-resistant ES cell clones were analysed by Southern blot to determine whether the integration was homologous. Genomic DNA was cut with EcoRI/Kpnl and probed with a region of exon J. The expected fragments and the probe are as indicated in $\mathbf{b}$. d. Homologous recombination was also verified by DNA amplification with a primer exterior to the targeting vector $(\mathrm{A})$ and a neo primer (C). Primers $\mathrm{A}, \mathrm{B}$ and $\mathrm{C}$ are indicated in $\mathbf{b}$. e, The presence of the processing mutation was verified by sequencing genomic ES cell DNA. The $N 1^{V} \quad G / 0 x /+$ animals were genotyped by PCR of the intron containing the loxP site insertion. $\mathbf{f}, \mathrm{A}$ PCR reaction distinguishing all three genotypes resulting from a cross of $\mathrm{N}^{V} \mathrm{Glox} /+$ animals is shown.
E.S. and R.K., manuscript in preparation). However, ligand-dependent Notch processing is greatly reduced by these point mutations ${ }^{6}$. Therefore, in vivo Notch1 should be minimally and 'inefficiently' processed and should direct a hypomorphic phenotype if processing at this site is critical for Notch signalling activity as it is for activated forms of Notch1 protein in tissue culture ${ }^{6}$. No phenotype is expected if intramembranous proteolysis of Notch 1 is not required for signalling.

Using the strategy outlined in Fig. 1, we generated heterozygous animals carrying two germline mutations: the V1744G mutation in exon $\mathrm{F}$, and a 42-base pair (bp) pLox site insertion in the intron separating exons $\mathrm{E}$ and $\mathrm{F}$ (this allele is designated $\mathrm{N1}^{V} \quad$ Glox ; Fig. 1b). We isolated homozygous embryos from heterozygous crosses of $N 1^{V G l o x} /+$ mice at gestational day 8.5 (E8.5) until E10.5. The percentage of homozygous embryos ranged from 20 to $30 \%$, within the expected mendelian frequency (25\%; Table 1). As reported for two null alleles of $\operatorname{Notch} 1\left(N 1^{\Delta 1} \text { and } N 1^{i n 32}\right)^{3,4}$, embryo absorption was detected between E10 and E12, and no homozygous embryos were recovered past E12. In a total of 12 litters, no homozygous mice were born from heterozygous crosses.

The striking similarity of embryos expressing the processingdeficient Notch 1 allele to the Notch 1 null embryos is consistent with the hypothesis that efficient Notch processing is necessary for the early embryonic developmental aspects of Notch activity. As homozygous $N 1^{V \text { Glox }}$ embryos die, these results are consistent with the hypothesis that efficient processing of Notch 1 is essential for survival past E10 and suggest that $N 1^{V}$ Glox is a severe hypomorphic allele. Alternatively, our strategy may have resulted in loss of Notch1 protein expression as a consequence of inserting foreign sequences (the 42-bp pLox site) into an intron. We prepared RNA from

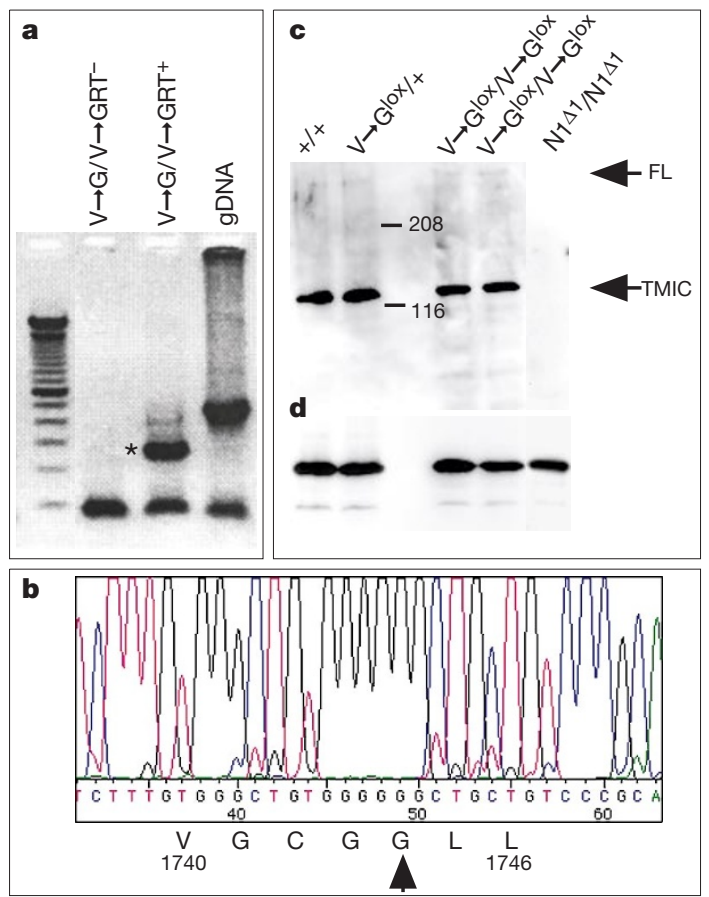

Figure 2 The targeted Notch1 allele containing the V1744G mutation is both transcribed and translated. a, Example of RT-PCR of E10.5 $N 1^{V} \quad G / N 1^{V} \quad{ }^{G}$ animals. Lane 2, RNA without RT. Lane 3, RNA with RT, producing a cDNA product of $240 \mathrm{bp}$ and a gDNA product of $440 \mathrm{bp}$. $\mathbf{b}$, Sequence of a homozygous $N 1^{V}{ }^{G}$ embryo from the product shown by asterisk in a. c. Western blot of protein extracted from E9.5 animals (genotypes indicated) detecting Notch1 protein with anti-mN1A. Arrows indicate the position of fulllength $(\mathrm{FL})$ and transmembrane-tethered carboxy-terminal product of the furin cleavage containing the intracellular domain (TMIC) of Notch1 protein. $\mathbf{d}$, The same western blot stripped and re-analysed with anti- $\beta$-catenin showing protein in all lanes. 
homozygous $N 1^{V G} / N 1^{V G}$ embryos at E10.5, and carried out reverse transcription using primers within exon $F$ and exon $G$, to distinguish between amplification of genomic DNA and complementary DNA generated from messenger RNA or heteronuclear RNA (hnRNA) (Fig. 2a). Sequencing the amplified messenger RNA product (Fig. 2a, asterisk) confirmed that embryos homozygous for the Notch1 intracellular processing mutation produced mRNA coding for glycine at position 1,744 (glycine, GGG, instead of valine, GTG; Fig. 2b). If most of the embryonic mRNA lacks exon $\mathrm{F}$ owing to aberrant splicing at the E/F junction, we would expect little if any Notch1 protein to be translated owing to frameshifts. To demonstrate that Notch1 protein is efficiently translated in $N 1^{V}$ Glox $/ N 1^{V}$ Glox embryos, equivalent amounts of total protein (as determined by $\beta$-catenin immunodetection, Fig. $2 d$ ) were analysed by western blot using an antibody raised against the CDC-NCR region of Notch1 (Fig. 2c). Comparable amounts of mature Notch1 protein are present in both the processing-deficient embryos and their heterozygous and wild-type littermates. Notch1 protein is not detected in $N 1^{\Delta 1}$ homozygous embryos, demonstrating the specificity of this antibody to Notch1, as homozygous null embryos do express Notch2 (ref. 4). Thus, we conclude that the targeted Notch1 intracellular processing-deficient allele is both transcribed and translated with similar efficiency to the wild-type allele. Production of a processing-deficient Notch1 mutant protein even at wild-type levels is therefore functionally analogous to a Notch1 protein null in regard to viability.

A comparison between homozygous $N 1^{V}$ Glox and $N 1^{\Delta 1}$ null embryos $^{3}$ might identify developmental decisions either that are independent of Notch1 processing or that can occur with inefficient Notch1 processing. We compared the phenotypes of $N 1^{\Delta 1}$ and $N 1^{V}$ Glox at E10.5 to determine whether embryos lacking Notch1 protein display developmental abnormalities not observed in the processing-deficient embryos (Fig. 3a-c). Morphological comparison revealed that $N 1^{\Delta 1}$ null and $N 1^{V}$ Glox embryos are almost indistinguishable. The development of Notch1 mutant embryos is retarded as compared with their heterozygous and wild-type littermates. $N 1^{V}$ Glox embryos at E9.5 form 19-23 somites compared with 22-26 for their heterozygous and wild-type littermates. The $N 1^{\Delta 1}$ embryos are even more delayed, forming only $14-18$ somites by E9.5. Another prominent phenotype is a distended pericardial sac in both $N 1^{\Delta 1}$ and $N 1^{V}$ Glox embryos, but both develop a beating heart. Embryos of both genotypes form morphologically normal forelimb buds, and otic and optic vesicles.

A new phenotype, which may contribute to embryonic lethality, was described for Notch1 null embryos in the C57Bl6/J congenic background (ref. 18; and T. Gridley, personal communication). These embryos have severe defects in angiogenic vascular remodelling in the yolk sac at E9.5 (ref. 18). A similar yolk-sac defect is observed in embryos lacking all Presenilin activity ${ }^{11}$. In all $N 1^{V}$ Glox

\begin{tabular}{|c|c|c|c|}
\hline $\begin{array}{l}\text { V } G^{\mathrm{lox} /}+\times \mathrm{V} \quad \mathrm{G}^{\mathrm{lox} /} \\
+\end{array}$ & $+/+$ & V $G^{\operatorname{lox} /+}$ & $V G^{\operatorname{lox}} N G^{l o x}$ \\
\hline $\begin{array}{l}\text { E8.5 } \\
\text { Expected }\end{array}$ & $\begin{array}{l}7(28 \%) \\
6(25 \%)\end{array}$ & $\begin{array}{l}13(52 \%) \\
13(50 \%)\end{array}$ & $\begin{array}{l}5(20 \%) \\
6(25 \%)\end{array}$ \\
\hline $\begin{array}{l}\text { E9.5 } \\
\text { Expected }\end{array}$ & $\begin{array}{l}40(24 \%) \\
42(25 \%)\end{array}$ & $\begin{array}{l}77 \text { (46\%) } \\
83 \text { (50\%) }\end{array}$ & $\begin{array}{l}50(30 \%) \\
42(25 \%)\end{array}$ \\
\hline $\begin{array}{l}10.5 \\
\text { Expected }\end{array}$ & $\begin{array}{l}22(29 \%) \\
19(25 \%)\end{array}$ & $\begin{array}{l}38 \text { (50\%) } \\
38 \text { (50\%) }\end{array}$ & $\begin{array}{l}16(21 \%) \\
19(25 \%)\end{array}$ \\
\hline $\begin{array}{l}\text { E12.5 } \\
\text { Expected }\end{array}$ & $\begin{array}{l}5(36 \%) \\
3.5(25 \%)\end{array}$ & $\begin{array}{l}5(36 \%) \\
7(50 \%)\end{array}$ & $\begin{array}{l}4(28 \%)^{\star} \\
3.5(25 \%)\end{array}$ \\
\hline $\begin{array}{l}\text { At birth } \\
\text { Expected }\end{array}$ & $\begin{array}{l}37(37 \%) \\
25(25 \%)\end{array}$ & $\begin{array}{l}64 \text { (63\%) } \\
51 \text { (50\%) }\end{array}$ & $\begin{array}{c}0 \\
25(25 \%)\end{array}$ \\
\hline
\end{tabular}

The percentage of each genotype is shown with the expected numbers of each genotypic class given in parentheses. E designates embryonic day.

${ }^{\star}$ Absorbed embryos.

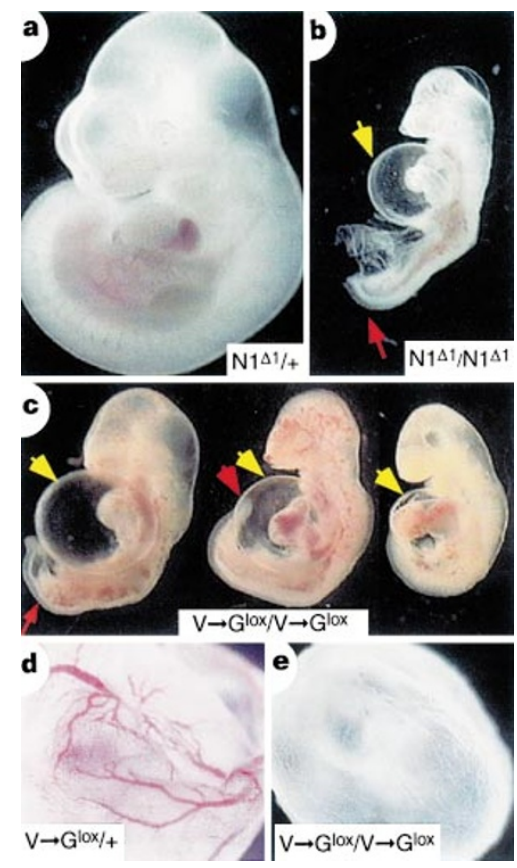

Figure 3 Overall morphological phenotypes of the following genotypes: a, $N 1^{\Delta 1} /+$; b, $N 1^{\Delta 1} / N 1^{\Delta 1}$ (Notch1 null); c,e, $N 1^{V}$ Glox $/ N 1^{V}$ Glox ; d, $N 1^{V}$ Glox $/+$. Extra-embryonic tissue was used to genotype each embryo. Arrows point to the variable deficit in posterior development (b and $\mathbf{c}$ ) and the expanded pericardial sac at E10.5. $N 1^{V}$ Glox $/ N 1^{V}$ Glox embryos show a lack of vascular morphogenesis ${ }^{18}$ at E9.5 (e) compared with their heterozygous litter mate (d).

embryos that we examined, the yolk sac displays similar defects to those described for Notch1 null $\left(N 1^{\text {in32 }}\right)^{18}$ and the Presenilin double mutant ${ }^{11}$ embryos (Fig. 3e).

We performed whole-mount in situ mRNA hybridization to ascertain whether there are any other detectable phenotypic differences between $N 1^{V}$ Glox and $N 1^{\Delta 1}$ embryos. The myotome and the sclerotome lineages (as detected by myogenin, Fig. 4c and data not shown; and Uncx4.1, Fig. 4a, b, d-g) are formed in the $N 1^{V}$ Glox as in the $N 1^{\Delta 1}$ embryos $^{3}$. Somitogenesis is not completely disrupted in $N 1^{\Delta 1}$, but rather the consistent metameric repeated pattern is poorly maintained. Uncx4.1, whose expression reflects this metameric pattern in the caudal compartment of the sclerotome ${ }^{19}$, further illustrates this point (Fig. $4 \mathrm{a}, \mathrm{b}, \mathrm{d}-\mathrm{g}$ ). Disruptions in size and bilateral symmetry of the somites are observed in $N 1^{\Delta 1}$ null embryos (Fig. 4a, b). The anterior somite phenotype of the $N 1^{V}$ Glox embryos shows similar disruptions in the metameric pattern (Fig. 4c), but at lower penetrance than in the $N 1^{\Delta 1}$. No irregularities in somite size were detected in the posterior region of the $22 N 1^{V}$ Glox embryos that we analysed (Fig. 4e, f). Neural tube kinks are observed in the $N 1^{\Delta 1}$ embryos, extending posterior to the forelimb (Fig. 4a). Whereas only 1 out of 23 wild-type embryos displayed similar kinks in the anterior region, 14 out of $22 N 1^{V}$ Glox embryos displayed neural tube kinks anterior to the forelimb (Fig. 4c, g). No neural tube defects are seen posterior to the forelimb (Fig. 4e, f). Thus, in the anterior region of both mutant Notch1 alleles, the phenotype is comparable albeit at lower penetrance.

Alteration in ligand expression is detected in $N 1^{\Delta 1}$ embryos. Delta1 is expressed in the presomitic mesoderm, the caudal half of each somite, the forebrain and the neuroepithelium of the presumptive midbrain region, and in isolated cells in the neural tube ${ }^{20}$. In E8.5 embryos, Delta1 expression in all Notch1 alleles is almost indistinguishable from wild type (Fig. 5a-c); however, as shown previously $^{21}$, Deltal expression is upregulated in the neural tube in E8.5 N1 ${ }^{\Delta 1}$ embryos (Fig. 5c), although to a lesser extent than 

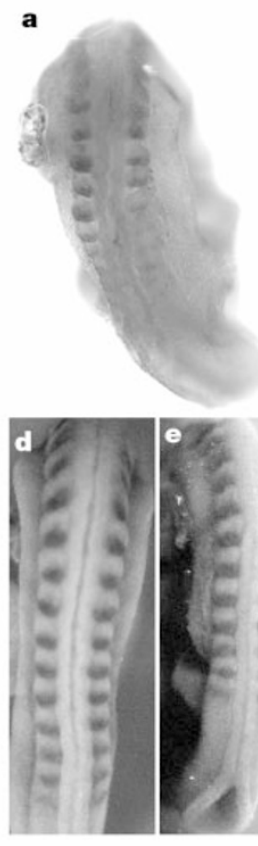
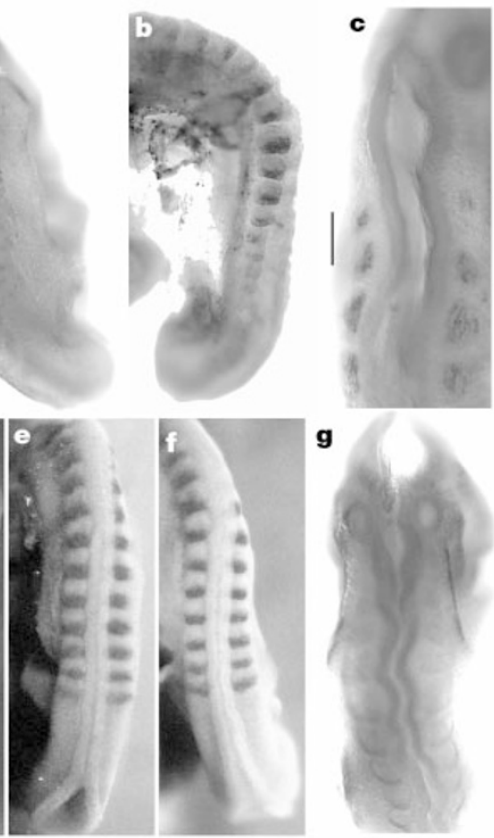

g

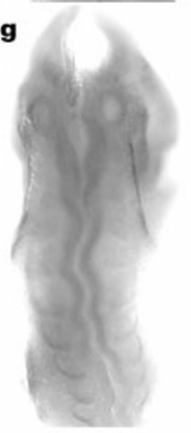

Figure 4 In situ hybridization analysis of E9.5 animals. Genotypes: a,b, $N 1^{\Delta 1} / N 1^{\Delta 1}$; c, e-g, $N 1^{V}$ Glox $/ N 1^{V}$ Glox; d, wild type. All panels show hybridizations with an Uncx4.1 RNA probe was used except in $\mathbf{c}$ where a myogenein RNA probe was used. Compare the posterior view of somitogenesis $(\mathbf{a}, \mathbf{b}, \mathbf{d}-\mathbf{f})$. A disturbance in patterning of anterior somites (indicated by the lines) is shown in $\mathbf{c}$. Neural tube kinks in the anterior of $N 1^{v}$ Glox $/ N 1^{V}$ Glox embryos are shown in $\mathbf{c}$ and $\mathbf{g}$; no neural tube kinks are detected in the posterior of $N 1^{V G l o x} / N 1^{V}$ Glox embryos $(\mathbf{e}, \mathbf{f})$, but kinks are visible in the posterior region of $N 1^{\Delta 1} / N 1^{\Delta 1}$ embryos (a).

in $\mathrm{CSL}^{\mathrm{RBPjk}}$ null embryos or Presenilin1/Presenilin2 double homozygotes $^{10}$. We find similar Delta1 upregulation in E9.5 $N 1^{V}$ Glox embryos in anterior regions (Fig. $5 \mathrm{f}$, inset). As in somitogenesis, the posterior effect is less pronounced (Fig. 5e, f). Therefore, a processing-defective Notch1 receptor has a similar effect on Delta1 expression in the anterior region as observed in a Notch1 null background ${ }^{21}$. We conclude that the overall phenotypes of $N 1^{V}$ Glox and $N 1^{\Delta 1}$ null are qualitatively equivalent, with some quantitative differences depending on the region analysed.

Why is there a difference between anterior and posterior regions in the $N 1^{V}$ Glox embryos? In the posterior region, where Notch1 expression is the highest in the embryo ${ }^{22}$, inefficient proteolysis may still produce NICD above threshold levels (Fig. 1a) ${ }^{6}$, resulting in restoration of normal morphology. We attempted to determine to what extent Notch1 is processed in the posterior of homozygous $N 1^{V}$ Glox embryos. Because our V1744G point mutation results in a ninefold reduction in Notch1 processing (Fig. 1a), we reasoned that 10 wild-type embryos will represent 100 mutant embryos, the upper limit of what we can produce and process. Although we have been able to enrich for NICD efficiently by immunoprecipitation with a CSL antibody (provided by R. Aguilera) from 293T cells transfected with a membrane-tethered, truncated, active Notch $1\left(\mathrm{~N}^{\Delta \mathrm{E}}\right)^{17}$, we have been unsuccessful in using the same strategy to purify NICD from pools of 10 wild-type E9.5 embryos. This result may reflect the small number of cells in which Notch has been activated at any given time, the short half-life of NICD in vivo ${ }^{23}$, or a combination of both. This finding is also consistent with the observation that very low nuclear concentrations of Notch1 are sufficient for productive signalling ${ }^{6}$. Our failure to detect NICD in wild-type embryos therefore leaves the hypothesis offered above as the most likely, but unproved, explanation for improved posterior development in $N 1^{V}$ Glox embryos.

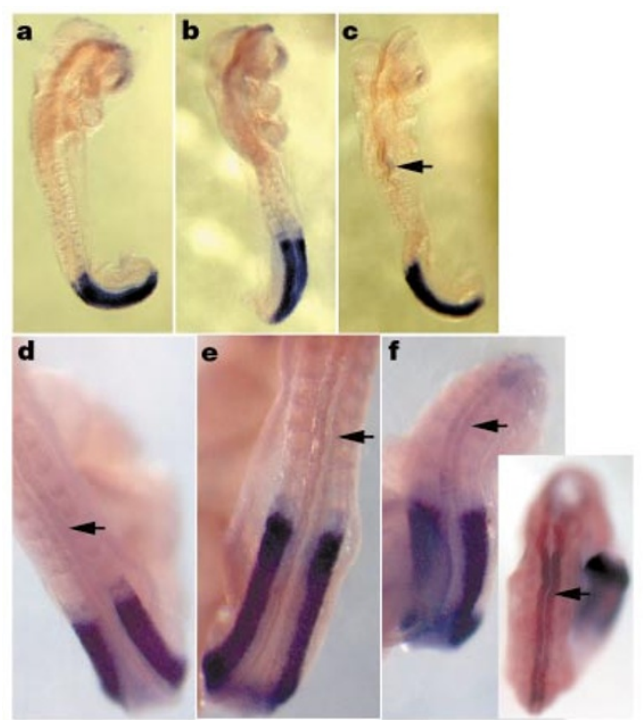

Figure $\mathbf{5}$ In situ hybridization of Delta1 (D/1). a-c, E8.5; $\mathbf{d}-\mathbf{f}$, E9.5. The embryos are wild type $(\mathbf{a}, \mathbf{d}), N 1^{V}$ Glox $/ N 1^{V}$ Glox $(\mathbf{b}, \mathbf{e}, \mathbf{f})$ and $N 1^{\Delta 1} / N 1^{\Delta 1}$ (c). Arrows point to D/1 expression in the neural tube. Note the difference in the level of $D / 1$ expression between the anterior and posterior views of the $N 1^{V}$ Glox $/ N 1^{V}$ Glox embryo (f).

In conclusion, our data show unequivocally that efficient Notch1 intracellular processing is required for viability and proper formation of yolk-sac vasculature in the mouse embryo. A processingindependent Notch1 signalling event would be predicted to function in a manner indistinguishable from that of wild-type Notch. Our analysis of mice expressing the processing-deficient Notch1 allele revealed that all the phenotypes described in the null genotypes were qualitatively reproduced. However, quantitative differences were described: the null-like phenotype in the anterior occurs at lower penetrance. The quantitative differences that we observe in the regions of high Notch1 expression may reflect either residual processing observed in V1744G mutants, or proteolysis-independent Notch1 signalling acting at the posterior but not the anterior of the embryo. The latter possibility is unlikely given that no fundamental differences between anterior and posterior somitogenesis are known to exist. Collectively, our data establish the processing-deficient allele as a strong hypomorph of Notch1. It remains to be determined whether late functions of Notch1 also depend on efficient cleavage at V1744.

\section{Methods}

\section{Gene targeting Notch1 intracellular processing mutation}

Genomic clones containing exon D up to exon J of Notch1 were isolated from a library made by R.K. The library was constructed as a Sau3AI partial, cloned into lambda DASH (Stratagene) using BamHI. The library was probed with the ankyrin region of Notch1. A clone of roughly 10 kilobases was subcloned into BlueScript. We generated a subclone spanning the region from exon $\mathrm{D}$ to $\mathrm{J}$ into which we inserted a neo-selection cassette disrupting the StuI site in the intron between exon E and F. The processing mutation was cloned into this vector in two steps (details available upon request). The vector was linearized with SalI and electroporated into RW4 embryonic stem cells (T. Ley; http:llmedicine.wustl.edu/ escore/ ). Correctly targeted clones were verified by Southern blot analysis using an external probe from exon J and by polymerase chain reaction (PCR) with a primer located $5^{\prime}$ outside of the targeting vector ([A] exon C, $5^{\prime}$-CGG CCG GCT GCC TCT TTG-3' ${ }^{\prime}$, and [C]Neo, $5^{\prime}$-TCG CCT TCT ATC GCC TTC TTG-3'). Embryonic stem (ES) cell clones 44 and 93 were injected into C57Bl6/J blastocysts (Jackson Laboratory) to obtain germline transmission.

Heterozygous animals transmitting the targeted allele, as verified through PCR, were sequenced to confirm that the targeted allele contained the processing mutation using primers Motch 33, 5' -CAG AGA TCT CTG CAC CTC ATG TAC GTG-3', and Motch 49, 5'-CGA ACT AGT CTC TGA CAC TTT GAA ACC-3'. Embryos containing the neoselection cassette from both ES cell clones (44 and 93) were initially analysed and displayed identical phenotypes. In these animals, the neo-expression cassette inserted in reverse orientation to the Notch transcript encodes a cryptic splice acceptor site, which can 
strongly reduce the amount of RNA produced from the targeted allele $e^{24}$. To confine the analysis to the effects of reduced Notchl processing, we mated $N 1^{V}{ }^{G} /+$ mice with mice containing cre-recombinase under the control of the $\beta$-actin promoter $^{25}$ (provided by G. Martin), generating a second line of mice, in an out-bred background, in which the neoselection cassette was excised ( $\mathrm{V} \quad \mathrm{G}^{\text {lox }}$ chromosome; derived from ES cell line 93). These animals were identified by the 42-bp EcoRI footprint that remained. This allele is designated as Notch ${ }^{\text {tmlKop }}$

\section{Transfection, reporter gene assays and co-precipitations}

These were done as described 6 .

\section{Analysis of mutant embryos}

Embryos were genotyped by PCR of yolk-sac DNA using the following primer sets: EintF5', 5'-TGG CGG GTC ACA GGC AGG CGG TCT C-3', and Neo, 5'-TCG CCT TCT ATC GCC TTC TTG- $3^{\prime}$, which amplifies a 412-bp fragment in the processing mutant allele $\left(\mathrm{NI}^{V}{ }^{G}\right)$; EintF5' and EintF3', $5^{\prime}$-AAG GAT TTA GGG GGA TTT TCA AGA TAC AA-3', which amplifies a 340-bp fragment wild-type allele, and a 382-bp fragment in the neoexcised processing mutant allele $\left(\mathrm{NI}^{V} \quad\right.$ Glox $)$. In situ mRNA hybridization was performed as described $^{26}$. The probes used for hybridization were Uncx4.1 (ref. 19), myogenin (provided by M. J. Thayer) and Deltal (provided by D. Henrique). Whole-mount immunohistochemistry was done as described ${ }^{3}$.

\section{RT-PCR}

RNA was isolated from 10.5 day $N 1^{V}{ }^{G}$ embryos using TRIzol Reagent (Gibco BRL). Reverse transcription was carried out using an Enhanced Avian RT-PCR kit (Sigma) and primers within exon F (Motch33) and exon G (Motch94, 5'-CCA CTC GTT CTG ATT GTC GTC CAT- $\left.3^{\prime}\right)$. The cDNA amplifies a fragment of $240 \mathrm{bp}$ and the hnRNA and genomic DNA amplifies a fragment of $440 \mathrm{bp}$. The 240-bp fragment was gel purified and sequenced using Motch 33 and Big Dye cycle sequencing (Nucleic Acid Chemistry).

\section{Western analysis}

Single embryos were homogenized in $35 \mu \mathrm{l}$ of Laemmili buffer with $0.01 \mathrm{M}$ dithiothreitol. The extract was heated to $65^{\circ} \mathrm{C}$ for $30 \mathrm{~min}$ and then stored at $-80^{\circ} \mathrm{C}$. The extracts were run on a $6 \%$ SDS-PAGE gel and quantified by Coomassie blue. Western analysis was done as described ${ }^{6}$. Notchl protein was detected by m1NA antibody. $\beta$-catenin was detected by an antibody produced by Transduction Laboratories.

\section{mN1A monoclonal antibody production}

The mN1A mouse IgG1 monoclonal antibody, generated against the cdc10-NCR region of mNotch1 (mN1-IC $\Delta \mathrm{OP})$, was produced using standard methods of immunization and hybridoma production. mN1-IC $\Delta \mathrm{OP}$ cDNA was cloned into pGEX-5X (Promega), expressed as a GST fusion protein, and affinity-purified protein was use $\mathrm{d}^{27}$ to immunize mice. Splenocytes from animals producing mN1-specific antibodies were fused to SP2/0 cells and resulting hybridomas screened by ELISA for anti- $\mathrm{mN} 1$ secretion. Individual hybridoma clones were injected IP into syngeneic mice, and purified antibody was obtained by Protein A-Sepharose affinity chromatography of the ascites fluids produced. A detailed description will be published elsewhere (L.M. et al. in preparation).

Received 7 January; accepted 11 May 2000.

1. Chan, Y. M. \& Jan, Y. N. Roles for proteolysis and trafficking in Notch maturation and signal transduction. Cell 94, 423-426 (1998).

2. Jarriault, S. et al. Signalling downstream of activated mammalian Notch. Nature 377, 355-358 (1995)

3. Conlon, R. A., Reaume, A. G. \& Rossant, J. Notch1 is required for the coordinate segmentation of somites. Development 121, 1533-1545 (1995).

4. Swiatek, P. J., Lindsell, C. E., Amo, F. F. d., Weinmaster, G. \& Gridley, T. Notchl is essential for postimplantation development in mice. Genes Dev. 8, 707-719 (1994).

5. Kidd, S., Lieber, T. \& Young, M. W. Ligand-induced cleavage and regulation of nuclear entry of Notch in Drosophila melanogaster embryos. Genes Dev. 12, 3728-3740 (1998).

6. Schroeter, E. H., Kisslinger, J. A. \& Kopan, R. Notch-1 signalling requires ligand-induced proteolytic release of intracellular domain. Nature 393, 382-386 (1998).

7. De Strooper, B. et al. A presenilin-1-dependent gamma-secretase-like protease mediates release of Notch intracellular domain. Nature 398, 518-521 (1999).

8. Lecourtois, M. \& Schweisguth, F. Indirect evidence for Delta-dependent intracellular processing of Notch in Drosophila embryos. Curr. Biol. 8, 771-774 (1998).

9. Struhl, G. \& Adachi, A. Nuclear access and action of Notch in vivo. Cell 93, 649-660 (1998).

10. Donoviel, D. B. et al. Mice lacking both presenilin genes exhibit early embryonic patterning defects. Genes Dev. 13, 2801-2810 (1999)

11. Herreman, A. et al. Presenilin 2 deficiency causes a mild pulmonary phenotype and no changes in amyloid precursor protein processing but enhances the embryonic lethal phenotype of presenilin 1 deficiency. Proc. Natl Acad. Sci. USA 96, 11872-11877 (1999).

12. Li, X. \& Greenwald, I. HOP-1, a Caenorhabditis elegans presenilin, appears to be functionally redundant with SEL-12 presenilin and to facilitate LIN-12 and GLP-1 signaling. Proc. Natl Acad. Sci. USA 94, 12204-12209 (1997).

13. Westlund, B., Parry, D., Clover, R., Basson, M. \& Johnson, C. D. Reverse genetic analysis of Caenorhabditis elegans presenilins reveals redundant but unequal roles for sel-12 and hop-1 in Notchpathway signaling. Proc. Natl Acad. Sci. USA 96, 2497-2502 (1999).

14. Artavanis-Tsakonas, S., Rand, M. D. \& Lake, R. J. Notch signaling: cell fate control and signal integration in development. Science 284, 770-776 (1999).

15. Ye, Y. H., Lukinova, N. \& Fortini, M. E. Neurogenic phenotypes and altered Notch processing in Drosophila Presenilin mutants. Nature 398, 525-529 (1999).
16. Berechid, B. E., Thinakaran, G., Wong, P. C., Sisodia, S. S. \& Nye, J. S. Lack of requirement for Presenilin1 in Notch1 signaling. Curr. Biol. 9, 1493-1496 (1999).

17. Kopan, R., Schroeter, E. H., Weintraub, H. \& Nye, J. S. Signal transduction by activated mNotch: importance of proteolytic processing and its regulation by the extracellular domain. Proc. Natl Acad. Sci. USA 93, 1683-1688 (1996).

18. Krebs, L. T. et al. Notch signaling is essential for vascular morphogenesis in mice. Genes Dev. 14, 13431352 (2000).

19. Neidhardt, L. M., Kispert, A. \& Herrmann, B. G. A mouse gene of the paired-related homeobox class expressed in the caudal somite compartment and in the developing vertebral column, kidney and nervous system. Dev. Genes Evol. 207, 330-339 (1997).

20. Bettenhausen, B., de Angelis, M. H., Simon, D., Guenet, J. -L. \& Gossler, A. Transient and restricted expression during mouse embryogenesis of Dll1, a murine gene closely related to Drosophila Delta. Development 121, 2407-2418 (1995).

21. de la Pompa, J. L. et al. Conservation of the Notch signalling pathway in mammalian neurogenesis. Development 124, 1139-1148 (1997).

22. Reaume, A. G., Conlon, R. A., Zirngibl, R., Yamaguchi, T. P. \& Rossant, J. Expression analysis of a Notch homologue in the mouse embryo. Dev. Biol. 154, 377-387 (1992).

23. Schweisguth, F. Dominant-negative mutation in the $\beta 2$ and $\beta 6$ proteasome subunit genes affect alternative cell fate decisions in the Drosophila sense organ lineage. Proc. Natl Acad. Sci. USA 96, 11382-11386 (1999).

24. Carmeliet, P. et al. Abnormal blood vessel development and lethality in embryos lacking a single VEGF allele. Nature 380, 435-439 (1996).

25. Lewandoski, M. \& Martin, G. R. Cre-mediated chromosome loss in mice. Nature Genet. 17, 223-225 (1997).

26. Yuan, W. et al. The mouse SLIT family: Secreted ligands for ROBO expressed in patterns that suggest a role in morphogenesis and axon guidance. Dev. Biol. 212, 290-306 (1999).

27. Milner, L. A. et al. Inhibition of granulocytic differentiation by mNotch1. Proc. Natl Acad. Sci. USA 93 , 13014-13019 (1996).

28. Girard, L. et al. Frequent provirus insertional mutagenesis of Notch1 in thymomas of MMTVD/myc transgenic mice suggests a collaboration of c-myc and Notchl for oncogenesis. Genes Dev. 10, 19301944 (1996).

\section{Acknowledgements}

We thank T. Ley, E. Ross, D. Ornitz and S. Hua for technical help; R. Conlon and T. Gridley for providing animals and communicating results before publication; R. Aguilera, D. Henrique, B. Herrmann, G. Martin, J. Sanes, M. Thayer and S. Troyanovsky for reagents; R. Cagan and O. Pourquie for reading and commenting on the manuscript; and members of the Kopan lab-X. Tian, A. Nichols, M.-H. Lin, J. Kisslinger, B. Hadland and J. Books. This work was supported by the NIH.

Correspondence and requests for materials should be addressed to R.K. (e-mail: kopan@molecool.wustl.edu).

\section{An extracellular activator of the Drosophila JAK/STAT pathway is a sex-determination signal element}

\section{Louise Sefton, John R. Timmer, Yan Zhang, Florence Béranger \& Thomas W. Cline}

Department of Molecular and Cell Biology, 401 Barker Hall, University of California, Berkeley, California 94720-3204, USA

Metazoans use diverse and rapidly evolving mechanisms to determine sex. In Drosophila melanogaster an X-chromosomecounting mechanism determines the sex of an individual by regulating the master switch gene, Sex-lethal $(S x l)^{1}$. The X-chromosome dose is communicated to $S x l$ by a set of $\mathrm{X}$-linked signal elements (XSEs), which activate transcription of $S x l$ through its 'establishment' promoter, $S x l_{P e}$. Here we describe a new XSE called sisterless $C$ (sisC) whose mode of action differs from that of previously characterized XSEs, all of which encode transcription factors that activate $S x l_{P e}$ directly. In contrast, sisC encodes a secreted ligand for the Drosophila Janus kinase (JAK) and 'signal transducer and activator of transcription' (STAT) signal transduction pathway and is allelic to outstretched (os, also called unpaired). We conclude that $s i s C$ works indirectly on $S x l$ through this signalling pathway because mutations in sis $C$ or in the genes encoding Drosophila JAK or STAT reduce expression of $S x l_{P e}$ 